\title{
Current Approaches for Glioma Gene Therapy and Virotherapy
}

\author{
Kaushik Banerjee ${ }^{1,2}$, Felipe J. Núñez ${ }^{3}$, Santiago Haase ${ }^{1,2}$, Brandon L. McClellan ${ }^{1,4}$, \\ Syed M. Faisal ${ }^{1,2}$, Stephen V. Carney ${ }^{1,5}$, Jin $\mathrm{Yu}^{1+}$, Mahmoud S. Alghamri, ${ }^{1,2}$, \\ Antonela S. Asad ${ }^{6}$, Alejandro J. Nicola Candia ${ }^{6}$, Maria Luisa Varela ${ }^{1,2}$, \\ Marianela Candolfi ${ }^{6}$, Pedro R. Lowenstein ${ }^{1,2}$ and Maria G. Castro ${ }^{1,2 *}$
}

1 Department of Neurosurgery, University of Michigan Medical School, Ann Arbor, MI, United States, ${ }^{2}$ Department of Cell and Developmental Biology, University of Michigan Medical School, Ann Arbor, MI, United States, ${ }^{3}$ Laboratory of Molecular and Cellular Therapy, Fundación Instituto Leloir, Buenos Aires, Argentina, ${ }^{4}$ Immunology Graduate Program, University of Michigan Medical School, Ann Arbor, MI, United States, ${ }^{5}$ Cancer Biology Graduate Program, University of Michigan Medical School, Ann Arbor, MI, United States, ${ }^{6}$ Departamento de Biología e Histología, Facultad de Medicina, Universidad de Buenos Aires, Buenos Aires, Argentina

Glioblastoma (GBM) is the most common and aggressive primary brain tumor in the adult population and it carries a dismal prognosis. Inefficient drug delivery across the blood brain barrier (BBB), an immunosuppressive tumor microenvironment (TME) and development of drug resistance are key barriers to successful glioma treatment. Since gliomas occur through sequential acquisition of genetic alterations, gene therapy, which enables to modification of the genetic make-up of target cells, appears to be a promising approach to overcome the obstacles encountered by current therapeutic strategies. Gene therapy is a rapidly evolving field with the ultimate goal of achieving specific delivery of therapeutic molecules using either viral or non-viral delivery vehicles. Gene therapy can also be used to enhance immune responses to tumor antigens, reprogram the TME aiming at blocking glioma-mediated immunosuppression and normalize angiogenesis. Nano-particles-mediated gene therapy is currently being developed to overcome the BBB for glioma treatment. Another approach to enhance the anti-glioma efficacy is the implementation of viro-immunotherapy using oncolytic viruses, which are immunogenic. Oncolytic viruses kill tumor cells due to cancer cell-specific viral replication, and can also initiate an anti-tumor immunity. However, concerns still remain related to off target effects, and therapeutic and transduction efficiency. In this review, we describe the rationale and strategies as well as advantages and disadvantages of current gene therapy approaches against gliomas in clinical and preclinical studies. This includes different delivery systems comprising of viral, and non-viral delivery platforms along with suicide/prodrug, oncolytic, cytokine, and tumor suppressor-mediated gene therapy approaches. In addition, advances in glioma treatment through BBB-disruptive gene therapy and anti-EGFRvIII/NEGFR gene therapy are also discussed. Finally, we discuss the results of gene therapy-mediated human clinical trials for gliomas. In summary, we highlight the progress, prospects and remaining challenges of gene therapies aiming at broadening our understanding and highlighting the therapeutic arsenal for GBM.

Keywords: gene therapy, glioma, viral vectors, non-viral vectors, HSV1-TK, mutant IDH1 3, immunotherapy, FMS-like tyrosine kinase 3 ligand 


\section{INTRODUCTION}

\section{Molecular Alterations in Gliomas}

Gliomas are group of heterogeneous primary brain neoplasms which differ in grade of malignancy, histology and genomic alterations. They may arise from neural stem cells (NSCs), NSC-derived astrocyte or oligodendrocyte precursor cells (Zong et al., 2012, 2015) and represent almost 30\% of the central nervous system (CNS) tumors, and $80 \%$ of malignant CNS tumors (Ostrom et al., 2015, 2018). Most gliomas are diffuse and have been traditionally classified based either on histologic type: astrocytoma, oligodendroglioma, oligoastrocytoma (a rare mixed glioma) (Perry and Wesseling, 2016) or on their malignancy grade: World Health Organization (WHO), grades I-IV (Louis et al., 2007, 2016; Reifenberger et al., 2017). Recently, the WHO classification was refined (Louis et al., 2016). The presence and distribution of genetic alterations in brain tumors is now a criterion to differentiate glioma subtypes (Louis et al., 2016; Masui et al., 2016; Wesseling and Capper, 2018) that can be related with a particular WHO grade and tumor histology (Parsons et al., 2008; Sturm et al., 2012; Brennan et al., 2013; Cancer Genome Atlas Research et al., 2015; Ceccarelli et al., 2016) (Table 1).

A recurrent point mutation in isocitrate dehydrogenase 1 (IDH1), usually at arginine $132(\mathrm{R} 132 \mathrm{H})$, is detected with high frequency in adult diffuse-gliomas, being particularly high in diffuse low-grade gliomas (LGGs; WHO grade II) (Cancer Genome Atlas Research et al., 2015; Ceccarelli et al., 2016; Delgado-Lopez et al., 2017; Ostrom et al., 2018). This mutation is also found in anaplastic astrocytomas (WHO grade III), and in a smaller proportion of glioblastomas originated from LGGs (secondary glioblastomas; WHO grade IV) (Cancer Genome Atlas Research, 2008; Bai et al., 2016; Ceccarelli et al., 2016; Louis et al., 2016). Mutant IDH1 gliomas are sub-classified, according with the loss of $1 \mathrm{p} / 19 \mathrm{q}$ chromosomal segments, in mutant IDH1-1p/19q-codel and mutant IDH1-noncodel. Mutant IDH1 1p/19q-codel gliomas frequently harbor TERT promoter (TERTp) and CIC mutations, and are associated with oligodendrogliomas; whereas mutant IDH1-non-codel harbor mutations in alpha-thalassemia X-linked mental retardation $(A T R X)$ and TP53, and associated with astrocytoma and oligoastrocytoma (Cancer Genome Atlas Research et al., 2015; Bai et al., 2016; Ceccarelli et al., 2016; Louis et al., 2016; Venteicher et al., 2017).

In adults, wild-type IDH1 (wt-IDH1) glioma patients retain ATRX function, and typically present TP53 and TERTp mutations, and alterations in regulators of the receptor tyrosine kinase (RTK)-RAS-PI3K signaling cascade, including EGFR amplification and PTEN mutation or loss (Brennan et al., 2013; Louis et al., 2016; Masui et al., 2016; Reifenberger et al., 2017). Pediatric gliomas are mostly wt-IDH1, and they also can harbor TP53 and ATRX inactivating mutations, additionally mutations in H3F3A, HIST1H3B, HIST1H3C, and $B R A F$ (Rapidly Accelerated Fibrosarcoma type B) are frequent in pediatric high-grade gliomas (HGGs) (Bjerke et al., 2013; Venteicher et al., 2017). Based on these alterations, four pediatric HGG subtypes can be distinguished: H3.3-K27M; H3.1-K27M,

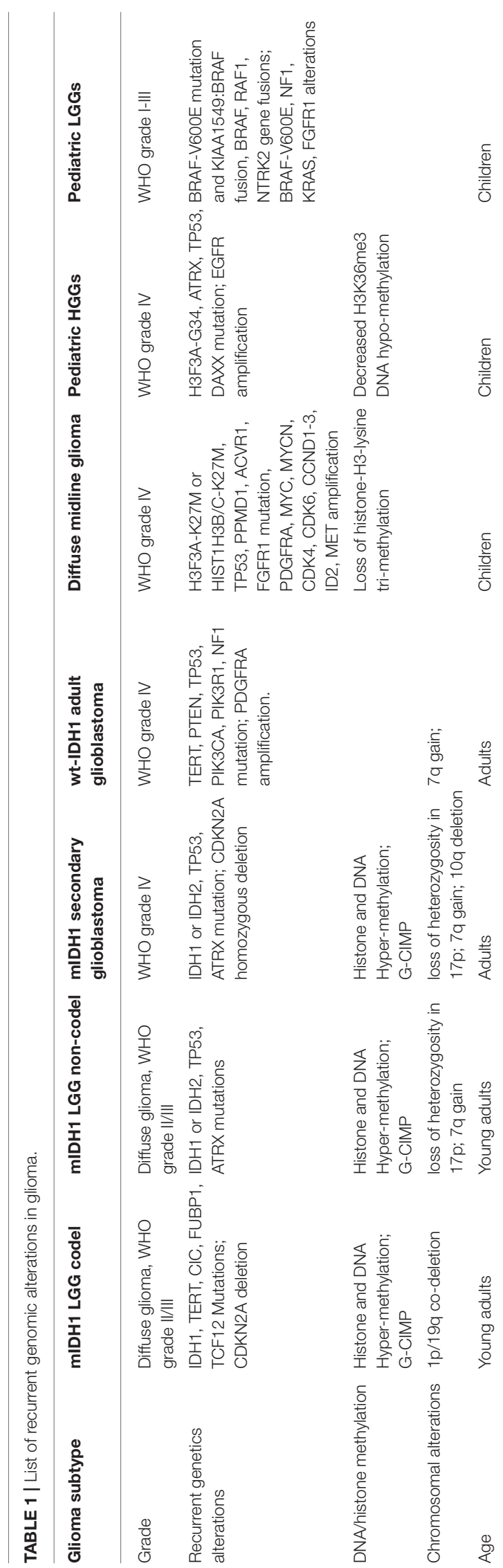


characteristic of high grade midline gliomas, including diffuse intrinsic pontine glioma (DIPG); H3.3G34-R/V; and BRAFV600E (Jones et al., 2017). BRAF alterations are also found in pediatric LGGs (Packer et al., 2017).

In addition, DNA methylation in CpG islands describes the CpG-island methylator phenotype (G-CIMP) which is associated with better prognosis and tightly related with IDH1 mutation (Noushmehr et al., 2010; Wiestler et al., 2014). Recently, a study performed over more than 1,000 diffuse glioma (TCGA) patients, identified glioma DNA methylation clusters (LGm1LGm6) which are linked to molecular glioma subtypes (Ceccarelli et al., 2016). Also, the methylation of CpG islands in the O6methylguanine-DNA methyltransferase (MGMT) promoter has been identified as a molecular marker of better response to treatment with DNA alkylating agents (Wick et al., 2014).

The genetic lesions described in gliomas impact tumor biology and signaling pathways. Important signaling pathways altered in gliomas include the growth factor receptor tyrosine kinase (RTK) signaling pathways, partly as a result of PDGF and EGFR overexpression (Verhaak et al., 2010; Nazarenko et al., 2012). RAS, PI3K/PTEN/AKT, RB/CDK N2A-p16INK4a, and TP53/MDM2/MDM 4/CDKN2A-p14ARF pathways are commonly activated in gliomas and has been involved in cancer cells proliferation (Nakada et al., 2011; Crespo et al., 2015). In addition, NOTCH signaling activity has been reported in WHO grade IV gliomas, and can be associated with hypoxia, PI3K/AKT/mTOR and ERK/MAPK molecular pathways, increase malignant features of gliomas (Gersey et al., 2019).

In pediatric gliomas the MAPK pathway or its downstream effectors, which contribute to tumorigenesis and growth of many types of cancers, can be activated as a consequence of NF1 and BRAF gene mutations (Truong and Nicolaides, 2015; Mackay et al., 2017) In addition, BMP signaling, is also active in pediatric HGG tumor cells (Mendez et al., 2020). Approximately 25\% of childhood brainstem gliomas harbor somatic mutations in Activin A receptor type I (ACVR1) (Fontebasso et al., 2014) which encode the type I BMP receptor ALK2, inducing BMP pathway activation (Olsen et al., 2014). Signaling pathway alterations, resulting from specific genetic lesions in gliomas, represent a valuable target to develop novel targeted gene therapies.

\section{Barriers to Drug and Gene Delivery}

One of the most challenging aspects in developing effective therapies for gliomas is the ability of the therapeutic agents to reach the tumor site at sufficient therapeutic concentrations (Shergalis et al., 2018). This is due to the presence of the Blood Brain Barrier (BBB), composed of a monolayer of endothelial cells held together by restrictive tight junctions (Vorbrodt and Dobrogowska, 2003). Pericytes, astrocytes, nerve terminals and central nervous system-border associated macrophages (BAMs), a specific myeloid subpopulation are closely associated with the endothelium and play critical roles in $\mathrm{BBB}$ development, maintenance and function (Abbott et al., 2010; Rajan et al., 2020). The BBB is a neuroprotective barrier that can block the passage of noxious agents but also the delivery of anti-tumor drugs including gene therapy delivery vehicles (Karim et al.,
2016). Different strategies have emerged to offset these protective effects of the BBB, such as direct delivery of chemotherapeutics to the brain as well as the passive targeting based on the increased permeability and retention (EPR) effects ( $\mathrm{Yu}$ et al., 2016). However, the passive targeting strategy is not sufficient to target invasive tumor cells, as the EPR effects tend to be weak near the infiltrating cancer cell tumor region (Juillerat-Jeanneret, 2008; Kim et al., 2015a). The blood-brain tumor barrier (BBTB), is also known to prevent drugs from accessing the tumor bulk, contributing to chemo-resistance and tumor recurrence. New strategies for actively targeting the BBB have been developed, such as disruptions in tight junctions (Karim et al., 2016), efflux transporter inhibition (Hoosain et al., 2015; Parrish et al., 2015) receptor-mediated transcytosis and/or endocytosis (Wei et al., 2014; Lajoie and Shusta, 2015).

Another consideration is the presence of P-glycoprotein efflux pumps that can actively transport lipophilic drugs out of the brain capillary endothelial cells that form the BBB. Although the $\mathrm{BBB}$ is altered at the tumor site, the dense endothelial cells' layer is not compromised and therefore the $\mathrm{BBB}$ remains effective at preventing drugs from reaching the tumor cells (Sarkaria et al., 2018). These issues need to be addressed during the preclinical phase, before bringing therapeutic candidates into clinical trials for brain cancer (Shergalis et al., 2018).

Due to the inefficient drug delivery across the BBB and development of drug resistance, gene therapy was envisioned as a promising strategy to overcome limitations of conventional therapies. Gene therapy for cancer treatment conventionally includes the introduction of growth regulating or tumor suppressor genes, RNA interference (RNAi) to inhibit the activity of oncogenes. It can also involve the delivery of suicide genes which can convert non-toxic prodrugs into active anticancer compounds. Other approaches include oncolytic and immunomodulatory gene therapy approaches (Candolfi et al., 2009; Puntel et al., 2010; Foreman et al., 2017; Mendez et al., 2020).

Delivery vectors such as viral vectors, non-polymeric nanoparticles (NPs) and polymeric NPs have been used to deliver the therapeutic payload in GBM and LGG (Caffery et al., 2019). To elicit therapeutic effects in the brain, nucleic acids used as therapeutic moieties need to surmount several barriers. Once they enter the blood circulation, they will encounter nuclease degradation, systemic elimination, reticuloendothelial system (RES) uptake before they can successfully cross the $\mathrm{BBB}$, which is impermeable to hydrophilic macromolecules. After sufficient diffusion throughout the brain and into the tumor mass, the therapeutic gene needs to be endocytosed into targeted cells followed by endosome escape to avoid lysosomal degradation and eventually reach the cytoplasm for siRNA or further transport into the nucleus for plasmid DNA (Lu and Jiang, 2017). Viral vectors are attractive delivery vehicles, but they have not yet been clinically approved due in part to manufacturing challenges, high-cost, immunogenic and inflammatory responses, oncogenic mutations and limited loading capacity (Bergen et al., 2008; Rogers and Rush, 2012; Gomes et al., 2015). Non-viral delivery strategies offer alternative approaches that can be developed used to overcome the 
barriers of gene delivery. Many non-viral vectors, including polymeric and non-polymeric are non-immunogenic and can be functionalized with targeting moieties to increase receptormediated uptake of vectors into tumor tissue.

\section{Immune Responses in Glioma}

Immunotherapy has proven successful against a growing number of tumors, unfortunately ongoing attempts to develop new immunotherapies for GBM have not yet demonstrated any significant improvement in glioma patients' survival. In Phase-III clinical trials, immune-checkpoint blockade immunotherapies, which looked highly promising in other solid cancers such as melanoma and lung cancer, were ineffective in GBM (Havel et al., 2019; Zhang et al., 2020). GBM exploits numerous strategies contributing to the evolution of an immunologically suppressive TME that eventually promotes systemic immunosuppression and antagonizes anti-GBM immune responses. GBM mediated immunosuppression is achieved by the production of cytokines and chemokines in the TME and subsequent recruitment of immunosuppressive cells, blocking intra-tumoral T-cell migration and activation (Perng and Lim, 2015). Systemic immunosuppression has been demonstrated by compromised adaptive immunity in murine GBM models and human subjects (Bloch et al., 2013; Chae et al., 2015). TGF-b and IL-10 play a central in maintaining the immunosuppressive TME, these cytokines are not only produced by GBM-infiltrating Tregs, but also by the GBM cells themselves (Perng and Lim, 2015). Another anti-inflammatory cytokine, IL-10 suppresses the activation and effector functions of DCs, macrophages and T cells, and inhibits the MHC-II expression in monocytes (Moore et al., 2001; Perng and Lim, 2015). Additionally, IL-10 promotes the expansion of myeloid-derived suppressor cells (MDSCs), Tregs (Tanikawa et al., 2012) and augments PD-L1 expression in monocytes and tumor-associated macrophages (TAMs) (Bloch et al., 2013). TGF$\mathrm{b}$ is preferentially expressed in GBM cells, and involved in the blockade of $\mathrm{T}$ cell proliferation and activation in murine GBM models and human GBM patients (Bodmer et al., 1989). Higher TGF-b expression levels are correlated with poor prognosis and higher glioma grades (Zhang et al., 2014).

GBMs also produce large amounts of indolamine 2,3dioxygenase (IDO) that triggers the recruitment of Tregs and suppresses effector $\mathrm{T}$ cells' activity by depleting tryptophan from the TME (Wainwright et al., 2012). GBM produces other immunosuppressive factors including colony stimulating factor 1 (CSF-1), NO, PGE2, Arg I, Gal-1, and VEGF (Nduom et al., 2015). PGE2 stimulates anti-inflammatory Th2 cytokines such as IL-4, Il-6, and IL-10 and suppress the production of Th1 cytokines. CSF-1 has been demonstrated to polarize the macrophages to M2 phenotype which enhances the glioma progression (Pyonteck et al., 2013). VEGF inhibits the DCs maturation and promotes angiogenesis (Gabrilovich et al., 1996). GBM derived chemokines CCL22 and CCL2 recruits Tregs which expresses CCR4 into the TME and blockade of these chemokines could improve antitumor immunity (Galvao and Zong, 2013).

Progression of GBM is dependent on the genetic lesions encountered within the tumor cells and also epigenetic alterations resulting in an immunosuppressive glioma microenvironment. Immunosuppressive cells abundant within the glioma microenvironment include of MDSCs (Kamran et al., 2017; Guo et al., 2018), TAMs (Wei et al., 2020), and Tregs (Chang et al., 2016). MDSCs have been shown to promote tumor angiogenesis via secretion of VEGF as well as MMP-9, and also augment the expression of checkpoint receptor ligand PD-L1 (Mirghorbani et al., 2013). We have recently demonstrated that depletion of MDSCs in glioma-bearing mice prominently augments the efficacy of our immune stimulatory gene therapy (Kamran et al., 2017). Immunotherapeutic strategies currently being investigated to treat GBM include passive immunotherapy with antibodies (Kamran et al., 2016), chimeric antigen receptor (CAR) T-cell therapy (Pituch et al., 2018; Choi et al., 2019) autologous activated lymphocytes therapy (Walker et al., 2019; Lee-Chang et al., 2021), immune-mediated gene therapy (Ali et al., 2005; Curtin et al., 2009; Mineharu et al., 2012; Kamran et al., 2017), oncolytic viral therapy (Mooney et al., 2019; Chastkofsky et al., 2020), or active immunotherapy with tumor cell based vaccines, peptides, or dendritic cells (Hdeib and Sloan, 2015; Polivka et al., 2017).

\section{T-cell Exhaustion, TAMs, MDSCs, Tregs}

In glioma, most of the macrophages found within the tumor microenvironment have immune suppressive functionality and support tumor progression (Hambardzumyan et al., 2016). This population of tumor associated macrophages, TAMs, can constitute up to one-third the total mass of the tumor (Roesch et al., 2018). Brain-resident microglial cells and bone marrow derived macrophages (BMDMs) are distinct myeloid cell populations with many shared features including their immunoregulatory abilities and many surface markers (Roesch et al., 2018). Distinguishing features of these populations are that naïve-mature microglia expresses $\mathrm{CD} 45^{\mathrm{lo} / \text { int }}$ and BMDMs express CD45 ${ }^{\text {hi }}$ (Roesch et al., 2018).

MDSCs play a major immune suppressive role in the TME and are correlated with glioma progression and therapeutic resistance (Kamran et al., 2018b; Ostrand-Rosenberg and Fenselau, 2018). MDSCs are divided into two main subpopulations polymorphonuclear-MDSCs (PMN-MDSCs) and monocytic-MDSCs (M-MDSCs) (Kamran et al., 2018b). They are characterized by different sets of surface markers (Kamran et al., 2018b). MDSCs in GBM have also been found to express high levels of the T-cell exhaustion promoting molecule PD-L1 (Kumar et al., 2016). Study revealed that immune suppressive cells work, in part, by inducing $\mathrm{T}$ cell exhaustion. Many T cells within the TME of GBM exhibit an exhausted $\mathrm{T}$ cell phenotype, with lower secretion of IFN- $\gamma$, IL-2, and TNF- $\alpha$ (Woroniecka and Fecci, 2018; Woroniecka et al., 2018). In addition, exhausted $\mathrm{T}$ cells may highly express multiple "inhibitory" receptors, including PD-1, 2B4 (CD244), BTLA, CTLA-4, CD160, LAG-3, and Tim-3 (Wherry and Kurachi, 2015; Osuch et al., 2020). Currently, therapies targeting the classical immune checkpoint pathways responsible for inducing the exhausted T cell phenotype, PD-1 to PD-L1 and CD80/CD86 to CTLA4, are being used to reverse the dysfunctional state and enhance anti-tumor immune response (Kamran et al., 2017; Woroniecka and Fecci, 2018; Woroniecka et al., 2018). Although 
blocking the immune checkpoints with anti-PD-1, anti-PD-L1 and anti-CTLA4 has shown promising results and is an effective strategy for many other types of cancers, their ability to bolster the immune response is limited in the case of GBM (Woroniecka and Fecci, 2018; Woroniecka et al., 2018). High frequencies of Tregs are found in gliomas and this occurrence has also been associated with tumor progression and immune evasion (Mu et al., 2017). Tumor cells recruit Tregs by the CCL22/CCR4 and CCL28/CCR10 signaling axes in GBM. IDO expression on GBM tumor cells has also been shown to stimulate Treg recruitment (Mu et al., 2017).

\section{GENE THERAPY AND VIROTHERAPY IN GLIOMA}

Gene therapy is a therapeutic approach that consists in utilizing genetic elements in order to treat or prevent disease. Whole genes, regulatory elements or oligonucleotides may be delivered to the target cells in glioma patients either by mechanical methods or using delivery vehicles. In order to achieve high therapeutic efficacy, gene therapy vectors must be chosen with caution, taking into consideration therapeutic transgene expression levels, distribution of gene expression within the TME, immunogenicity and biosafety (Castro et al., 2014; Asad et al., 2017; Kamran et al., 2018a). Gene therapy viral and nonviral vectors have shown efficacy in many pre-clinical studies since their first development in the 90s (Okura et al., 2014), but their clinical implementation still presents many challenges (Lowenstein et al., 2009), which we will highlight below. One of the advantages of gene therapy is that its local administration may overcome the challenges posed by the BBB for systemic delivery approaches. Virotherapy is also an attractive therapeutic approach for glioma; it entails the use of genetically engineered viruses, which are no longer virulent and thus, cannot cause disease, but have the capacity of replicating within tumor cells, causing tumor cell death and release of oncolytic viral particles which can continue to infect and kill neighboring tumor cells.

\section{Viral Vectors for Gene Therapy Adenoviral Vectors}

Adenoviruses are non-enveloped, double stranded DNA viruses that exhibit many advantages i.e., feasibility for genetic manipulation, high titers, low biosafety risks, and excellent safety profile after delivery into the brain. They are able to transduce dividing and non-dividing cells, while their genome remains episomal, thus reducing the risk of insertional mutagenesis. Adenoviral vectors (AdV) genome consists of $\sim 35 \mathrm{kbp}$. They possess high cell tropism, since $\mathrm{AdV}$ are able to bind to the target cells via the interaction between their knob domain and the coxsackie and adenovirus receptor (Castro et al., 2014). AdV can also enter cells by endocytosis after interacting with cell surface integrins (Castro et al., 2014).

First-generation AdV were initially produced by deletion of E1 and E3 regions, which makes them non-replicative (Castro et al., 2014) and are replaced by the expression cassette, which could be up to $8 \mathrm{kbp}$. Several strategies have been developed for GBM using AdVs. AdVs encoding for the conditionally cytotoxic enzyme Herpes Simplex Virus thymidine kinase (HSVTK) has exhibited very promising results in clinical trials in GBM. Expression of HSV-TK in glioma cells confers sensitivity to ganciclovir (GCV), as explained below (van Putten et al., 2010). An interesting immunotherapeutic strategy involved the development of a dendritic cell (DC)-specific AdV that targets DEC205, a DC surface receptor, expressing human gliomaspecific antigen (CMV-IE) (Kim et al., 2018). This approach showed prolonged survival in a GBM model and, when rechallenged, brain tumor cells were completely rejected (Kim et al., 2018). Since AdV are not completely devoid of viral genes, they are immunogenic, which leads to transient transgene expression (Barcia et al., 2007).

Adeno-associated viruses (AAV) are small replicationdefective non-enveloped single stranded DNA viruses from the non-pathogenic parvovirus family (Asad et al., 2017). AAV require a helper virus for its replication inside the host cell, such as adenovirus or HSV (van Putten et al., 2010). AAV have many advantages (Santiago-Ortiz and Schaffer, 2016) and among them AAV have a genome of $4.7 \mathrm{kbp}$, allows them to rapidly penetrate solid tumors, such as gliomas (Enger et al., 2002). It was reported that a single intracranial injection of AAV encoding human interferon (IFN)- $\beta$ in human and murine GBM models increases tumor cell death and promotes long-term survival (GuhaSarkar et al., 2017). Many researchers have developed highefficiency AAV for GBM cells, by selection in culture of a chimeric AAV capsid library generated by DNA shuffling of different cap genes, with several different AAV serotypes (Maguire et al., 2010; Zolotukhin et al., 2013). Despite of the many advantages of this vector, at the moment they are not being evaluated in clinical trials; this should be expected soon.

\section{Retroviral Vectors}

Retroviruses are single stranded positive sense RNA viruses, whose RNA genome is reverse transcribed into DNA that integrates into the genome of the host cell (Murphy and Rabkin, 2013). They have a cloning capacity of $\sim 8 \mathrm{kbp}$, with stable expression of the therapeutic transgene, and can only infect dividing cells (Murphy and Rabkin, 2013). Retroviral vectors (RV) encoding HSV-TK were the first viral vectors to be evaluated in clinical trials for glioma (NCT00001328). This study showed anti-tumor activity, but only in smaller tumors (Caffery et al., 2019). A tumor-selective non-lytic replicating RV, Toca 511, and an extended-release formulation of 5-fluorocytosine (5-FC), Toca FC, enables highly efficient transduction of glioma cells with cytosine deaminase (CD), an enzyme that activates the conversion of 5-FC into the anticancer drug 5-fluorouracil (5FU) directly within the infected cells (Takahashi et al., 2014). Researchers showed that this treatment also sensitizes GBM cells to radiotherapy (Takahashi et al., 2014). A previous study also revealed tumor eradication and prolonged survival in immunocompetent mice (Ostertag et al., 2012).

\section{Lentiviral Vectors}

Lentiviruses are single stranded positive sense RNA viruses that have been widely evaluated for the treatment of GBM (Del 
Vecchio et al., 2019). They are similar to RV but exhibit several advantages, mostly because lentiviral vectors (LV) integrate into the host genome but are less prone to insertional mutagenesis. The best-known lentivirus is the human immunodeficiency virus type (HIV)-1, which in 1994 was first seen to transduce lymphocytes (Parolin et al., 1994) and non-dividing cells (Naldini et al., 1996). Third generation HIV-based vectors have been developed with higher transduction efficiency and safety. These vectors may be modified in order to achieve tissue tropism by pseudotyping and exhibit low immunogenicity due to the lack of viral protein expression (Del Vecchio et al., 2019). Lymphocytic choriomeningitis virus-pseudotyped LV were developed to achieve higher transduction efficiency in GBM cells, including glioma stem cells, in relation to normal brain cells (Miletic et al., 2004; Huszthy et al., 2009). LV are the vectors of choice to express silencing RNA (Luan et al., 2015) or for engineering $\mathrm{T}$ cells so that they express chimeric antigen receptors specific for GBM antigens (Yu et al., 2017). Researchers developed a LV with a $2 \mathrm{~A}$ peptide-enabled dual expression system allowing the expression of tumor suppressor proteins growth arrest specific (GAS)-1 and PTEN under the control of a CMV promoter (Sanchez-Hernandez et al., 2018). This vector inhibited the growth of human GBM cells in vitro and elicited inhibition of glioma progression in a human GBM xenograft model (SanchezHernandez et al., 2018). A LV encoding a shRNA specific for TLX, an orphan nuclear receptor (NR2E1), essential for neural-stem cell renewal, inhibited human glioma stem cell tumorigenicity in mice, and induced the expression of DNA hydroxylase ten eleven translocation 3 (TET3), a potent tumor suppressor downstream of TLX (Cui et al., 2016). LVs have also been used to encode the Clustered Regularly Interspaced Short Palindromic Repeats (CRISPR) and CRISPR-associated (Cas) 9 system. Using this system, it was reported that TEA domain transcription factor 1 (TEAD1) ablation inhibited human GBM cell migration and altered the migratory and epithelial mesenchymal transition (EMT) transcriptome signatures (Tome-Garcia et al., 2018).

\section{Non-viral Vectors for Gene Therapy}

Non-viral vectors are emerging as attractive platforms for gene therapy approaches for GBM. Recent studies discussed below, have demonstrated the potential of these delivery technologies.

\section{Non-polymeric Delivery System Liposomes}

Liposomes are artificial, lipid-based microvesicles that are considered as a possible valuable system to achieve therapeutic efficacy in glioma. On this backdrop, a liposomal vector was devised in early 2000s to carry a plasmid coding for HSV-TK which was given to patients with recurrent GBM in a Phase I/II trial via intratumoral infusion, followed by administration of the prodrug ganciclovir (Reszka et al., 2005). This therapy was well-tolerated without major side effects. Also, they observed $>50 \%$ reduction of tumor volume in patients. Although this was a small Phase I trial and thus, it was not powered to determine therapeutic efficacy. Moreover, Kato et al. demonstrated that siRNA-based downregulation of MGMT could enhance the chemosensitivity of malignant gliomas against TMZ using novel liposome, LipoTrust EX Oligo. Such liposome transduced glioma cells are found to be sensitized to TMZ both in vivo and in vitro models (Kato et al., 2010). A dual targeting with T7 and A7R peptides was developed to target vascular endothelial growth factor receptors 2 (VEGFR2) (Zhang et al., 2017). PEGconjugated liposomes modified with the Transferrin receptor (TfR) monoclonal antibody (OX26) and chlorotoxin (CTX) significantly promoted cell transfection, increased the transport of plasmid DNA bearing hTERTC27 gene across the BBB and efficiently targeted brain glioma cells both in vitro and in vivo. This dual targeting therapeutic strategy of OX26/CTX-pL/pC27 against glioma exhibits significant therapeutic efficacy leading to diminished tumor volume and extended survival of glioma bearing rats (Yue et al., 2014). Other liposomal formulations with modified surface and core include magnetite-core cationic liposomes that can be used to activate a heat-shock sensitive promoter in the DNA carried by the liposome, thus regulating expression of the therapeutic gene such as TNF $\alpha$ in glioma cells (Ito et al., 2000).

\section{Nanoparticles}

NU-0129 is a spherical nucleic acid gold nanoparticle containing siRNAs targeting Bcl-2-like protein 12 (Bcl2L12) is now in early phase I clinical trials (NCT03020017) for patients with recurrent glioblastoma. It can cross $\mathrm{BBB}$ in xenograft GBM mice after systemic administration which results in increased apoptosis of glioma cells and reduced tumor progression (Jensen et al., 2013). RNA nanoparticles are also used to deliver anti-miR21 in xenograft GBM mice, resulting in tumor regression and increased survival (Lee et al., 2017). Intravenously-administered chlorotoxin (CTX) coupled stable nucleic acid lipid particle (SNALP) formulated anti-miR21 oligo preferentially accumulates within the brain tumor and efficiently silence miR21 expression. This results in increased mRNA and protein levels of RhoB, leading to reduced tumor load and proliferation without inducing any systemic immunogenicity (Costa et al., 2015). Moreover, combined treatment of both nanoparticles formulated anti-miR21 oligo and tyrosine kinase inhibitor Sunitinib exerts enhanced apoptosis and improved survival in mice (Costa et al., 2015).

Development of a library with PBAE based nanoparticles carrying herpes simplex virus type I thymidine kinase (HSV-TK) DNA, resulted in apoptosis of transfected glioma cells. This led to increased median survival of glioma bearing animals when delivered intracranially (Choi et al., 2020). Furthermore, when HSV-TK DNA loaded nanoparticles are delivered in combination with the prodrug ganciclovir (GCV) to glioma cells in vivo, they elicited induction of apoptosis and reduction of tumor load in glioma bearing rats (Mangraviti et al., 2015). Another important type of anti-GBM treatment in gene therapy uses different types of RNA such as dsRNA, siRNA or miR101 associated to nanoparticulate systems resulting in enhanced apoptosis of GBM cells. Also inhibition of growth and migration of these cells can be induced through targeting miR34 or proteins like SOX9 and Ras with the same nanoparticulate systems (Shu et al., 2014; Kim et al., 2015b; Alphandery, 2020). 
We have recently demonstrated that local treatment of glioma with sHDL (synthetic High-density lipoprotein) mimicking nanodiscs containing ApoAI mimetic peptide, phospholipids, immunogenic cell death inducing chemotherapeutics (ICD) docetaxel and adjuvant CpG oligodeoxynucleotide, effectively elicit anti-glioma T-cell activity and induce immunological memory response against tumor relapse (Kadiyala et al., 2019). We also engineered an albumin based NPs equipped with cellpenetrating iRGD peptide, containing siRNA against Signal Transducer and Activation of Transcription 3 factor (STAT3i) and demonstrated that when administered in combination with ionizing radiation, these NPs activate anti-GBM immunologic memory which results in tumor regression and long term survival of GBM bearing mice (Gregory et al., 2020). Other peptide modifications on nano-platforms have been explored to minimize off-target accumulation and facilitate active tumor targeting or mediate $\mathrm{BBB}$ transport. For example, IL-13R $\alpha 2$ is overexpressed on glioma cells, therefore it is an attractive target for peptide-modified nanotherapies (Madhankumar et al., 2006). A study revealed that IL-13-conjugated nanoplatform enhanced therapeutic efficacy in a subcutaneous mouse model of glioma (Madhankumar et al., 2006). Moreover, transferrin receptor (TfR) has been extensively researched as a target for gliomas, because TfR is over-expressed on glioma cells (Kang et al., 2015). Despite exploiting the use of TfR as a target for decades, translation of systems leveraging these finding have been limited (Johnsen et al., 2019). On this backdrop, a seven amino acid peptide (sequence: HAIYPRH, T7), which has a greater affinity for TfR has been used for glioma targeting to deliver siRNA (Wei et al., 2016), coupled with other targeting ligands to demonstrate increased transport across the BBB and greater tumor penetration (Zong et al., 2014).

\section{Oncolytic Viruses}

Several oncolytic viruses have been evaluated in preclinical studies or clinical trials for the treatment of GBM. Specificity must be seriously evaluated, taking into consideration the infection capacity of the vector. Oncolytic viruses (OVs) are designed to recognize tumor receptors or to replicate under oncogene promoters in order to improve their tropism and avoid non-neoplastic cells. It was observed that the immunosuppression present in the tumor microenvironment promotes the OV infection capacity and improves the oncolysis (Tobias et al., 2013; Davola and Mossman, 2019). Once infected, the dying tumor cells start the presentation of tumor epitopes, triggering a viral-specific and tumor-specific $\mathrm{T}$ cell-mediated immune response, critical for the efficiency of the oncolytic virotherapy ( $\mathrm{Li}$ et al., 2017). When tumor cells are lysed, tumor-associated antigens (TAA) are released into the tumor microenvironment and recognized by the immune system, which stimulates the recruitment of activated immune cells which overcome the tumor-mediated immunosuppression and activate a systemic response (Figure 1) (Marelli et al., 2018). When using antitumor viral gene therapy, the administration and distribution of the vectors must be evaluated, taking into consideration their ability to overcome antiviral immune responses and to cross the BBB.
A genetically engineered third generation oncolytic HSV, G47 $\Delta$ that is armed with IL-12 showed increased survival in a syngeneic murine GBM stem cell model (Cheema et al., 2013). G47 $\Delta$ was evaluated in a phase II clinical trial in patients with GBM, who received repeated intratumoral stereotactic injections, in addition to TMZ (Todo, 2019).

Newcastle disease virus (NDV) based vectors have a natural tropism for tumor cells, together with oncolytic potential and immuno-stimulatory properties (Schirrmacher et al., 2019). It was shown that the complementary treatment with LaSota strain of the naturally oncolytic NDV induces increased apoptosis in glioma cells, comparing with TMZ alone (Bai et al., 2018). The combination treatment also significantly extended survival in a rat xenograft tumor model (Bai et al., 2018).

Finally, in vivo immunovirotherapy with measles virus (MV) strains in combination with anti-PD-L1 blockade synergistically increased the survival of a murine syngeneic GBM model, together with the enhanced infiltration of activated $\mathrm{CD} 8^{+} \mathrm{T}$ cells (Hardcastle et al., 2017). MV has already been evaluated in a dose-escalating phase I clinical trial in recurrent GBM in which no dose limiting toxicities were observed (NCT00390299) (Table 3).

\section{APPROACHES TO GENE THERAPY}

This section was structured taking into account the gene therapeutic approaches against glioma (Table 2) that are currently under Phase-I/II/III clinical trials (Table 3). We will discuss advantages and limitations of the proposed approaches. We have included the clinical trials that were listed, in clinicaltrials.gov using the key words: "Condition or disease: glioma;" "Study type: interventional studies (clinical trials)"; "Status: Recruiting, not recruiting, not yet recruiting, and active;" "Phase: Phase 1, Phase 2, Phase 3." For "other terms" we used the following words: gene therapy, virus, and antibody. Table 3 was updated in October 2020 and includes all the clinical trials found under those key words. Trials were organized depending upon 10 major viral vectors currently used in clinical trials.

\section{Suicide Gene Therapy: Conditional Cytotoxic Therapy}

Suicide gene therapy is the most studied gene therapy approach for the treatment of glioma. This strategy is based on genes encoding for an enzyme that converts a non-toxic prodrug into a cytotoxic drug. Gene therapy vectors allow restricting enzyme expression to the transduced brain tumor cells, without altering the normal brain parenchyma. In addition, this strategy is toxic for cells that are replicating, and thus, specifically targets dividing tumor cells.

Genetically engineered neural or mesenchymal stem cells (NSC, MSC) may be used as vectors for suicide gene therapy, given their ability to migrate toward tumor cells. Recently, Tamura and colleagues evaluated the efficacy of a LV encoding HSV-TK under the control of a tet-inducible system for the treatment of GBM using neural stem/progenitor cells (NS/PCs) derived from induced pluripotent stem cells (hiPSCs). Results 


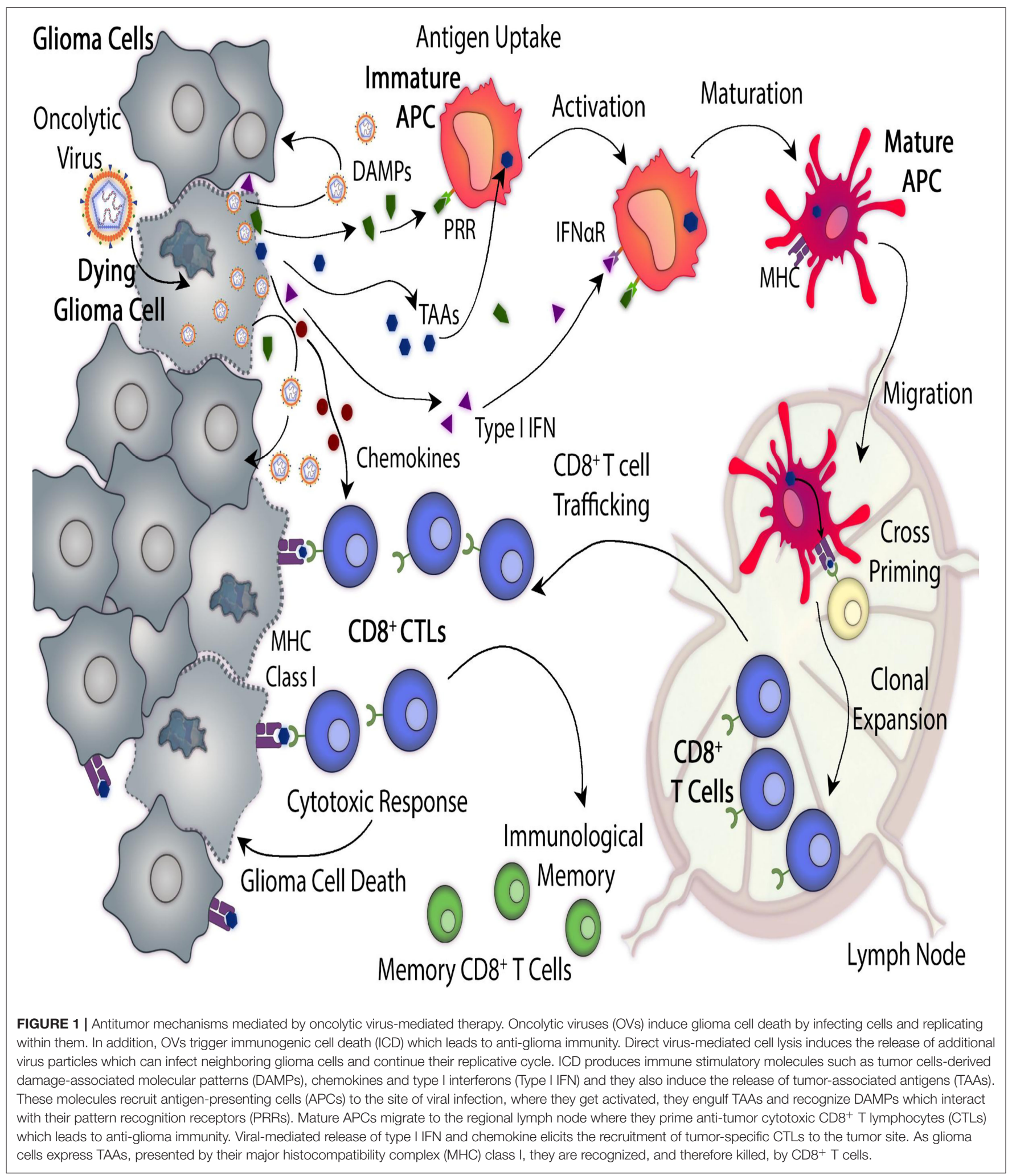

showed the directional migration of these NS/PCs and the consequent inhibition in tumor growth in a human GBM xenograft model (Tamura et al., 2020). Currently, there are around 20 Phase-I/II clinical trials testing the effectiveness of $\mathrm{AdV}$ in different types of glioma (Table 3). The great majorities of these are studying either the effect of HSV-tk 
TABLE 2 | List of Viral vectors used in glioma gene therapy.

\begin{tabular}{|c|c|c|c|}
\hline Vectors & Genome & Advantages & Disadvantages \\
\hline Adenovirus (AdV) & $\begin{array}{l}\text { Non-enveloped } \\
\text { dsDNA } \\
\text { Cloning capacity: } 8 \text { kbp }\end{array}$ & $\begin{array}{l}\text { Production in high titers. } \\
\text { Transduction of diving and non-dividing cells. } \\
\text { Non-integrative, avoids insertional mutagenesis. } \\
\text { Replicative or oncolytic. } \\
\text { Transduce wide varieties of cells. } \\
\text { Feasibility for being safely manipulated. } \\
\text { Robust expression. }\end{array}$ & $\begin{array}{l}\text { Highly Immunogenic. } \\
\text { Existence of anti-AdV immunity in the population, } \\
\text { leading to the clearance of the vector. }\end{array}$ \\
\hline Adeno-associated virus (AAV) & $\begin{array}{l}\text { Non-enveloped } \\
\text { dsDNA } \\
\text { Cloning capacity: } 8 \mathrm{kbp} \\
\text { Parvovirus family }\end{array}$ & $\begin{array}{l}\text { Helper virus-dependent replication. } \\
\text { They remain episomal in the absence of helper virus. } \\
\text { Transduce dividing and non-dividing cells. } \\
\text { Lack of immunogenicity } \\
\text { Its small size allows the penetration into solid tumors. } \\
\text { Transduce wide varieties of cells. } \\
\text { Long-term expression. }\end{array}$ & $\begin{array}{l}\text { Possibility of insertional mutagenesis. } \\
\text { Low transduction in certain cell types. } \\
\text { Existence of anti-AdV immunity in the population, } \\
\text { leading to the clearance of the vector. } \\
\text { Small cloning capacity. }\end{array}$ \\
\hline Retrovirus (RV) & $\begin{array}{l}\text { Enveloped } \\
\text { ss(+)DNA } \\
\text { Cloning capacity: } 8 \text { kbp }\end{array}$ & $\begin{array}{l}\text { Stable transgene expression. } \\
\text { Feasibility to be modified to achieve higher tropism. }\end{array}$ & $\begin{array}{l}\text { Possibility of inserional mutagenesis. } \\
\text { Infection of dividing cells only. } \\
\text { Production in low titers } \\
\text { Their manipulation requires more biosafety. }\end{array}$ \\
\hline Lentivirus (LV) & $\begin{array}{l}\text { Enveloped } \\
\text { ss(+)DNA } \\
\text { Cloning capacity: } 8 \mathrm{kbp}\end{array}$ & $\begin{array}{l}\text { Transduce dividing and non-dividing cells. } \\
\text { Stable transgene expression. } \\
\text { Their integration is less prone to insertional mutagenesis } \\
\text { than RV. } \\
\text { Transduce hematopoietic cells. } \\
\text { Feasibility for being engineered to avoid integration, } \\
\text { increasing biosafety. } \\
\text { Feasibility to be modified to achieve higher tropism }\end{array}$ & $\begin{array}{l}\text { Possibility of insertional mutagenesis. } \\
\text { Engineered non-integrative LV have less stable } \\
\text { transgene expression. } \\
\text { Production in low titers. } \\
\text { Their manipulation requires more biosafety. }\end{array}$ \\
\hline Baculovirus (BV) & $\begin{array}{l}\text { Enveloped } \\
\text { dsDNA } \\
\text { Cloning capacity: } 38 \mathrm{kbp}\end{array}$ & $\begin{array}{l}\text { Non-integrative, avoids insertional mutagenesis. } \\
\text { They do not replicate in human cells, which makes them } \\
\text { very safe. } \\
\text { There is no pre-existent anti-BV immunity in the } \\
\text { population. } \\
\text { Transduction of wide varieties of cells. } \\
\text { Feasibility to be modified to achieve higher tropism. } \\
\text { Large cloning capacity. }\end{array}$ & $\begin{array}{l}\text { They have not been evaluated in clinical trials. } \\
\text { Unstable long-term storage. }\end{array}$ \\
\hline Herpes simplex virus (HSV) & $\begin{array}{l}\text { Enveloped } \\
\text { dsDNA } \\
\text { Cloning capacity: } 20 \mathrm{kbp}\end{array}$ & $\begin{array}{l}\text { Non-integrative, avoids insertional mutagenesis. } \\
\text { Replicative or oncolytic. } \\
\text { Feasibility to be modified to achieve higher tropism. } \\
\text { Large cloning capacity. }\end{array}$ & $\begin{array}{l}\text { Pathogen to humans, so they must be } \\
\text { engineered. } \\
\text { Immunogenicity. } \\
\text { Existence of anti-HSV immunity in the population, } \\
\text { leading to the clearance of the vector. } \\
\text { Production in low titers. }\end{array}$ \\
\hline Newcastle disease virus (NDV) & $\begin{array}{l}\text { Enveloped } \\
\text { ss(-)RNA } \\
\text { Paramyxoviridae family }\end{array}$ & $\begin{array}{l}\text { Non-pathogen to humans. } \\
\text { High tropism } \\
\text { Oncolytic } \\
\text { Selective replication in tumor cells }\end{array}$ & $\begin{array}{l}\text { Limited gene insertion. } \\
\text { Limited manipulation. }\end{array}$ \\
\hline Measles virus (MV) & $\begin{array}{l}\text { Enveloped } \\
\text { ss(-)RNA } \\
\text { Paramyxoviridae family }\end{array}$ & $\begin{array}{l}\text { High tropism. } \\
\text { Feasibility to be modified for being retargeted. } \\
\text { Oncolytic } \\
\text { Selective replication in tumor cells. }\end{array}$ & $\begin{array}{l}\text { Pathogen to humans, so attenuated strains must } \\
\text { be used. } \\
\text { Limited gene insertion. }\end{array}$ \\
\hline
\end{tabular}

gene therapy or studying the effect of oncolytic AdVs in combination with valacyclovir/ganciclovir or standard of care (SOC) therapies (Chiocca et al., 2011) (Table 3). However, encouraging results from a multi-institutional Phase-II study (NCT00589875) (Wheeler et al., 2016) contrasted with negative results from a Phase-III randomized open-label trial using a similar approach (NCT00870181) (Ji et al., 2016). A Phase-I trial is currently evaluating the intratumoral delivery of Ad-TK and oral administration of the prodrug valacyclovir coupled with SOC and the checkpoint inhibitor Nivolumab in newly diagnosed patients with HGG (NCT03576612). Also, a phase III clinical trial revealed that adjuvant therapy with HSV-tk and ganciclovir through retroviral gene therapy delivered to the surgical resection cavity in combination with radiation in adults with previously untreated GBM failed to improve the overall survival of (Rainov, 2000). Although the feasibility and good biosafety profile of this gene therapy strategy were supported in this study. The failure of this specific protocol may be due mainly to the presumably poor rate of delivery of the HSV-tk gene to the tumor cells. In addition, the current mode of manual injection of vector-producing cells 
TABLE 3 | List of Viral vectors under clinical trials for glioma.

\begin{tabular}{|c|c|c|c|c|c|c|c|c|}
\hline $\begin{array}{l}\text { Sr. } \\
\text { no. }\end{array}$ & $\begin{array}{l}\text { Viral } \\
\text { vector }\end{array}$ & Gene therapy & Combination therapy & Condition & Phase & Clinical trial & Status & ID \\
\hline 1 & AdV & HSV-TK & Valacyclovir + Std treatment & $\begin{array}{l}\text { GBM, Anaplastic } \\
\text { astrocytoma }\end{array}$ & I-II & $\begin{array}{l}\text { HSV-tk and XRT and } \\
\text { chemotherapy for newly } \\
\text { diagnosed GBM }\end{array}$ & Recruiting & NCT03603405 \\
\hline 2 & & HSV-TK & Valacyclovir + radiation & $\begin{array}{l}\text { Recurrent GBM, } \\
\text { Astrocytoma grade III }\end{array}$ & $|-| \mid$ & $\begin{array}{l}\text { HSV-tk + Valacyclovir + SBRT + } \\
\text { chemotherapy for recurrent GBM }\end{array}$ & Recruiting & NCT03596086 \\
\hline 3 & & AdV-TK & Ganciclovir + chemotherapy & High grade glioma & $\|$ & $\begin{array}{l}\text { ADV-TK Improves outcome of } \\
\text { recurrent high-grade glioma }\end{array}$ & Completed & NCT00870181 \\
\hline 4 & & HSV-TK & Valacyclovir + radiation & $\begin{array}{l}\text { Malignant glioma, GBM, } \\
\text { Anaplastic astrocytoma }\end{array}$ & $\mathrm{Ib}$ & $\begin{array}{l}\text { Phase } 1 \mathrm{~b} \text { study of AdV-tk + } \\
\text { Valacyclovir combined with } \\
\text { radiation therapy for malignant } \\
\text { gliomas }\end{array}$ & Completed & NCT00751270 \\
\hline 5 & & HSV-TK & Valacyclovir + Std treatment & $\begin{array}{l}\text { Malignant glioma, GBM, } \\
\text { Anaplastic astrocytoma }\end{array}$ & Ila & $\begin{array}{l}\text { Phase 2a study of AdV-tk with } \\
\text { standard radiation therapy for } \\
\text { malignant glioma (BrTK02) }\end{array}$ & Completed & NCT00589875 \\
\hline 6 & & HSV-TK + Flt3L & & Malignant glioma, GBM & I & $\begin{array}{l}\text { Combined cytotoxic and } \\
\text { immune-stimulatory therapy for } \\
\text { glioma }\end{array}$ & Active & NCT01811992 \\
\hline 7 & & HSV-TK & Ganciclovir + Chemotherapy & Brain and CNS tumors & I & $\begin{array}{l}\text { Gene therapy in treating patients } \\
\text { with primary brain tumors }\end{array}$ & Completed & NCT00002824 \\
\hline 8 & & p53 & & Brain and CNS tumors & 1 & $\begin{array}{l}\text { Gene therapy in treating patients } \\
\text { with recurrent malignant gliomas }\end{array}$ & Completed & NCT00004041 \\
\hline 9 & & p53 & & Brain and CNS tumors & 1 & $\begin{array}{l}\text { Gene therapy in treating patients } \\
\text { with recurrent or progressive } \\
\text { brain tumors }\end{array}$ & Completed & NCT00004080 \\
\hline 10 & & AdV-TK & Valacyclovir + Radiation & $\begin{array}{l}\text { Pedriatic brain tumors } \\
\text { including GBM, anaplastic } \\
\text { astrocytoma, recurrent } \\
\text { ependymomas }\end{array}$ & I & $\begin{array}{l}\text { A phase I study of AdV-tk }+ \\
\text { prodrug therapy in combination } \\
\text { with radiation therapy for } \\
\text { pediatric brain tumors }\end{array}$ & Active & NCT00634231 \\
\hline 11 & & Delta-24-RGD (oncolytic AdV) & & Recurrent GBM & I-II & $\begin{array}{l}\text { Safety study of } \\
\text { replication-competent } \\
\text { adenovirus (delta-24-rgd) in } \\
\text { patients with recurrent } \\
\text { glioblastoma }\end{array}$ & Completed & NCT01582516 \\
\hline 12 & & DNX-2440 (oncolytic AdV) & & Recurrent GBM & I & $\begin{array}{l}\text { DNX-2440 oncolytic adenovirus } \\
\text { for recurrent glioblastoma }\end{array}$ & Active & NCT03714334 \\
\hline 13 & & $\begin{array}{l}\text { DNX-2401 (conditionally } \\
\text { replicative and oncolytic AdV) }\end{array}$ & $\mathrm{IFN}-\gamma$ & $\begin{array}{l}\text { Recurrent GBM or } \\
\text { gliosarcoma }\end{array}$ & $\mathrm{lb}$ & $\begin{array}{l}\text { DNX-2401 with interferon } \\
\text { gamma (IFN- } \gamma \text { ) for recurrent } \\
\text { glioblastoma or gliosarcoma } \\
\text { brain tumors (TARGET-I) }\end{array}$ & Completed & NCT02197169 \\
\hline 14 & & $\begin{array}{l}\text { DNX-2401 (conditionally } \\
\text { replicative and oncolytic AdV) }\end{array}$ & TMZ & Recurrent GBM & I & $\begin{array}{l}\text { Virus DNX2401 and } \\
\text { temozolomide in recurrent } \\
\text { glioblastoma }\end{array}$ & Completed & NCT01956734 \\
\hline
\end{tabular}


TABLE 3 | Continued

\begin{tabular}{|c|c|c|c|c|c|c|c|c|}
\hline $\begin{array}{l}\text { Sr. } \\
\text { no. }\end{array}$ & $\begin{array}{l}\text { Viral } \\
\text { vector }\end{array}$ & Gene therapy & Combination therapy & Condition & Phase & Clinical trial & Status & ID \\
\hline 15 & & AdV-TK & Ganciclovir + Chemotherapy & $\begin{array}{l}\text { Recurrent high grade } \\
\text { gliomas }\end{array}$ & $\|$ & $\begin{array}{l}\text { ADV-TK improves outcome of } \\
\text { recurrent high-grade glioma }\end{array}$ & Completed & NCT00870181 \\
\hline 16 & & $\begin{array}{l}\text { DNX-2401 (conditionally } \\
\text { replicative and oncolytic AdV) }\end{array}$ & Pembrolizumab & GBM or gliosarcoma & $\|$ & $\begin{array}{l}\text { Combination Adenovirus }+ \\
\text { pembrolizumab to trigger } \\
\text { immune virus effects (CAPTIVE) }\end{array}$ & Active & NCT02798406 \\
\hline 17 & & $\begin{array}{l}\text { DNX-2401 (conditionally } \\
\text { replicative and oncolytic AdV) }\end{array}$ & & $\begin{array}{l}\text { Recurrent high grade } \\
\text { gliomas }\end{array}$ & 1 & $\begin{array}{l}\text { Oncolytic Adenovirus DNX-2401 } \\
\text { in treating patients with recurrent } \\
\text { high-grade glioma }\end{array}$ & Recruiting & NCT03896568 \\
\hline 18 & & Ad-RTS-hIL12* & Veledimex & $\begin{array}{l}\text { GBM or anaplastic } \\
\text { oligoastrocytoma }\end{array}$ & 1 & $\begin{array}{l}\text { A study of Ad-RTS-hlL- } 12 \text { with } \\
\text { veledimex in subjects with } \\
\text { glioblastoma or malignant glioma }\end{array}$ & Active & NCT02026271 \\
\hline 19 & & $\begin{array}{l}\text { Neural stem cells loaded with } \\
+ \text { oncolytic AdV }\end{array}$ & Radio and Chemotherapy & Malignant glioma & I & $\begin{array}{l}\text { Neural stem cell based } \\
\text { virotherapy of newly diagnosed } \\
\text { malignant glioma }\end{array}$ & Completed & NCT03072134 \\
\hline 20 & & Ad-RTS-hIL12 & Veledimex & $\begin{array}{l}\text { Pedriatic brain tumors or } \\
\text { diffuse intrinsic pontine } \\
\text { glioma }\end{array}$ & 1 & $\begin{array}{l}\text { A study of Ad-RTS-hIL- } 12+ \\
\text { Veledimex in pediatric subjects } \\
\text { with brain tumors or DIPG }\end{array}$ & Active & NCT03330197 \\
\hline 21 & HSV-1 & M032-HSV* + IL-12 & & $\begin{array}{l}\text { Recurrent GBM, } \\
\text { progressive GBM, } \\
\text { anaplastic astrocytoma or } \\
\text { gliosarcoma }\end{array}$ & I & $\begin{array}{l}\text { Genetically engineered HSV-1 } \\
\text { phase } 1 \text { study for the treatment } \\
\text { of recurrent malignant glioma } \\
\text { (M032-HSV-1) }\end{array}$ & Recruiting & NCT02062827 \\
\hline 22 & & $\mathrm{C} 134-\mathrm{HSV}^{*}+\mathrm{IRS}-1$ & & $\begin{array}{l}\text { GBM, anaplastic } \\
\text { astrocytoma, gliosarcoma }\end{array}$ & 1 & $\begin{array}{l}\text { Trial of C134 in patients with } \\
\text { recurrent GBM (C134-HSV-1) }\end{array}$ & Recruiting & NCT03657576 \\
\hline 23 & & G207 (oncolytic HSV-1) & & Recurrent brain cancer & $\mid-I I$ & $\begin{array}{l}\text { Safety and effectiveness study of } \\
\text { G207, a tumor-killing virus, in } \\
\text { patients with recurrent brain } \\
\text { cancer }\end{array}$ & Completed & NCT00028158 \\
\hline 24 & & G207 (oncolytic HSV-1) & Radiotherapy & $\begin{array}{l}\text { Pediatric recurrent or } \\
\text { refractory cerebellar brain } \\
\text { tumors }\end{array}$ & I & $\begin{array}{l}\text { HSV G207 in children with } \\
\text { recurrent or refractory cerebellar } \\
\text { brain tumors }\end{array}$ & Recruiting & NCT03911388 \\
\hline 25 & & G207 (oncolytic HSV-1) & Radiotherapy & $\begin{array}{l}\text { Pediatric progressive or } \\
\text { recurrent supratentorial } \\
\text { brain tumors }\end{array}$ & 1 & $\begin{array}{l}\text { HSV G207 alone or with a single } \\
\text { radiation dose in children with } \\
\text { progressive or recurrent } \\
\text { supratentorial brain tumors }\end{array}$ & Recruiting & NCT02457845 \\
\hline 26 & & G47delta (oncolytic HSV-1) & TMZ & GBM & $\|$ & $\begin{array}{l}\text { Results of a phase II clinical trial } \\
\text { of oncolytic herpes virus G } 47 \Delta \\
\text { in patients with glioblastoma }\end{array}$ & Completed & Todo, 2019 \\
\hline
\end{tabular}


TABLE 3 | Continued

\begin{tabular}{|c|c|c|c|c|c|c|c|c|}
\hline $\begin{array}{l}\text { Sr. } \\
\text { no. }\end{array}$ & $\begin{array}{l}\text { Viral } \\
\text { vector }\end{array}$ & Gene therapy & Combination therapy & Condition & Phase & Clinical trial & Status & ID \\
\hline 27 & LV & Temferon ${ }^{*}$ & & $\begin{array}{l}\text { GBM with unmethylated } \\
\text { MGMT promoter }\end{array}$ & I-Ila & $\begin{array}{l}\text { A Phase I/lla study evaluating } \\
\text { temferon in patients with } \\
\text { glioblastoma and unmethylated } \\
\text { MGMT (TEM-GBM) }\end{array}$ & Recruiting & NCT03866109 \\
\hline 28 & & NK-92/5.28.z & & GBM & I & $\begin{array}{l}\text { Intracranial injection of } \\
\text { NK-92/5.28.z cells in patients } \\
\text { with recurrent HER2-positive } \\
\text { glioblastoma (CAR2BRAIN) }\end{array}$ & Recruiting & NCT03383978 \\
\hline 29 & & $\begin{array}{l}\text { Modified } \gamma \delta \text { T cells, resistant to } \\
\text { chemotherapy }\left(\left.\mathrm{DR}\right|^{*}\right)\end{array}$ & TMZ & GBM & 1 & $\begin{array}{l}\text { Novel gamma-delta }(\gamma \delta) T \text { cell } \\
\text { therapy for treatment of patients } \\
\text { with newly diagnosed } \\
\text { Glioblastoma (DRI) }\end{array}$ & Recruiting & NCT04165941 \\
\hline 30 & & $\begin{array}{l}\text { CAR T cells with a chlorotoxin } \\
\text { tumor targeting domain }\end{array}$ & & $\begin{array}{l}\text { Recurrent or progressive } \\
\text { MPP2+ GBM, recurrent } \\
\text { grade III glioma, recurrent } \\
\text { grade II glioma }\end{array}$ & 1 & $\begin{array}{l}\text { Chimeric antigen receptor (CAR) } \\
\text { T cells with a chlorotoxin } \\
\text { tumor-targeting domain for the } \\
\text { treatment of MPP2 } 2^{+} \text {recurrent or } \\
\text { progressive glioblastoma }\end{array}$ & Recruiting & NCT04214392 \\
\hline 31 & & $\begin{array}{l}\text { IL13R } \alpha 2 \text {-specific hinge } \\
\text { optimized } 41 \text { BB-co-stimulatory } \\
\text { CAR truncated CD19+ } \\
\text { autologous T cells* }\end{array}$ & & $\begin{array}{l}\text { Recurrent or refractory } \\
\text { GBM }\end{array}$ & 1 & $\begin{array}{l}\text { Genetically modified T-cells in } \\
\text { treating patients with recurrent or } \\
\text { refractory malignant glioma }\end{array}$ & Recruiting & NCT02208362 \\
\hline 32 & & $\begin{array}{l}\text { HER2(EQ)BBzeta/CD19t }{ }^{+} \mathrm{T} \\
\text { cells* }^{*}\end{array}$ & & $\begin{array}{l}\text { Recurrent or refractory } \\
\text { GBM }\end{array}$ & 1 & $\begin{array}{l}\text { Memory-enriched T cells in } \\
\text { treating patients with recurrent or } \\
\text { refractory grade III-IV glioma }\end{array}$ & Recruiting & NCT03389230 \\
\hline 33 & & 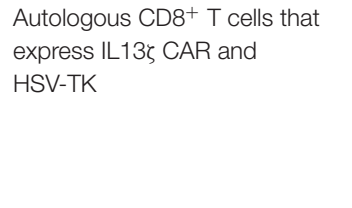 & Ganciclovir & $\begin{array}{l}\text { Recurrent or refractory } \\
\text { high-grade malignant } \\
\text { glioma }\end{array}$ & 1 & $\begin{array}{l}\text { Cellular adoptive immunotherapy } \\
\text { using genetically modified } \\
\text { T-lymphocytes in treating } \\
\text { patients with recurrent or } \\
\text { refractory high-grade malignant } \\
\text { glioma }\end{array}$ & Completed & NCT00730613 \\
\hline 34 & MV & $\begin{array}{l}\text { Carcinoembryonic Antigen } \\
\text { (CEA) }\end{array}$ & & Recurrent GBM & 1 & $\begin{array}{l}\text { Viral therapy in treating patients } \\
\text { with recurrent glioblastoma } \\
\text { multiforme }\end{array}$ & Completed & NCT00390299 \\
\hline 35 & NDV & NDV-HUJ & & Recurrent GBM & $|-| \mid$ & $\begin{array}{l}\text { Phase I/I trial of intravenous } \\
\text { NDV-HUJ oncolytic virus in } \\
\text { recurrent glioblastoma } \\
\text { multiforme }\end{array}$ & Completed & $\begin{array}{l}\text { Freeman et al., } \\
2006\end{array}$ \\
\hline 36 & $\mathrm{RV}$ & $\begin{array}{l}\text { Autologous T cells expressing } \\
\text { receptors anti-mutated } \\
\text { neoantigens }\end{array}$ & & $\begin{array}{l}\text { GBM, non-small cell lung } \\
\text { cancer, ovarian cancer, } \\
\text { breast cancer, } \\
\text { gastrointestinal cancer, } \\
\text { genitourinary cancer }\end{array}$ & $\|$ & $\begin{array}{l}\text { Administration of autologous } \\
\text { T-cells genetically engineered to } \\
\text { express T-cell receptors reactive } \\
\text { against mutated neoantigens in } \\
\text { people with metastatic cancer }\end{array}$ & Recruiting & NCT03412877 \\
\hline
\end{tabular}


TABLE 3 | Continued

\begin{tabular}{|c|c|c|c|c|c|c|c|c|}
\hline $\begin{array}{l}\text { Sr. } \\
\text { no. }\end{array}$ & $\begin{array}{l}\text { Viral } \\
\text { vector }\end{array}$ & Gene therapy & Combination therapy & Condition & Phase & Clinical trial & Status & ID \\
\hline 37 & & Toca 511 & Toca FC & $\begin{array}{l}\text { Recurrent GBM, } \\
\text { anaplastic astrocytoma, } \\
\text { anaplastic } \\
\text { oligodendroglioma, } \\
\text { anaplastic } \\
\text { oligoastrocytoma }\end{array}$ & 1 & $\begin{array}{l}\text { A study of a retroviral replicating } \\
\text { vector combined with a prodrug } \\
\text { administered to patients with } \\
\text { recurrent malignant glioma }\end{array}$ & Completed & NCT01156584 \\
\hline 38 & & $\begin{array}{l}\text { Leukocytes expressing } \\
\text { anti-EGFRvIll CAR* }\end{array}$ & $\begin{array}{l}\text { Aldesleukin, Fludarabine, } \\
\text { Cyclophosphamide }\end{array}$ & $\begin{array}{l}\text { Malignant glioma, GBM, } \\
\text { brain cancer, gliosarcoma }\end{array}$ & $|-| \mid$ & $\begin{array}{l}\text { CART cell receptor } \\
\text { immunotherapy targeting } \\
\text { EGFRvill for patients with } \\
\text { malignant gliomas expressing } \\
\text { EGFRvlll }\end{array}$ & Completed & NCT01454596 \\
\hline 39 & & $\begin{array}{l}\text { Autologous HER2-CD28 } \\
\text { CMV-T cells }\end{array}$ & & GBM & 1 & $\begin{array}{l}\text { CMV-specific cytotoxic T } \\
\text { lymphocytes expressing CAR } \\
\text { TARGETING HER2 in patients } \\
\text { with GBM (HERT-GBM) }\end{array}$ & Completed & NCT01109095 \\
\hline 4 & & $\begin{array}{l}\mathrm{CD} 34^{+} \text {cells are transduced } \\
\text { with a fibronectin assisted RV } \\
\text { expressing MGMT }\end{array}$ & $\begin{array}{l}\text { Filgrastim, iomustine, } \\
\text { procarbazine hydrochloride, } \\
\text { vincristine sulfate }\end{array}$ & $\begin{array}{l}\text { Bone marrow } \\
\text { suppression, brain and } \\
\text { CNS tumors }\end{array}$ & 1 & $\begin{array}{l}\text { Combination chemotherapy plus } \\
\text { gene therapy in treating patients } \\
\text { with CNS tumors }\end{array}$ & Completed & NCT00005796 \\
\hline 41 & & $\begin{array}{l}\text { Neural stem cells that express } \\
\text { cytosine deaminase }\end{array}$ & 5-fluorocytosine & $\begin{array}{l}\text { Recurrent high-grade } \\
\text { gliomas }\end{array}$ & Pilot & $\begin{array}{l}\text { A pilot feasibility study of oral } \\
5 \text {-fluorocytosine and } \\
\text { genetically-modified neural stem } \\
\text { cells expressing } E \text {. coli cytosine } \\
\text { deaminase for treatment of } \\
\text { recurrent high grade gliomas }\end{array}$ & Completed & NCT01172964 \\
\hline 42 & & Toca 511 & $\begin{array}{l}\text { Toca FC } \pm \text { lomustine, } \\
\text { bevacizumab }\end{array}$ & $\begin{array}{l}\text { Recurrent GBM, } \\
\text { anaplastic astrocytoma, } \\
\text { anaplastic } \\
\text { oligodendroglioma, } \\
\text { anaplastic } \\
\text { oligoastrocytoma }\end{array}$ & 1 & $\begin{array}{l}\text { Study of a retroviral replicating } \\
\text { vector combined with a prodrug } \\
\text { to treat patients undergoing } \\
\text { surgery for a recurrent malignant } \\
\text { brain tumor }\end{array}$ & Completed & NCT01470794 \\
\hline 43 & & Toca 511 & Toca FC & $\begin{array}{l}\text { Recurrent GBM, } \\
\text { anaplastic astrocytoma, } \\
\text { anaplastic } \\
\text { oligodendroglioma, } \\
\text { anaplastic } \\
\text { oligoastrocytoma }\end{array}$ & 1 & $\begin{array}{l}\text { Study of a retroviral replicating } \\
\text { vector given intravenously to } \\
\text { patients undergoing surgery for } \\
\text { recurrent brain tumor }\end{array}$ & Completed & NCT01985256 \\
\hline 44 & & $\begin{array}{l}\text { Chemoprotected autologous } \\
\text { stem cells }\end{array}$ & $\begin{array}{l}\text { Radiation, carmustine, } \\
\text { O6-benzylguanine }\end{array}$ & GBM or gliosarcoma & $|-| \mid$ & $\begin{array}{l}\text { O6-benzylguanine-mediated } \\
\text { tumor sensitization with } \\
\text { chemoprotected autologous } \\
\text { stem cell in treating patients with } \\
\text { malignant gliomas }\end{array}$ & Active & NCT00669669 \\
\hline
\end{tabular}


TABLE 3 | Continued

\begin{tabular}{|c|c|c|c|c|c|c|c|c|}
\hline $\begin{array}{l}\text { Sr. } \\
\text { no. }\end{array}$ & $\begin{array}{l}\text { Viral } \\
\text { vector }\end{array}$ & Gene therapy & Combination therapy & Condition & Phase & Clinical trial & Status & ID \\
\hline 45 & & $\begin{array}{l}\text { Allogenic CD8 }{ }^{+} \mathrm{T} \text { cells } \\
\text { expressing IL13- } \zeta \text { and HSV-TK }\end{array}$ & Aldesleukin & $\begin{array}{l}\text { Recurrent or refractory } \\
\text { malignant glioma }\end{array}$ & I & $\begin{array}{l}\text { Phase I study of cellular } \\
\text { immunotherapy for } \\
\text { recurrent/refractory malignant } \\
\text { glioma using intratumoral } \\
\text { infusions of GRm13Z40-2, an } \\
\text { allogeneic CD8+ cytolitic T-cell } \\
\text { line genetically modified to } \\
\text { express the IL 13-zetakine and } \\
\text { HyTK and to be resistant to } \\
\text { glucocorticoids, in combination } \\
\text { with interleukin-2 }\end{array}$ & Completed & NCT01082926 \\
\hline 46 & & HSV-TK & Ganciclovir and radiotherapy & GBM & III & $\begin{array}{l}\text { A phase III clinical evaluation of } \\
\text { herpes simplex virus type } 1 \\
\text { thymidine kinase and ganciclovir } \\
\text { gene therapy as an adjuvant to } \\
\text { surgical resection and radiation in } \\
\text { adults with previously untreated } \\
\text { glioblastoma multiforme }\end{array}$ & Completed & Rainov, 2000 \\
\hline 47 & $\begin{array}{l}\text { RV vs. } \\
\text { AdV }\end{array}$ & HSV-TK & Ganciclovir & Malignant glioma & & $\begin{array}{l}\text { Thymidine kinase gene therapy } \\
\text { for human malignant glioma, } \\
\text { using replication-deficient } \\
\text { retroviruses or adenoviruses }\end{array}$ & Completed & $\begin{array}{l}\text { Sandmair et al., } \\
2000\end{array}$ \\
\hline 48 & VACV & $\begin{array}{l}\text { TG6002 (oncolytic VACV) + } \\
\text { FCU1* }\end{array}$ & $5-\mathrm{FC}$ & Recurrent GBM & I & $\begin{array}{l}\text { Safety and efficacy of the } \\
\text { oncolytic virus armed for local } \\
\text { chemotherapy, TG6002/5-FC in } \\
\text { recurrent GBM patients } \\
\text { (ONCOVIRAC) }\end{array}$ & Recruiting & NCT03294486 \\
\hline 49 & PVS & PVSRIPO* & & Recurrent GBM & I & PVSRIPO for recurrent GBM & Active & NCT01491893 \\
\hline 50 & $\mathrm{H}-1 \mathrm{PV}$ & ParvOryx & & $\begin{array}{l}\text { Progressive primary or } \\
\text { recurrent GBM }\end{array}$ & $|-| \mid$ & $\begin{array}{l}\text { Parvovirus } \mathrm{H}-1 \text { (ParvOrxy) in } \\
\text { patients with progressive primary } \\
\text { or recurrent GBM. (ParvOryx01) }\end{array}$ & Completed & NCT01301430 \\
\hline
\end{tabular}

*(18) IL-12 under the transcriptional control of the RheoSwith Therapeutic System (RTS). (21) MO32 is an oncolytic HSV that only infects and kills tumor cells. (22) C134 is an oncolytic HSV that safely replicate and kill glioma cells. (27) Temferon: autologous $C D 34^{+}$-enriched hematopoietic stem and progenitor cells exposed to transduction with a lentiviral vector driving myeloid specific interferon-alpha2 expression. (28) The NK-92/5.28.Z cell line (also referred to as HER2.taNK) represents a stable, lentiviral-transduced clone of ErbB2 (HER2)-specific, second-generation CAR-expressing derivative of clinically applicable NK-92 cells. 29) DRI, Drug resistant immunotherapy. (31) A preparation of ex vivo expanded, genetically modified autologous central memory-enriched T-cells (Tcm) transduced with a replication-incompetent, self-inactivating (SIN) lentiviral vector expressing a hinge-optimized, chimeric antigen receptor (CAR) specific for interleukin-13 receptor alpha 2 (L13Ra2), and containing the cluster of differentiation 137 (CD137; 4-1BB) co-stimulatory signaling domain fused to the signaling domain of the T cell antigen receptor complex zeta chain (CD3-ל), and a truncated form of human cluster of differentiation 19 (CD19t). (32) A preparation of genetically modified autologous central memory (Tcm) enriched T cells transduced with a lentiviral vector expressing a chimeric antigen receptor (CAR) consisting of an anti-human epidermal growth factor 2 (HER2) single chain variable fragment (scFv) derived from trastuzumab, with a 4-1BB (CD137) costimulatory domain that is linked to the signaling domain of the T-cell antigen receptor complex zeta chain (CD3-zeta) (BBz), and truncated CD19 (CD19t). (38) CAR, chimeric antigen receptor. (48) FCU1 encodes a bifunctional fusion protein that converts 5-FC into 5-FU. (49) PVSRIPO is an attenuated chimera that restricts the virus to infect CNS cells but not spinal cord motor neurons. 
with a non-migratory fibroblast phenotype limits the distribution of these cells and the released replication-deficient RV to the immediate vicinity of the needle track. Further evaluation of the $\mathrm{RV}$-mediated gene therapy strategy must incorporate refinements such as improved delivery of vectors and transgenes to the tumor cells and improved delivery of the prodrug across the BBB and blood-tumor barrier to the transduced tumor cells (Rainov, 2000).

Other clinical trials for recurrent glioblastoma or gliosarcoma evaluated directly injected, genetically modified, conditionally replicative and oncolytic human-derived adenovirus, DNX-2401 in combination with IFN $\gamma$ (NCT02197169). This trial established an active infection with the virus replicating in, and killing neighboring glioma cells. Similarly, patients with recurrent GBM were also treated with DNX-2401 which was delivered into brain tumor followed by up to two 28-day cycles of oral temozolomide (TMZ) using a schedule of 7 days on/7 days off to evaluate the efficacy of this combination (NCT01956734). Both these clinical trials showed encouraging results with respect to survival outcome. In another Phase-I/II trial (NCT01582516) recurrent GBM patients were treated with replication competent adenovirus i.e., Delta-24-RGD through convection-enhanced delivery (CED), showing similar results. Although these trials offered good safety data and indications of anti-glioma activity, one must await results of Phase 3 clinical trials in order to assess therapeutic benefits.

Another example of a conditional cytotoxic approach involves the expression of the yeast or bacterial enzyme CD in cancer cells, activates the conversion of the prodrug 5-FC into the anticancer drug 5-FU (Takahashi et al., 2014). CD is virtually absent in mammalian cells, which makes 5-FC non-toxic to human cells under normal conditions (Okura et al., 2014). Toca 511, is a replication competent RV encoding $\mathrm{CD}$ that has demonstrated to promote tumor eradication in mouse glioma models (Ostertag et al., 2012), together with durable antitumor immune responses (Mitchell et al., 2017). Vocimagene amiretrorepvec (Toca 511) or Toca 511 with flucytosine (Toca FC) have been evaluated in Phase I clinical trials which demonstrated safety and good tolerability, with tumor regression at the site of infusion and durable responses in patients with recurrent high-grade glioma (Cloughesy et al., 2018). However, a recent phase III clinical trial (NCT02414165) revealed that among 403 randomized patients who underwent tumor resection for first or second recurrence of GBM or anaplastic astrocytoma, administration of Toca511 or Toca FC compared with standard of care did not improve overall survival or other efficacy end points (Cloughesy et al., 2020).

Novel conditionally cytotoxic enzymes have been recently developed i.e., a novel isocytosine deaminase (ICD) named $\mathrm{Vcz}$ converts the prodrug 5-fluoroisocytosine (5-FIC) into 5-FU (Kazlauskas et al., 2019) and the purine nucleoside phosphorylase (PNP), which converts the prodrug fludarabine phosphate (FaraAMP) to diffusible toxic fludarabine (2-F-araA; 2-FA), these have yet to reach testing in the clinical arena.

\section{Targeted Toxins}

Toxins have been evaluated in several anti-glioma studies targeting IL13R $\alpha 2$, the urokinase-type plasminogen activator
(uPA) receptor, growth factor receptors and transferrin receptors, due to their differential expression status in glioma cells when compared to normal brain cells (Candolfi et al., 2011; Castro et al., 2011). The natural ligands of these receptors are fused to the catalytic and fusion domains of cytotoxic bacterial products such as Pseudomonas and Diphtheria exotoxins, which are then internalized and cause apoptosis within glioma cells.

Our group developed a regulatable AdV encoding a mutated human IL-13 fused to Pseudomonas exotoxin (PE), under the control of the tet-inducible promoter system that specifically binds to IL13R $\alpha 2$, expressed by GBM cells that differs from the physiological IL4R/IL13R receptor (Candolfi et al., 2010). When comparing this AdV with the hIL-13-PE protein formulation used in clinical trials (Cintredekin Besudotox) and a secondgeneration mhIL-13-PE, we found that even though both proteins exhibited severe neurotoxicity Ad-mediated delivery of IL-13-PE, in the presence of Doxycycline, led to tumor regression and long-term survival in over $70 \%$ of the animals without apparent neurotoxicity (Candolfi et al., 2010).

\section{Tumor Suppressor Gene Therapy}

The aim of tumor suppressor gene therapy is to restore the function of tumor suppressor genes which are commonly inactivated in glioma cells. These genes can regulate diverse cellular functions including cell-cycle regulation, regulation of cellular proliferation and death and DNA damage repair system.

\section{TP53 Gene}

p53 is well-documented tumor suppressor gene located on chromosome $17 \mathrm{p}$. Inactivation of $\mathrm{p} 53$ is one of the most commonly mutated tumor suppressors in glioma which accounts for $~ 50 \%$ in grade II and III glioma, 25-30\% in primary and 60$70 \%$ in secondary GBM (England et al., 2013). Tumor suppressor gene therapy using p53 as a target was first tested by delivering through replication-deficient adenovirus (Kwiatkowska et al., 2013). The most commonly used adenoviral vector for p53 is the type 5 adenovirus in which the E1 region is replaced with the cDNA of the wild type p53 gene and is driven under the control of a CMV promoter (Ad5CMV-p53) (Cirielli et al., 1999; Lang et al., 1999; Li et al., 1999; Shono et al., 2002). There was a marked inhibition of growth in implanted gliomas and significant prolongation of survival of animals following the delivery of wild type p53 gene (Badie et al., 1998; Cirielli et al., 1999; Li et al., 1999). Delivery of wild type p53 also suppressed angiogenesis in GBM (Van Meir et al., 1994). SGT-53 is a transferring receptor-targeted liposomal vector encapsulating wild-type p53 plasmid DNA that can cross the BBB and target GBM cells. This resulted in a reduction of MGMT and induction of apoptosis in GBM xenografts mice (Kim et al., 2014). Ad5CMV-p53 can be most effective when used in combination with radiation and chemotherapy (Biroccio et al., 1999; Shono et al., 2002). Similarly, combined treatment of p53 transfection with FasL, GM-CSF, and B7-1 gene enhances apoptosis and inhibits cell growth (Shinoura et al., 2000; Pan et al., 2010). All these results led to phase-I trials of Ad5CMV-p53 gene therapy in recurrent malignant glioma (NCT00004041, NCT00004080). In another study, combination of baculovirus mediated delivery of p53 gene 
with sodium butyrate, a histone deacetylase inhibitor markedly reduced the growth of glioma cells and enhanced the survival of glioma bearing animals (Guo et al., 2011).

Systemic delivery of a nano-platform encapsulating wild type p53 (scL)-p53 also sensitizes cancer stem cells (CSCs) and bulk tumor cells to TMZ and increase apoptosis (Kim et al., 2014). In another study, Misra et al. generated a p53-EGFP-C3 fusion construct which expressed GFP to allow an estimation of p53 mediated anti-glioma activity and delivered them to glioma cells through a cationic cholesterol based nanocarrier prepared by mixing cationic cholesterol Gemini (ChoL-5L) with natural lipid DOPE in a molar 1:4 ratio. Introduction of wild type p53 cDNA through this nanocarrier induced apoptosis and significantly reduced the tumor volume in mice (Misra et al., 2014). Similarly, a nanoplatform assembled by coupling $\beta$-cyclodextrin and the cationic polymer polyethyleneimine to a hydrophobic polymer pullulan (PPEICD) was used to codeliver the antitumor drug mitoxantrone and wild type p53 cDNA to glioma cells. Herein $\beta$-cyclodextrin serves as a nanocontainer for mitoxantrone while the cationic part can condense p53 cDNA. Delivery of this nanocomplex induced cell death in glioma cells (Mitha and Rekha, 2014).

\section{p16 Gene}

$\mathrm{P} 16 / \mathrm{CDK} 4 / \mathrm{Rb} / \mathrm{E} 2 \mathrm{~F}$ is the most commonly altered pathway in gliomas. Therefore, over-expression of p16 gene through recombinant replication-deficient adenovirus significantly reduced the invasion of glioma by suppressing the activity of MMP2 (Chintala et al., 1997). Moreover, data from a previous study revealed that retroviral delivery of $\mathrm{p} 16^{\mathrm{INK} 4 \mathrm{~A}}$ gene could effectively inhibit the progression of glioma but only when endogenous $\mathrm{pRb}$ is intact (Xande et al., 2020). Similarly, intratumor injection of pCL retrovirus encoding full-length human p16 cDNA resulted in 95\% reduction of gliomas in situ through necrosis and cell-cycle arrest (Hung et al., 2000). Another study also revealed that adenoviral delivery of p16 gene enhanced radiation induced cell killing possibly by a nonapoptotic mechanism with abnormal nucleation in glioma cells (Hama et al., 2003). Moreover, restoration of the wt-p16 activity into p16-null SNB19 glioma cells significantly inhibited tumor cell invasion (Chintala et al., 1997). Similarly, down-regulation of integrin $\alpha(\mathrm{v}) \beta(3)$ expression and integrin-mediated signaling in glioma cells by adenoviral transfer of antisense urokinase-type plasminogen activator receptor and wild type p16 cDNA resulted in decrease adhesion, migration, proliferation and enhanced survival (Adachi et al., 2001, 2002). However, sometimes cellcycle arrest following transfer of p16 gene to glioma cells resulted in the development of chemoresistance to some cytotoxic drugs such as cisplatin, paclitaxel, topotecan and ACNU (Fueyo et al., 1998; Hama et al., 1998).

Deregulation of E2F transcription factor, specifically E2F-1 is a critical target of any alteration of the $\mathrm{p} 16 / \mathrm{Rb} / \mathrm{E} 2 \mathrm{~F}$ pathway in glioma. E2F-1 positively regulates the transcription of Sphase genes and drives the cell-cycle progression through G1 checkpoint. Study revealed that transfer of E2F-1 along with p53 to gliomas induced apoptosis and appeared to be more effective than wild type p53 as it can induce apoptosis even in p53 resistant glioma cells (Fueyo et al., 1998). In fact, vectors expressing p16 and p21 were more effective than wild type p53 at improving survival (Wang et al., 2001). Thus, Adenovirus mediated transfer of E2F-1 alone or in combination with wild type p53 to glioma cells should propel the development of clinical trials for glioma treatment. Deregulated p16 expression also plays a crucial role in angiogenesis in glioma. Therefore, transfer of p16 cDNA through recombinant replication-defective adenoviral vector to glioma cells markedly inhibited angiogenesis through suppressing vascular endothelial growth factor (VEGF) expression (Harada et al., 1999).

However, in a recent report, when $\mathrm{p} 16^{\mathrm{INK} 4 \mathrm{~A}}$ was expressed under the control of Tet repressor system in glioma cells on a long-term basis, it decreased the expression of Rb, suggesting that this gene therapy approach involving $\mathrm{p} 16^{\mathrm{INK} 4 \mathrm{~A}}$, could ultimately have led to the selection of Rb-deficient gliomas (Simon et al., 2002).

\section{PTEN Gene}

Phosphatase and Tensin Homolog on chromosome number 10 (PTEN) is a tumor suppressor gene which contains a central catalytic phosphatase core domain that negatively regulates PI3K by dephosphorylation of $\mathrm{PIP}_{3}$ to $\mathrm{PIP}_{2}$ and can act as an excellent target for gene therapy (Kanu et al., 2009). PTEN is inactivated in $33 \%$ of all gliomas resulting in aberrant activation of PI3K pathways (Dunn et al., 2012). Therefore, the transfer of chromosome 10 to glioma cells induced thrombospandin1 and inhibited angiogenesis in glioma (Hsu et al., 1996). Restoration of PTEN activity in glioma cells led to suppression of their neoplastic phenotype (Cheney et al., 1998). Forced PTEN expression through $\mathrm{AdV}$ conferred sensitivity to temozolomide and/or ionizing radiation (Inaba et al., 2011). Adenoviral reexpression of PTEN in glioma cells inhibited Akt kinase activity, leading to tumor cell apoptosis (Davies et al., 1998). Additionally, adenoviral expression of PTEN demonstrated an anti-angiogenic response in glioma along with decreased proliferation and increased apoptosis in gliomas in vivo (Abe et al., 2003; Lu et al., 2004). Another study revealed that replication-defective adenoviral vector, i.e., MMCB mediated PTEN gene transfer to malignant glioma inhibited the growth and survival of the tumor cells, suppressing the tumorigenecity of malignant gliomas (Cheney et al., 1998). It has been found that, overexpression of EGFR and mutation/deletion of PTEN is one of the main genetic changes identified in gliomas. It was demonstrated that combined infection of glioma cells with antisense-hTERT and wt-PTEN bearing adenovirus significantly inhibited proliferation and reduced tumor load both in vivo and in vitro (You et al., 2007). Similarly, introduction of an expression plasmid carrying shRNA against hEGFR and wt-PTEN cDNA to glioma cells significantly suppressed the tumor cell proliferation, reduced the tumor invasion and promoted tumor cell apoptosis in gliomas (Han et al., 2010). TIMPs (the inhibitors of MMP2) and PTEN are known to be inhibitors of the invasive activities of malignant gliomas. Therefore, adenoviral delivery of TIMP2 and PTEN/MMAC1 cDNA to human glioma cells significantly inhibited invasive phenotype and growth of gliomas in vivo (Lu et al., 2004). 


\section{Gene Therapy Targeting Signaling Pathways EGFR and EGFRvIII}

EGFRvIII is the most common variant, leading to constitutively active EGFR signaling in glioma (Gan et al., 2013). EGFRvIII is often co-expressed with full-length EGFR in glioma cells. This complicates our understanding of its contribution to tumorigenesis (Shinojima et al., 2003; Fan et al., 2013). Delivery of both viral and non-viral vectors containing antisenseRNA to target EGFRvIII into intracranial glioma xenografts reduced tumor load significantly (Shir and Levitzki, 2002). Treatment with antisense-RNA or siRNA of U251 glioma expressing EGFRvIII also reduced tumor volume (Kang et al., 2006). This EGFR specific siRNA is directed against the TKdomain and were shown to cause $90 \%$ knockdown of EGFR mRNA (Kang et al., 2006). Thus, the overall median survival increased by almost 90\% (Kang et al., 2006). Blocking the gene expression of both EGFR and $\beta$-catenin significantly inhibited the glioma invasive ability (Wang et al., 2013). It was shown that cyclodextrin-modified dendritic polyamine complexes (DexAMs) were effective at delivering EGFRvIII siRNA efficiently and selectively to glioblastoma with minimal toxicity (Kim et al., 2011). Furthermore, co-delivery of EGFRvIII siRNA and erlotinib in GBM was found to significantly inhibit cell proliferation and induce apoptosis in glioblastoma cells (Kim et al., 2011). Similarly, the use of an expression plasmid Pgenesil-1 vector viz. psiRNA-EGFR-PTEN on U251 glioma resulted in the suppression of cell proliferation, arrest of cell cycle, reduction of cell invasion and promotion of apoptosis both in vitro and in vivo (Han et al., 2010). Herein the vector expresses a small hairpin RNA-targeting EGFR and wild-type PTEN cDNA in glioma cells (Han et al., 2010). In addition, ribozyme targeting EGFRvIII inhibits ERM5-1 and U87MG GBM cells (Halatsch et al., 2000). Herein, antiEGFRvIII hairpin ribozyme resulted in significant reduction in glioma proliferation (Halatsch et al., 2000). Moreover, treatment with anti-EGFRvIII hairpin ribozymes was shown to reduce EGFRvIII mRNA by $90 \%$ and inhibit anchorageindependent growth of U87MG glioma cells (Karpel-Massler et al., 2009). On the other hand, adjuvant miRNA-based therapies also showed potential for glioma treatment. miR7 appears to be an effective inhibitor of the EGFR signaling in glioma by direct inhibition of the EGFR and downregulation of Akt signaling, leading to decreased invasiveness of glioma. miR-7 treatment also helped to overcome the radioresistance properties of glioma (Padfield et al., 2015). Taking into account both the preclinical and clinical experience of targeting the EGFR signaling pathway for GBM therapeutics, it can be concluded that as a monotherapy this approach is unlikely that it will work in the clinical arena, due in part to the heterogeneity of GBM and also the numerous alternative growth promoting pathways that are used by glioma cells. Nevertheless, targeting the EGFR pathway would be a valuable adjuvant strategy to be used in combination with other therapeutic approaches.

\section{VEGF}

The expression of VEGF is up-regulated in gliomas. Therefore, targeting VEGF could a promising approach for glioma management. It was shown that efficient delivery of anti-sense VEGF cDNA via an adenoviral Ad5CMV- $\alpha$ VEGF vector, into subcutaneous human glioma tumors established in nude mice, inhibited tumor growth (Im et al., 1999). Moreover, direct intra-tumoral injection of a VEGF siRNA-encoding plasmid complexed with linear PEI, efficiently reduced the vascularization of tumors in xenografts (Niola et al., 2006). Like VEGF, high-affinity VEGF receptor Flk-1/KDR (VEGFR2) also plays a key role in tumor angiogenesis. Strategies to block VEGFR-2 signaling were successfully used to inhibit experimental tumor growth as this is the main signaling axis required for the proliferating tumor endothelium. It has been found that retroviral delivery of mutant-VEGFR1 that lacks the intracellular tyrosine kinase domain led to a strong reduction of glioma growth and angiogenesis in a xenografted C6 glioma model (Heidenreich et al., 2004). Also, the retroviral transfer of full-length VEGFR-1 cDNA caused a significant reduction of glioma growth. The inhibitory effects of the VEGFR-1 mutants and the full length VEGFR-1 were mediated through host tumor endothelial cells. The formation of heterodimers between VEGFR-2 and full length or truncated VEGFR-1 might contribute to the glioma inhibitory effect by modulating distinct signal transduction pathways (Heidenreich et al., 2004). Soluble vascular endothelial growth factor receptor (sFlt-1) also plays an important role in anti-glioma treatment. Co-delivery of sFlt-1 and angiostatin-endostatin fusion gene (Statin-AE) through non-viral sleeping-beauty (SB) transposons to glioma xenografts showed marked reduction in tumor vessel density and tumor load (Ohlfest et al., 2005). Similarly, co-infection of glioma cells with both anti-angiogenic gene therapy vectors Ad-Flk1-Fc, which expresses a soluble VEGF receptor and oncolytic virus d1922/947 whose replication and subsequent cytotoxicity are restricted to cancer cells, yielded significantly higher anti-glioma effect than monotherapy (Thorne et al., 2006). In another study, construction of an oncolytic adenovirus-based shRNA expression system i.e., Ad-DeltaB7-shVEGF revealed a marked reduction in glioma vasculature and tumor load in vivo. This study also demonstrated that the duration and magnitude of VEGF silencing by Ad-DeltaB7-shVEGF was greater than the efficacy elicited by the replication-incompetent adenovirus expressing sh-VEGF (Ad-DeltaE1-shVEGF) (Yoo et al., 2007). The delivery of a replication-incompetent adenovirus expressing, VEGF promoter-targeted transcriptional repressor Cys2-His2 zinc-finger proteins, F435-KOX namely Ad-DeltaE1-KOX significantly reduced angiogenesis and tumor load (Kang et al., 2008). Likewise, using the previously mentioned oncolytic adenovirus Ad-DeltaB7 expressing F435-KOX, namely AdDeltaB7-KOX, elicited similar anti-glioma efficacy in a human xenograft model (Kang et al., 2008). VEGF and high-affinity VEGF receptor Flk1/KDR (VEGFR2) are key regulators of glioma angiogenesis, thus, inhibition of VEGFR2 expression would inhibit the development of new blood vessels within the tumor microenvironment (TME) and inhibit glioma progression. 
Data also revealed that delivery of genetic sequences of antisense RNAs to alter the splicing pattern and expression of the VEGFR2 transcript using pAAV-U7-smOPT vector markedly reduced glioma growth in vivo (Muralidharan et al., 2019).

\section{Blood Brain Barrier Disruptive Gene Therapy}

Treatment of gliomas could be improved markedly by the development of non-invasive therapeutic approaches that elicit robust, endothelial cell-selective gene expression in specific brain regions. Focused ultrasound (FUS) is one such targeted and non-invasive technique that can be used to activate gas filled microbubbles (MBs) to oscillate within the bloodstream. MBs expand and contract upon sonication by FUS producing cavitation. Stable cavitation is induced by relatively lower amplitude of FUS zzzzz. Generally, FUS elicits endothelial selective transfection without opening the BBB. Study found that magnetic resonance (MR)-guided $\mathrm{MB}$ enhanced low intensity pulsed FUS (LIFU) transiently open the BBB and delivers a liposome loaded MGMT inhibitor, $\mathrm{O}^{6}$-(4-bromothenyl) guanine $\left(\mathrm{O}^{6} \mathrm{BTG}\right)$ in mice bearing TMZ-resistant gliomas, thereby sensitizing murine and human gliomas to TMZ both in vivo and in vitro (Papachristodoulou et al., 2019). In another study, researchers developed a VEGFR2-targeted and cationic microbubble (VCMB) gene vector with FUS exposure to allow transient gene delivery. They delivered pHSV-TK/GCV with VCMB under FUS exposure for transgene expression and antitumor effect (Chang et al., 2017). It was also found that there was a significant increase in median survival following single treatment of FUS with doxorubicin in 9L gliosarcoma bearing rats (Treat et al., 2012). Another example is 1,3bis(2-chloroethyl)-1-nitrosourea (BCNU) which showed only a relatively limited effect against glioma. However, FUS-mediated delivery of BCNU to glioma-bearing rats greatly increased the intracellular retention and inhibition of tumor progression in vivo (Deng et al., 2019). Moreover, Fan et al. fabricated PEGb-PMBSH-loaded MBs which are formed by boron-containing nanoparticles coupling with MBs for the treatment of GL261 bearing mouse glioma model (Fan et al., 2019). Thus, FUS in conjunction with MBs has emerged as a unique noninvasive modality for MR image-guided gene delivery to the brain which involves transient disruption of BBB which may induce a sterile inflammatory response. It was found that activating circulating cationic plasmid bearing MBs with pulsed low pressure (i.e., 0.1 MPa) 1.1-MHz FUS facilitates sonoselective gene delivery to the endothelium selectivity varied inversely with the FUS pressure that means with high pressures i.e., 0.3 $\mathrm{MPa}$ and 0.4 MPa FUS consistently inducing BBB opening and extravascular transfection.

\section{IMMUNE STIMULATORY GENE THERAPY Cytokine Mediated Gene Therapy}

Cytokine mediated gene therapy involves tumor-selective gene transfer and in situ expression of various cytokine genes such as IL2, IL4, IL12, and IFN $\beta / \gamma$ which can induce robust immune responses to glioma cells (Iwami et al., 2010; Tobias et al.,
2013). Gliomas can effectively evade the host immune response (Natsume and Yoshida, 2008; Kwiatkowska et al., 2013). The unique characteristics of the CNS immune system in the context of an intracranial glioma, these include a paucity of antigenpresenting DCs, high levels of anti-inflammatory TGF- $\beta$ and expression of immune checkpoint molecules by glioma cells and tumor infiltrating immunosuppressive cells. These mechanisms play important roles to protect the CNS from immunological attack. Therefore, it is challenging to stimulate the system to develop an effective anti-glioma response (Assi et al., 2012). The susceptibility of glioma stem cells to the cytotoxic effects of the immune system provides the basis for development of anti-glioma immune gene therapy.

\section{Interferon $\beta / \gamma$}

IFN $\beta$ is a pleiotropic cytokine with antitumoral activity. Therefore, when h-IFN $\beta$ expressing adenoviral vector viz. Ad.hIFN $\beta$ was introduced into human gliomas stereotactically, it induced increase amount of tumor cell apoptosis in vivo (Chiocca et al., 2008). Local administration of intracranial IFN $\beta$ gene delivery through adeno-associated viral vectors viz. AAV/P2Int-mIFN $\beta$ also successfully treats orthotopic gliomas with concomitant activation of microglia surrounding the tumors. It is interesting to note that treatment with $\mathrm{TMZ}$ prior to $\mathrm{AAV}$ IFN $\beta$ abrogated any benefits from the later, while the reverse order of treatment doubled the median survival compared to control population (GuhaSarkar et al., 2017). Moreover, cationic liposome mediated IFN $\beta$ gene transfer significantly changes antitumor immune responses and inhibits neovascularization. Many gliomas showed necrotic changes and increased infiltration of $\mathrm{CD}^{+}$T-cells and macrophages within the tumor following administration of Ad.hIFN $\beta$ (Wakabayashi et al., 2008). A phase I/early phase II clinical trial demonstrated the safety and efficacy of this liposomal approach to deliver a plasmid coding for IFN- $\beta$ in patients with recurrent malignant gliomas following resection of the tumor (Yoshida et al., 2004). This study revealed that there is upregulation of transgene expression and antitumor activity in most of the patients recruited for the study.

Direct injection of the IFN $\beta$ gene with a replication deficient adenovirus demonstrated tumor regression in human glioma xenograft, through the activation of NK cells. It also enhanced the generation of DC, $\mathrm{T}_{\mathrm{H}}$ and macrophage cells and stimulated the generation of cytotoxic T-cells activity. Survival was significantly increased in glioma bearing mice (Qin et al., 2001).

Similarly another proinflammatory cytokine IFN $\gamma$, produced by NK, DC, and T-cells diminishes the invasive phenotype of glioma cells by inhibiting its interactions with extracellular matrix molecules (Schroder et al., 2004). Use of adenovirus expressing TNF $\alpha$ or IFN $\gamma$ into tumors enhanced infiltration of $\mathrm{CD}^{+}$and $\mathrm{CD}^{+}{ }^{+} \mathrm{T}$ cells along with increased expression of $\mathrm{MHCI} / \mathrm{II}$ on the glioma cells in vivo. Intracranial administration of both these genes significantly increases the survival of glioma bearing animals (Ehtesham et al., 2002). In the ongoing trials, CD $34^{+}$-enriched hematopoietic stem and progenitor cells (HSPCs), NK-cells or different CAR T-cells are administered either with TMZ or with ganciclovir (Table 3). For instance, in a Phase-II trial, patients with GBM who have an unmethylated 
MGMT promoter administered with single dose of autologous $\mathrm{CD}_{3}{ }^{+}$-enriched HSPCs exposed to transduction with a $3 \mathrm{rd}$ generation LV driving myeloid-specific IFN- $\alpha 2$ expression (NCT03866109) (Table 3).

\section{IL12}

IL12 is one of the most potent anti-tumor cytokines, driving a Th1 response in tumor bearing animals (Tatsumi et al., 2003). Despite its therapeutic success in multiple animal models of cancer, the utility of systemically administered recombinant cytokine has been limited by its toxicity. This has encouraged the development of local IL12 delivery systems through gene transfer. Mice bearing GL-26 gliomas in the right corpus striatum when treated with direct intratumoral administration of replicationdeficient adenoviral AdmIL-12 vector, it significantly prolonged the survival of glioma bearing animals with robust infiltration of $\mathrm{CD}^{+}$and $\mathrm{CD} 8^{+}$T-cells (Liu et al., 2002). Another study using vaccinia virus expressing IL12 resulted in effective inhibition of subcutaneous C6 glioma growth in mice (Chen et al., 2001). Moreover, combination therapy of glioma with recombinant vaccinia virus mediated IL2 expression, resulted in significant tumor inhibition with concomitant elevation of $\mathrm{NK}, \mathrm{Mac}^{-}{ }^{+}$and NKT cells in blood and IFN $\gamma$ and TNF $\alpha$ expression in tumors (Chen et al., 2000, 2001). Neural stem cells (NSCs) isolated from hippocampi of human embryo were used for lipofectaminemediated transfer of the IL12 gene to rat glioma cells (Yang et al., 2004). Several other groups have delivered IL12 using different non-adenoviral gene therapy vectors. Among them,

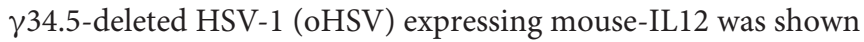
to exert its oncolytic activity and perform better than other IL12 bearing oHSVs in rodent models of GBM (Hellums et al., 2005). Similarly, Semliki forest virus (SVF) vectors were also used for the delivery of hIL-12 gene to RG2 rat glioma model (Roche et al., 2010). SVF carrying IL12 gene alone when administered through an implanted cannula to the brain, reduced the tumor load and prolonged the survival of RG2 glioma bearing animals not only through the oncolytic activity of SVF but also through activating an anti-tumor immune response (Roche et al., 2010). Despite this, the broad tropism of the SVF-based expression vector may limit its use as a glioma gene therapy vector unless this limitation can be overcome. Human umbilical cord bloodderived mesenchymal stem cell (UCB-MSC) have also been used as gene delivery vehicles, i.e., UCB-MSC-IL12M expressing IL12. It was shown that they inhibited GL26 intracranial tumor growth and prolonged survival when administered in the contralateral brain hemisphere (Ryu et al., 2011). Moreover, surviving mice generated memory response against tumor antigens (Ryu et al., 2011). Non-replicative AAV and replicative HSV have also been used to express IL12 in malignant glioma, resulting in significant inhibition of tumor growth and increased expression of IFN $\gamma$ with microglial activation and recruitment of $\mathrm{T}$ and NK cells (Ahn et al., 2016; Barrett et al., 2018). These data demonstrated that cytokine gene therapy through viral vector mediated IL12 gene expression may be a promising strategy for glioma treatment. Recently, two different Phase-1 dose-escalation trials (NCT02026271, NCT03330197) revealed that when the resection cavity walls were injected with a fixed dose of a regulatable ADVhIL12 vector i.e., Ad-RTS (RheoSwitch Therapeutic System)hIL12, together with an oral activator of IL12 expression, veledimex (VDX), the expression of IFN $\gamma$ increased in peripheral blood in the enrolled patients. To minimize systemic toxicity, the ligand-inducible expression switch, RTS was developed to locally control the production of IL12 in the tumor microenvironment, during fixed periods of time. Also increased infiltration of PD$1^{+}$immune population was observed, following Ad-RTS-hIL12 therapy in some of the re-resected tumor samples. Since this was a Phase I trial, it was not powered to assess therapeutic efficacy (Chiocca et al., 2019). Administration of Ad-RTShIL12 to glioma patients also revealed pseudo-progression with increased frequencies of tumor infiltrating lymphocytes (TILs) producing IFN $\gamma$ and expressing PD1 (Chiocca et al., 2019). These inflammatory infiltrates also support an immunological anti-glioma effect of h-IL12 (Barrett et al., 2018; Chiocca et al., 2019).

\section{ONCOLYTIC VIROTHERAPY}

Oncolytic virotherapy (OV) is based on genetically engineered viruses with the ability to infect and replicate within tumor cells and then lyse them, releasing new infectious viral particles that can infect neighboring cells leading to immunogenic cells death and immune stimulation (Figure 1). As such this approach cannot be considered as gene therapy, nevertheless, OV have been engineered to also harbor therapeutic transgenes, which we will discuss briefly below. In this case, they can be considered gene therapeutic platforms. In addition, OVs have been genetically engineered to express therapeutic transgenes to further boost antitumor immunity.

Among all the studied viruses, only one wild-type virus, an oncolytic double-stranded human RNA orthoreovirus (referred as reovirus) is under clinical trial as Reolysin in GBM patients (NCT00528684) (Samson et al., 2018). Reovirus is pathologically benign and it is tumor cytotoxic, making it an appealing OV for therapeutic development. Reovirus selectively targets transformed cells with activated Ras signaling pathways and can lyse cancer cells (Zhao et al., 2016). A dose escalation Phase-I clinical trial is currently evaluating the combination of intravenously administered Reolysin and subcutaneously administered GM-CSF in patients with recurrent HGG (NCT02444546).

The first attenuated mutant HSV serotype 1 TK deficient virus, called $d l s p t k$, was incapable of replicating in non-dividing cells like neurons but could replicate in human brain tumor cells and kill them in vitro (Martuza et al., 1991). HSV1719 is a first-generation virus that is devoid of the $\gamma 34.5(\Delta \gamma 34.5)$ gene that suppresses PKR/eIF-2a signaling pathway and IFNinduced anti-viral mechanisms. This virus was evaluated in three successful Phase I trials in GBM patients (summarized in Ning and Wakimoto, 2014). The second-generation vector G207 also contains a gene-disrupting insertion of lacZ reporter sequence into $\mathrm{U}_{\mathrm{L}} 39$, a gene encoding for the large subunit of the viral ribonucleotide reductase (ICP6), that is required for 
replication in non-cycling cells (Aghi et al., 2008). Oncolytic selectivity is thought to occur because mutations in viral ICP6 and $\gamma 34.5$ functions are respectively complemented by mammalian ribonucleotide reductase and GADD34, whose genes are expressed in cycling cells. Therefore, effective replication of OVs might be limited to a subpopulation of tumor cells, as the majority of tumor cells would not be cycling. This approach provides evidence that ICP6-negative OVs can replicate in quiescent tumor cells carrying specific oncogene deletions, independent of cell-cycle status. G207 successfully completed three trials in the USA, showing a well-tolerated antitumor response when the virus was inoculated after or before the tumor resection (Markert et al., 2000, 2009). Currently, there are two Phase I trials recruiting pediatric patients with recurrent or refractory cerebellar brain tumor (NCT03911388) or supratentioral brain tumors (NCT02457845) to determine the safety of G207 alone or combined with radiotherapy. On the other hand, the vector $\mathrm{C} 134$ is a chimeric hCMV/oHSV1 which encodes the protein kinase $\mathrm{R}$ evasion gene IRS1 under the control of human CMV, which maintains the late viral proteins synthesis in malignant glioma cells improving amplification and prolonging survival in two different mouse models implanted intracranially with U87MG and U251MG glioma cells (Shah et al., 2007). A Phase I trial is recruiting GBM patients to evaluate this vector (NCT03657576) (Table 3). The interim analysis of a study using the genetically engineered oncolytic HSV, G47 $\Delta$ showed that the 1-year survival rate of 13 patients was $92.3 \%$ which was significantly higher when compared to $15 \%$ survival rate in control population. A study also showed efficient induction of antitumor immunity and successful targeting of cancer stem cells. Another Phase-II trial (NCT00028158) with conditionally replicating oncolyticHSV1 viz. G207 demonstrated anti-tumor activity and long-term presence of viral DNA in patients, without any serious adverse effects. No patients developed HSV-encephalitis (Markert et al., 2000). Other clinical trials with HSV are still recruiting (Table 3). Moreover, in a Phase-I/II trial, patients with recurrentGBM were repeatedly administered with oncolytic HUJ, an attenuated lentogenic (nonvirulent) isolate of NDV revealed good tolerability with minimum adverse effects. This finding warrant continued evaluation of NDV-HUJ in GBM (Freeman et al., 2006).

The replication-competent adenovirus DNX-240, marketed as Tasadenoturev, was generated to restrict the viral replication to cells with retinoblastoma pathway deficiency (Fueyo et al., 2003). DNX-240 was first studied in a double-arm Phase-I trial to treat patients with recurrent glioblastoma (rGBM), reporting $20 \%$ of patients surviving more than 3 years and three complete responders (NCT00805376) (Lang et al., 2018). Another strategy involves the delivery of neural stem cells transduced with $\mathrm{OV}$ Ad5-DNX-2041 or NSC-CRAd-Survivin-pk7 in patients with rGBM and newly diagnosed malignant gliomas respectively (NCT03896568, NCT03072134). Moreover, a Phase II trial is still active, involving the delivery of genetically modified oncolytic adenovirus (DNX-2401) followed by intravenous immune checkpoint inhibitor pembrolizumab to evaluate the treatment efficacy (NCT02798406) (Table 3).
Several studies have shown the therapeutic potential of live attenuated oncolytic polio/rhinovirus recombinant (PVSPIRO) in patients with grade IV malignant glioma to evaluate the efficacy of this vector (NCT02986178) (Table 3). PVSPIRO has tropism toward CD155 that highly expressed in tumor cells, enables infected tumor cell cytotoxicity and stimulation of an inflammatory response (Brown et al., 2017). Finally, a third PVSRIPO-based therapy is ongoing for pediatric patients with rGBM (NCT03043391) (Table 3). Collectively, the successful accrual of these trials will demonstrate whether improved safety, tumor specificity, and efficacy of OVs alone or in combination with other therapies can be translated into the clinic arena.

\section{COMBINATION THERAPIES}

In an effort to overcome the shortcomings of monotherapies, combination therapies have been developed. Adenoviruses expressing a secretable angiostatin-like molecule (AdK3) in combination with $7.5 \mathrm{~Gy}$ radiation dosage in rat C6 gliomas appeared to be more cytotoxic than either treatment alone (Griscelli et al., 2000). Similarly, IL24 can also induce tumor cell death through various mechanisms including endoplasmic stress induced apoptosis, autophagy, anti-angiogenesis and immune activation (Emdad et al., 2009). In GBM models, the antitumor effects of Ad-bearing IL24 were also enhanced by radiation (Yacoub et al., 2003a,b). Histone deacetylase (HDAC) inhibitor was also shown to increase Ad-MDA-7/IL24 lethality through ER stress and activation of the extrinsic apoptotic pathways (Dent et al., 2010). Recently, a complex liposome was engineered to carry both a therapeutic gene TRAIL and a cytotoxic drug paclitaxel combined with re-targeting by inserting a peptide angiopep 2 that facilitates BBB crossing. This preparation can effectively deliver TRAIL to glioma cells in vitro (Sun et al., 2012). Thus, these approaches constitute a valuable adjuvant therapeutic strategies for glioma. Moreover, combination of drugs with different phase specific cytotoxicities such as combination of p19 and p53 gene therapy, where p19 is important to inactivate p53 inhibitors and p53 itself triggers apoptosis, appear promising to target gliomas. Combination therapy with systemically administered liposomal p53 i.e., SGT53 and TMZ enhanced antitumor efficacy compared to TMZ alone, demonstrating the ability of SGT-53 to improve chemosensitivity (Kim et al., 2014, 2015b).

We have pioneered the combination of Ad-Flt3L and Ad-TK. Combining both these two genes results in GCV phosphorylation which ultimately resulting in tumor cell death (Castro et al., 2014; Kamran et al., 2018a). This induces the release of tumor antigens into the tumor microenvironment and damageassociated molecular pattern molecules (DAMPs), which are molecules that when released into the TME or translocated to the cell membrane during cell death, they trigger an immune response against self-antigens (Kamran et al., 2018a; Altshuler et al., 2020). Our results indicate that release of DAMPs such as HMGB1 from Ad-TK infected tumors is required for the efficacy of Ad-TK+Ad-Flt3L mediated immunotherapy (Candolfi et al., 2009; Curtin et al., 2009). Flt3L increases the migration and 
infiltration of DCs into the TME. This glioma infiltrating DCs are able to phagocytose antigens that are released during TKinduced glioma cell death (Figure 2) (Curtin et al., 2009; Candolfi et al., 2012). Moreover, HMGB1 activates DCs through TLR2 and then activated DCs transport the antigens to the draining lymph node, generating T-cell mediated cytotoxic immune response (Curtin et al., 2009). This combination therapy provides longterm survival and immunological memory in multiple glioma models. In addition, we have also combined Ad-mediated gene therapy with DC vaccination (Mineharu et al., 2011). We found that compared to either therapy alone, combination of intratumoral Ad-Flt3L/Ad-TK with DC vaccination resulted in longterm survival in $90 \%$ of glioma bearing animals. Our findings indicated that Ad-Flt3L/Ad-TK modifies the TME that enhances the efficacy of DC vaccination (Figure 2) (Mineharu et al., 2011). Work from our team has also recently shown the combining Ad-Flt3L/Ad-TK-mediated gene therapy together with immunecheck point blockade, using CTLA4 or anti-PDL1, it significantly increased median survival when compared with either treatment used independently (Kamran et al., 2017). Similar results were obtained when we tested Flt3L/Ad-TK-mediated gene therapy in combination with depletion of immunosuppressive MDSCs (Kamran et al., 2017). Again, indicating that combination therapies are an attractive way forward to develop novel treatment for GBM.

In our first human Phase-I dose escalation trial (NCT01811992) using a combination of two adenoviral vectors expressing HSV1-tk and Flt3L for the treatment of newly diagnosed, resectable malignant gliomas we observed evidence of biological activity as evidenced by increased frequencies of DCs, CD4 and CD8 T cells within the TME (Lowenstein et al., 2019). Our results showed for the first time that reprogramming of the host's brain immune system to recognize gliomas could present an attractive approach for the treatment of malignant brain tumors (Lowenstein and Castro, 2018).

\section{DISCUSSION AND CONCLUSIONS}

Although innovative gene-mediated therapies and oncolytic virotherapies $(\mathrm{OV})$ have been developed to treat gliomas, to date, they have failed in improving patients' outcomes compared to current standard of care treatment modalities, including surgery, radiotherapy and chemotherapy. Moreover, drug design and clinical trial implementation all come at a considerable economic cost that often limits the timely development of potentially promising treatments. Opportunities to address the lack of clinical benefit of genetic-based therapies and OV in the clinical arena may be provided by accurate preclinical in vivo models which recapitulate the disease processes. We envisage that testing gene therapies in more representative models would be essential to allow scientists to differentiate effective from ineffective therapies before their implementation in the clinical setting (Calinescu et al., 2015; Nunez et al., 2020). The extensive molecular characterization of gliomas has been instrumental in improving our understanding of glioma progression and their response to therapies. Genetic lesions in gliomas also play a critical role in modulating the TME. We believe that all these characteristics need to be closely modeled in preclinical models in order to offer a stronger footing on which to base the development and implementation of gene therapy mediated clinical trials.

As of yet, despite showing promise in the preclinical setting, different innovative therapies have been failed to show efficacy in Phase III clinical trials for GBM. The failure of these treatments can be attributed to tumor heterogeneity, tumor immune escape, and development of resistance to the therapy, the presence of the $\mathrm{BBB}$, anatomical location, GBM invasiveness and immune suppressive TME. Gene therapy approaches that rely on the transduction of most of the tumor cells to be effective, can encounter unsurmountable challenges, due to the low transduction efficacy of currently available delivery platforms. This could be overcome by the use of convection enhanced delivery to achieved widespread transduction, manual delivery at multiple tumor locations and/or combination with immune stimulatory approaches which would rely of tumor antigen specific $\mathrm{T}$ cells to eradicate any remaining tumor cells.

In addition, the limitations of OV include limited replication capacity of OV after a few replicative cycles, the lack of widespread distribution of the oncology viruses throughout the tumor mass. Also the immune system of the host, may curtail replicative potential of the oncolytic viruses. As the idea of gene therapy gained hold, an ideal vector system quest began. Searching the database ClinicalTrials.gov for "gene therapy/transfer and the viral delivery system," adenovirus returns 69 studies, adeno-associated virus 41, herpes simplex virus 8, retro virus 61 and lentivirus 20 trials and plasmid delivery returns 19 studies. Currently, the use of AAV and lentiviral vectors is on the rise, while adenoviral vectors appear stable over time. Different viral vectors can be engineered to selectively replicate and kill tumor cells. In spite to the demonstrated safety of different viral and non-viral vector administration to glioma patients, gene therapy still needs to prove its potential as a valuable therapeutic tool for the treatment of gliomas. It has recently become apparent that there is a need for combinatorial treatments in order to elicit higher therapeutic efficacy and better outcomes in the clinical arena. Combinatorial immune-gene therapies offer promising approaches for improving patient survival in GBM. Considering the numerous therapeutic approaches developed, the several possible targets, the improved current SOC and alternative dosing regimens and delivery routes, the number of potential combinations has increased exponentially. Several combinatorial approaches are today under clinical trials.

In this respect, results from a Phase I clinical trial in which anti-PD-L1 was administered before and after GBM resection, demonstrated the importance of the selection of the starting point of the treatment. Moreover, as drug penetration in the brain is an issue for GBM treatment, different ways of administering these agents are being assessed and, so far, intracranial delivery, though invasive, has demonstrated to be the most efficient in several approaches. Nanoparticles have emerged as a new and safe method for the delivery of agents targeting brain tumors and preclinical results are 


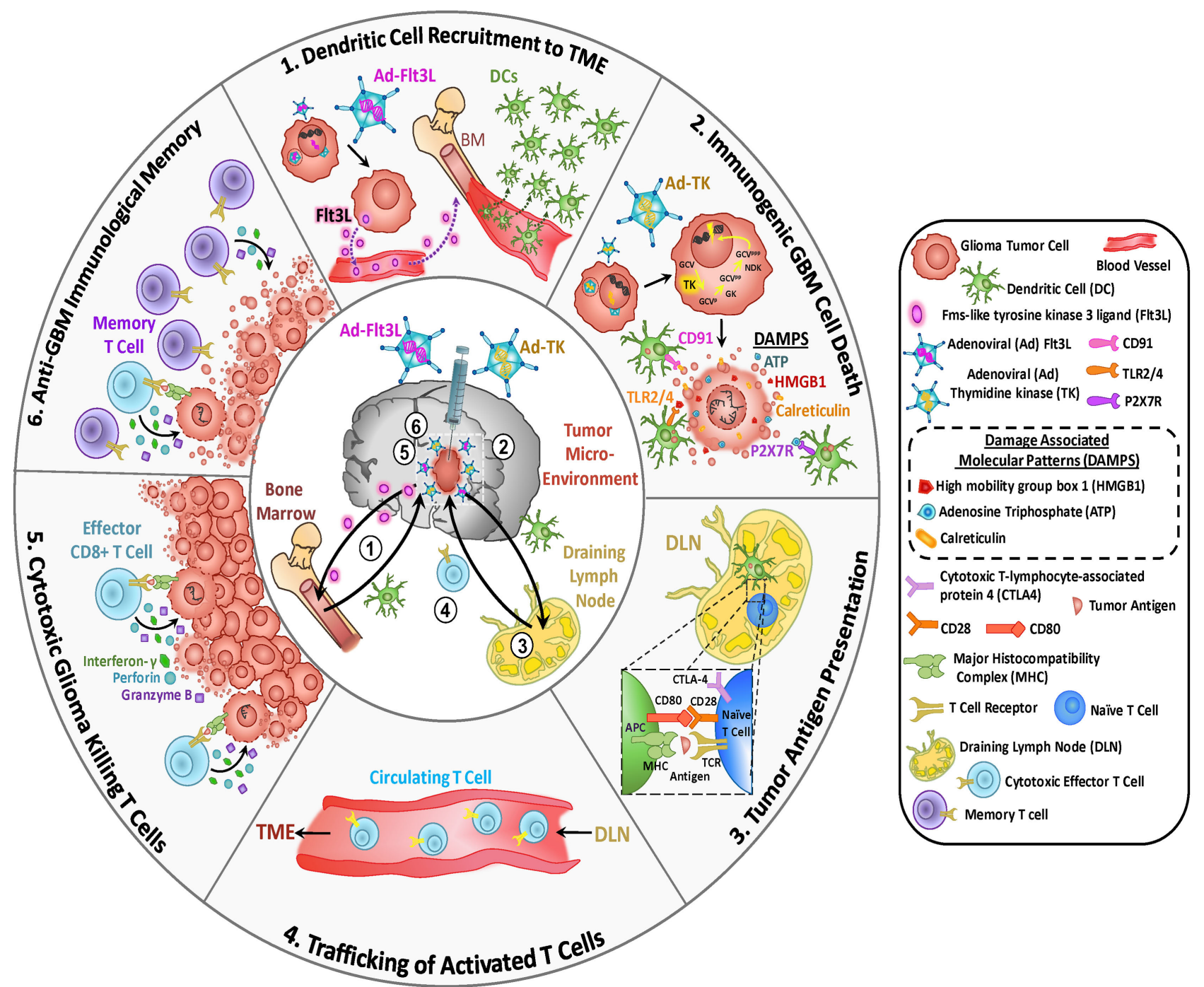

FIGURE 2 | Mechanism underlying the anti-glioma immune response following TK/Flt3L gene therapy. First generation adenoviral vectors (Ad) encoding HSV1-Thymidine Kinase (TK) and HSV1- FMS-like tyrosine kinase 3 ligand (Flt3L) are injected into the tumor cavity following surgical resection. (1) Dendritic Cell Recruitment to Tumor Microenvironment (TME): Tumor cells infected with Ad-Flt3L express Flt3L (pink circles) releasing it into the circulation. Flt3L in the bone marrow (BM) to induces dendritic cells (DCs) expansion, migration, and accumulation within the TME. (2) Immunogenic Glioblastoma (GBM) Cell Death: The prodrug ganciclovir (GCV) is administered systemically. Tumor cells infected with Ad-TK express TK protein which is capable of converting GCV to GCV-monophosphate (GCVp). This intermediate is further phosphorylated by cellular kinases: guanylate kinase (GK) and nucleoside diphosphokinase (NDK). GCV triphosphate (GCVppp) is a purine analog that selectively inhibits DNA replication in proliferating tumor cells leading to DNA breaks and apoptosis. The expression of TK in the presence of GCV mediates the release of damage associated molecular patterns (DAMPs), i.e., HMBG1, Calreticulin, and ATP from dying tumor cells. Expression of Flt3L recruits DCs into the tumor milieu where they take up brain tumor antigens released from the dying glioma cells. These DAMPs bind their corresponding receptors expressed on DCs. HMGB1 binds to TLR2/4, which promotes the production of cytokines and tumor antigen cross-presentation. The binding of extracellular ATP to purigenic receptor P2X7R further promotes the recruitment of DCs. Calreticulin binds to the CD91 receptor, which plays a major role in immunosurvillence. (3) Tumor Antigen Presentation: The DCs loaded with tumor antigens migrate to the cervical draining lymph node (DLN) where they present tumor antigens (Ag) to naiive T cells on MHC, priming tumor specific anti-glioma effector T cells. (4) Trafficking of Activated T cells: Primed CD8 ${ }^{+}$effector T cells enter circulation from DLN and migrate toward the TME. (5) Cytotoxic Glioma Killing T Cells: The tumor specific effector T cells enter the TME and kill residual glioma cells via the production of granzyme B, perforin and effector cytokine IFN-y. (6) Anti-GBM Immunological Memory: Continual exposure of T cells to tumor antigens promotes immunological memory. Memory T cells (CD103 and CD69) facilitate an anti-tumor response resulting in inhibition of tumor recurrence.

encouraging. It would be interesting to test the efficacy of these particles for the delivery of immune-stimulatory agents in the clinical setting. Finally, there is an urgent need for increased translational research and novel clinical trials to determine the potential efficacy of these novel therapies in glioma patients. 


\section{AUTHOR CONTRIBUTIONS}

KB, FN, SH, BLM, SVF, SC, JY, MSA, AA, AC, MLV, MC, PL, and MGC wrote the manuscript with overall guidance, revisions, and edits from PRL and MGC. All authors read and approved the final version of the manuscript.

\section{FUNDING}

This work was supported by the National Institutes of Health/National Institute of Neurological Disorders and Stroke (NIH/NINDS) Grants R21-NS091555, R37NS094804, and R01NS074387 to MGC; R01NS076991, R01NS082311, and R01NS096756 to PRL; Rogel Cancer Center Scholar Award and Forbes Senior Research Scholar Award to MGC;

\section{REFERENCES}

Abbott, N. J., Patabendige, A. A., Dolman, D. E., Yusof, S. R., and Begley, D. J. (2010). Structure and function of the blood-brain barrier. Neurobiol. Dis. 37, 13-25. doi: 10.1016/j.nbd.2009.07.030

Abe, T., Terada, K., Wakimoto, H., Inoue, R., Tyminski, E., Bookstein, R., et al. (2003). PTEN decreases in vivo vascularization of experimental gliomas in spite of proangiogenic stimuli. Cancer Res. 63, 2300-2305.

Adachi, Y., Chandrasekar, N., Kin, Y., Lakka, S. S., Mohanam, S., Yanamandra, N., et al. (2002). Suppression of glioma invasion and growth by adenovirusmediated delivery of a bicistronic construct containing antisense uPAR and sense p16 gene sequences. Oncogene 21, 87-95. doi: 10.1038/sj.onc.1204999

Adachi, Y., Lakka, S. S., Chandrasekar, N., Yanamandra, N., Gondi, C. S., Mohanam, S., et al. (2001). Down-regulation of integrin alpha(v)beta(3) expression and integrin-mediated signaling in glioma cells by adenovirusmediated transfer of antisense urokinase-type plasminogen activator receptor (uPAR) and sense p16 genes. J. Biol. Chem. 276, 47171-47177. doi: $10.1074 /$ jbc.M104334200

Aghi, M., Visted, T., Depinho, R. A., and Chiocca, E. A. (2008). Oncolytic herpes virus with defective ICP6 specifically replicates in quiescent cells with homozygous genetic mutations in p16. Oncogene 27, 4249-4254. doi: 10.1038/onc.2008.53

Ahn, H. M., Hong, J., and Yun, C. O. (2016). Oncolytic adenovirus coexpressing interleukin-12 and shVEGF restores antitumor immune function and enhances antitumor efficacy. Oncotarget 7, 84965-84980. doi: 10.18632/oncotarget.13087

Ali, S., King, G. D., Curtin, J. F., Candolfi, M., Xiong, W., Liu, C., et al. (2005). Combined immunostimulation and conditional cytotoxic gene therapy provide long-term survival in a large glioma model. Cancer Res. 65, 7194-7204. doi: 10.1158/0008-5472.CAN-04-3434

Alphandery, E. (2020). Nano-therapies for glioblastoma treatment. Cancers 12:242. doi: $10.3390 /$ cancers 12010242

Altshuler, D. B., Kadiyala, P., Nunez, F. J., Nunez, F. M., Carney, S., Alghamri, M. S., et al. (2020). Prospects of biological and synthetic pharmacotherapies for glioblastoma. Expert Opin. Biol. Ther. 20, 305-317. doi: 10.1080/14712598.2020.1713085

Asad, A. S., Moreno Ayala, M. A., Gottardo, M. F., Zuccato, C., Nicola Candia, A. J., Zanetti, F. A., et al. (2017). Viral gene therapy for breast cancer: progress and challenges. Expert Opin. Biol. Ther. 17, 945-959. doi: 10.1080/14712598.2017.1338684

Assi, H., Candolfi, M., Baker, G., Mineharu, Y., Lowenstein, P. R., and Castro, M. G. (2012). Gene therapy for brain tumors: basic developments and clinical implementation. Neurosci. Lett. 527, 71-77. doi: 10.1016/j.neulet.2012.08.003

Badie, B., Kramar, M. H., Lau, R., Boothman, D. A., Economou, J. S., and Black, K. L. (1998). Adenovirus-mediated p53 gene delivery potentiates the radiationinduced growth inhibition of experimental brain tumors. J. Neurooncol. 37, 217-222. doi: 10.1023/A:1005924925149

Bai, H., Harmanci, A. S., Erson-Omay, E. Z., Li, J., Coskun, S., Simon, M., et al. (2016). Integrated genomic characterization of IDH1-mutant glioma malignant progression. Nat. Genet. 48, 59-66. doi: 10.1038/ng.3457
National institutes of Health/National Institute of Biomedical Imaging and Bioengineering (NIH/NIBIB) Grant R01-EB022563 to PRL and MGC; University of Michigan M-Cube; the Department of Neurosurgery; the University of Michigan Rogel Comprehensive Cancer Center; the Pediatric Brain Tumor Foundation, Leah's Happy Hearts Foundation, and the Chad Tough Foundation to MGC and PRL. MSA was supported by a Post-doctoral Fellowship funded by NIH/NCI T32-CA009676.

\section{ACKNOWLEDGMENTS}

We thank Karin Muraszko for her academic leadership and M. Edwards, Brandye Hill, and Katherine Wood for administrative and technical assistance.

Bai, Y., Chen, Y., Hong, X., Liu, X., Su, X., Li, S., et al. (2018). Newcastle disease virus enhances the growth-inhibiting and proapoptotic effects of temozolomide on glioblastoma cells in vitro and in vivo. Sci. Rep. 8:11470. doi: 10.1038/s41598-018-29929-y

Barcia, C., Jimenez-Dalmaroni, M., Kroeger, K. M., Puntel, M., Rapaport, A. J., Larocque, D., et al. (2007). One-year expression from high-capacity adenoviral vectors in the brains of animals with pre-existing anti-adenoviral immunity: clinical implications. Mol. Ther. 15, 2154-2163. doi: 10.1038/sj.mt.6300305

Barrett, J. A., Cai, H., Miao, J., Khare, P. D., Gonzalez, P., DalsingHernandez, J., et al. (2018). Regulated intratumoral expression of IL-12 using a RheoSwitch Therapeutic System((R)) (RTS $((\mathrm{R})))$ gene switch as gene therapy for the treatment of glioma. Cancer Gene Ther. 25, 106-116. doi: 10.1038/s41417-018-0019-0

Bergen, J. M., Park, I. K., Horner, P. J., and Pun, S. H. (2008). Nonviral approaches for neuronal delivery of nucleic acids. Pharm. Res. 25, 983-998. doi: 10.1007/s11095-007-9439-5

Biroccio, A., Bufalo, D. D., Ricca, A., D’Angelo, C., D’Orazi, G., Sacchi, A., et al. (1999). Increase of BCNU sensitivity by wt-p53 gene therapy in glioblastoma lines depends on the administration schedule. Gene Ther. 6, 1064-1072. doi: 10.1038/sj.gt.3300935

Bjerke, L., Mackay, A., Nandhabalan, M., Burford, A., Jury, A., Popov, S., et al. (2013). Histone H3.3. mutations drive pediatric glioblastoma through upregulation of MYCN. Cancer Discov. 3, 512-519. doi: 10.1158/2159-8290.CD-12-0426

Bloch, O., Crane, C. A., Kaur, R., Safaee, M., Rutkowski, M. J., and Parsa, A. T. (2013). Gliomas promote immunosuppression through induction of B7-H1 expression in tumor-associated macrophages. Clin. Cancer Res. 19, 3165-3175. doi: 10.1158/1078-0432.CCR-12-3314

Bodmer, S., Strommer, K., Frei, K., Siepl, C., de Tribolet, N., Heid, I., et al. (1989). Immunosuppression and transforming growth factor-beta in glioblastoma. Preferential production of transforming growth factor-beta 2. J. Immunol. 143, 3222-3229.

Brennan, C. W., Verhaak, R. G., McKenna, A., Campos, B., Noushmehr, H., Salama, S. R., et al. (2013). The somatic genomic landscape of glioblastoma. Cell 155, 462-477. doi: 10.1016/j.cell.2013.09.034

Brown, M. C., Holl, E. K., Boczkowski, D., Dobrikova, E., Mosaheb, M., Chandramohan, V., et al. (2017). Cancer Immunotherapy with recombinant poliovirus induces IFN-dominant activation of dendritic cells and tumor antigen-specific CTLs. Sci. Transl. Med. 9:eaan4220. doi: 10.1126/scitranslmed.aan4220

Caffery, B., Lee, J. S., and Alexander-Bryant, A. A. (2019). Vectors for glioblastoma gene therapy: viral \& non-viral delivery strategies. Nanomaterials 9:105. doi: 10.3390/nano9010105

Calinescu, A. A., Nunez, F. J., Koschmann, C., Kolb, B. L., Lowenstein, P. R., and Castro, M. G. (2015). Transposon mediated integration of plasmid DNA into the subventricular zone of neonatal mice to generate novel models of glioblastoma. J. Vis. Exp. 22:52443. doi: 10.3791/52443

Cancer Genome Atlas Research, N. (2008). Comprehensive genomic characterization defines human glioblastoma genes 
and core pathways. Nature 455, 1061-1068. doi: 10.1038/nature 07385

Cancer Genome Atlas Research, N., Brat, D. J., Verhaak, R. G., Aldape, K. D., Yung, W. K., Salama, S. R., et al. (2015). Comprehensive, integrative genomic analysis of diffuse lower-grade gliomas. N. Engl. J. Med. 372, 2481-2498. doi: 10.1056/NEJMoa1402121

Candolf, M., King, G. D., Yagiz, K., Curtin, J. F., Mineharu, Y., Muhammad, A. K., et al. (2012). Plasmacytoid dendritic cells in the tumor microenvironment: immune targets for glioma therapeutics. Neoplasia 14, 757-770. doi: $10.1593 /$ neo. 12794

Candolfi, M., Kroeger, K. M., Xiong, W., Liu, C., Puntel, M., Yagiz, K., et al. (2011). Targeted toxins for glioblastoma multiforme: pre-clinical studies and clinical implementation. Anticancer. Agents Med. Chem. 11, 729-738. doi: $10.2174 / 187152011797378689$

Candolfi, M., Xiong, W., Yagiz, K., Liu, C., Muhammad, A. K., Puntel, M., et al. (2010). Gene therapy-mediated delivery of targeted cytotoxins for glioma therapeutics. Proc. Natl. Acad. Sci. U.S.A. 107, 20021-20026. doi: $10.1073 /$ pnas. 1008261107

Candolfi, M., Yagiz, K., Foulad, D., Alzadeh, G. E., Tesarfreund, M., Muhammad, A. K., et al. (2009). Release of HMGB1 in response to proapoptotic glioma killing strategies: efficacy and neurotoxicity. Clin. Cancer Res. 15, 4401-4414. doi: 10.1158/1078-0432.CCR-09-0155

Castro, M. G., Candolfi, M., Kroeger, K., King, G. D., Curtin, J. F., Yagiz, K., et al. (2011). Gene therapy and targeted toxins for glioma. Curr. Gene Ther. 11, 155-180. doi: 10.2174/156652311795684722

Castro, M. G., Candolfi, M., Wilson, T. J., Calinescu, A., Paran, C., Kamran, N., et al. (2014). Adenoviral vector-mediated gene therapy for gliomas: coming of age. Expert Opin. Biol. Ther. 14, 1241-1257. doi: $10.1517 / 14712598.2014 .915307$

Ceccarelli, M., Barthel, F. P., Malta, T. M., Sabedot, T. S., Salama, S. R., Murray, B. A., et al. (2016). Molecular profiling reveals biologically discrete subsets and pathways of progression in diffuse glioma. Cell 164, 550-563. doi: 10.1016/j.cell.2015.12.028

Chae, M., Peterson, T. E., Balgeman, A., Chen, S., Zhang, L., Renner, D. N., et al. (2015). Increasing glioma-associated monocytes leads to increased intratumoral and systemic myeloid-derived suppressor cells in a murine model. Neurooncology 17, 978-991. doi: 10.1093/neuonc/nou343

Chang, A. L., Miska, J., Wainwright, D. A., Dey, M., Rivetta, C. V., Yu, D., et al. (2016). CCL2 produced by the glioma microenvironment is essential for the recruitment of regulatory T cells and myeloid-derived suppressor cells. Cancer Res. 76, 5671-5682. doi: 10.1158/0008-5472.CAN-16-0144

Chang, E. L., Ting, C. Y., Hsu, P. H., Lin, Y. C., Liao, E. C., Huang, C. Y., et al. (2017). Angiogenesis-targeting microbubbles combined with ultrasoundmediated gene therapy in brain tumors. J. Control. Release 255, 164-175. doi: 10.1016/j.jconrel.2017.04.010

Chastkofsky, M., Pituch, K. C., Katagi, H., Zannikou, M., Ilut, L., Xiao, T., et al. (2020). Mesenchymal stem cells successfully deliver oncolytic virotherapy to diffuse intrinsic pontine glioma. Clin. Cancer Res. 1499. doi: 10.1158/1078-0432.CCR-20-1499. [Epub ahead of print].

Cheema, T. A., Wakimoto, H., Fecci, P. E., Ning, J., Kuroda, T., Jeyaretna, D. S., et al. (2013). Multifaceted oncolytic virus therapy for glioblastoma in an immunocompetent cancer stem cell model. Proc. Natl. Acad. Sci. U.S.A. 110, 12006-12011. doi: 10.1073/pnas.1307935110

Chen, B., Timiryasova, T. M., Andres, M. L., Kajioka, E. H., Dutta-Roy, R., Gridley, D. S., et al. (2000). Evaluation of combined vaccinia virus-mediated antitumor gene therapy with p53, IL-2, and IL-12 in a glioma model. Cancer Gene Ther. 7, 1437-1447. doi: 10.1038/sj.cgt.7700252

Chen, B., Timiryasova, T. M., Haghighat, P., Andres, M. L., Kajioka, E. H., DuttaRoy, R., et al. (2001). Low-dose vaccinia virus-mediated cytokine gene therapy of glioma. J. Immunother. 24, 46-57. doi: 10.1097/00002371-20010100000006

Cheney, I. W., Johnson, D. E., Vaillancourt, M. T., Avanzini, J., Morimoto, A., Demers, G. W., et al. (1998). Suppression of tumorigenicity of glioblastoma cells by adenovirus-mediated MMAC1/PTEN gene transfer. Cancer Res. 58, 2331-2334.

Chintala, S. K., Fueyo, J., Gomez-Manzano, C., Venkaiah, B., Bjerkvig, R., Yung, W. K., et al. (1997). Adenovirus-mediated p16/CDKN2 gene transfer suppresses glioma invasion in vitro. Oncogene 15, 2049-2057. doi: 10.1038/sj.onc.1201382
Chiocca, E. A., Aguilar, L. K., Bell, S. D., Kaur, B., Hardcastle, J., Cavaliere, R., et al. (2011). Phase IB study of gene-mediated cytotoxic immunotherapy adjuvant to up-front surgery and intensive timing radiation for malignant glioma. J. Clin. Oncol. 29, 3611-3619. doi: 10.1200/JCO.2011.35.5222

Chiocca, E. A., Smith, K. M., McKinney, B., Palmer, C. A., Rosenfeld, S., Lillehei, K., et al. (2008). A phase I trial of Ad.hIFN-beta gene therapy for glioma. Mol. Ther. 16, 618-626. doi: 10.1038/sj.mt.6300396

Chiocca, E. A., Yu, J. S., Lukas, R. V., Solomon, I. H., Ligon, K. L., Nakashima, H., et al. (2019). Regulatable interleukin-12 gene therapy in patients with recurrent high-grade glioma: Results of a phase 1 trial. Sci. Transl. Med. 11:eaaw5680. doi: 10.1126/scitranslmed.aaw5680

Choi, B. D., Maus, M. V., June, C. H., and Sampson, J. H. (2019). Immunotherapy for glioblastoma: adoptive T-cell strategies. Clin. Cancer Res. 25, 2042-2048. doi: 10.1158/1078-0432.CCR-18-1625

Choi, J., Rui, Y., Kim, J., Gorelick, N., Wilson, D. R., Kozielski, K., et al. (2020). Nonviral polymeric nanoparticles for gene therapy in pediatric CNS malignancies. Nanomedicine 23:102115. doi: 10.1016/j.nano.2019.102115

Cirielli, C., Inyaku, K., Capogrossi, M. C., Yuan, X., and Williams, J. A. (1999). Adenovirus-mediated wild-type p53 expression induces apoptosis and suppresses tumorigenesis of experimental intracranial human malignant glioma. J. Neurooncol. 43, 99-108. doi: 10.1023/A:1006289505801

Cloughesy, T. F., Landolfi, J., Vogelbaum, M. A., Ostertag, D., Elder, J. B., Bloomfield, S., et al. (2018). Durable complete responses in some recurrent high-grade glioma patients treated with Toca $511+$ Toca FC. Neurooncology 20, 1383-1392. doi: 10.1093/neuonc/noy075

Cloughesy, T. F., Petrecca, K., Walbert, T., Butowski, N., Salacz, M., Perry, J., et al. (2020). Effect of vocimagene amiretrorepvec in combination with flucytosine vs standard of care on survival following tumor resection in patients with recurrent high-grade glioma: a randomized clinical trial. JAMA Oncol. 6, 1939-1946. doi: 10.1001/jamaoncol.2020.3161

Costa, P. M., Cardoso, A. L., Custodia, C., Cunha, P., Pereira de Almeida, L., and Pedroso de Lima, M. C. (2015). MiRNA-21 silencing mediated by tumor-targeted nanoparticles combined with sunitinib: a new multimodal gene therapy approach for glioblastoma. J. Control. Release 207, 31-39. doi: 10.1016/j.jconrel.2015.04.002

Crespo, I., Vital, A. L., Gonzalez-Tablas, M., Patino Mdel, C., Otero, A., Lopes, M. C., et al. (2015). Molecular and genomic alterations in glioblastoma multiforme. Am. J. Pathol. 185, 1820-1833. doi: 10.1016/j.ajpath.2015.02.023

Cui, Q., Yang, S., Ye, P., Tian, E., Sun, G., Zhou, J., et al. (2016). Downregulation of TLX induces TET3 expression and inhibits glioblastoma stem cell self-renewal and tumorigenesis. Nat. Commun. 7:10637. doi: 10.1038/ncomms10637

Curtin, J. F., Liu, N., Candolfi, M., Xiong, W., Assi, H., Yagiz, K., et al. (2009). HMGB1 mediates endogenous TLR2 activation and brain tumor regression. PLoS Med. 6:e10. doi: 10.1371/journal.pmed.1000010

Davies, M. A., Lu, Y., Sano, T., Fang, X., Tang, P., LaPushin, R., et al. (1998). Adenoviral transgene expression of MMAC/PTEN in human glioma cells inhibits Akt activation and induces anoikis. Cancer Res. 58, 5285-5290.

Davola, M. E., and Mossman, K. L. (2019). Oncolytic viruses: how "lytic" must they be for therapeutic efficacy? Oncoimmunology 8:e1581528. doi: 10.1080/2162402X.2019.1596006

Del Vecchio, C., Calistri, A., Parolin, C., and Mucignat-Caretta, C. (2019). Lentiviral vectors as tools for the study and treatment of glioblastoma. Cancers 11:417. doi: 10.3390/cancers11030417

Delgado-Lopez, P. D., Corrales-Garcia, E. M., Martino, J., Lastra-Aras, E., and Duenas-Polo, M. T. (2017). Diffuse low-grade glioma: a review on the new molecular classification, natural history and current management strategies. Clin. Transl. Oncol. 19, 931-944. doi: 10.1007/s12094-017-1631-4

Deng, Z., Sheng, Z., and Yan, F. (2019). Ultrasound-induced blood-brain-barrier opening enhances anticancer efficacy in the treatment of glioblastoma: current status and future prospects. J. Oncol. 2019, 2345203. doi: 10.1155/2019/2345203

Dent, P., Yacoub, A., Hamed, H. A., Park, M. A., Dash, R., Bhutia, S. K., et al. (2010). MDA-7/IL-24 as a cancer therapeutic: from bench to bedside. Anticancer. Drugs 21, 725-731. doi: 10.1097/CAD.0b013e32833cfbel

Dunn, G. P., Rinne, M. L., Wykosky, J., Genovese, G., Quayle, S. N., Dunn, I. F., et al. (2012). Emerging insights into the molecular and cellular basis of glioblastoma. Genes Dev. 26, 756-784. doi: 10.1101/gad.187922.112

Ehtesham, M., Samoto, K., Kabos, P., Acosta, F. L., Gutierrez, M. A., Black, K. L., et al. (2002). Treatment of intracranial glioma with in situ interferon-gamma 
and tumor necrosis factor-alpha gene transfer. Cancer Gene Ther. 9, 925-934. doi: 10.1038/sj.cgt.7700516

Emdad, L., Lebedeva, I. V., Su, Z. Z., Gupta, P., Sauane, M., Dash, R., et al. (2009). Historical perspective and recent insights into our understanding of the molecular and biochemical basis of the antitumor properties of mda-7/IL-24. Cancer Biol. Ther. 8, 391-400. doi: 10.4161/cbt.8.5.7581

Enger, P. O., Thorsen, F., Lonning, P. E., Bjerkvig, R., and Hoover, F. (2002). Adeno-associated viral vectors penetrate human solid tumor tissue in vivo more effectively than adenoviral vectors. Hum. Gene Ther. 13, 1115-1125. doi: $10.1089 / 104303402753812511$

England, B., Huang, T., and Karsy, M. (2013). Current understanding of the role and targeting of tumor suppressor p53 in glioblastoma multiforme. Tumour Biol. 34, 2063-2074. doi: 10.1007/s13277-013-0871-3

Fan, C. H., Wang, T. W., Hsieh, Y. K., Wang, C. F., Gao, Z., Kim, A., et al. (2019). Enhancing boron uptake in brain glioma by a boron-polymer/microbubble complex with focused ultrasound. ACS Appl. Mater. Interfaces 11, 11144-11156. doi: $10.1021 /$ acsami.8b22468

Fan, Q. W., Cheng, C. K., Gustafson, W. C., Charron, E., Zipper, P., Wong, R. A., et al. (2013). EGFR phosphorylates tumor-derived EGFRvIII driving STAT3/5 and progression in glioblastoma. Cancer Cell 24, 438-449. doi: 10.1016/j.ccr.2013.09.004

Fontebasso, A. M., Papillon-Cavanagh, S., Schwartzentruber, J., Nikbakht, H., Gerges, N., Fiset, P. O., et al. (2014). Recurrent somatic mutations in ACVR1 in pediatric midline high-grade astrocytoma. Nat. Genet. 46, 462-466. doi: 10.1038/ng.2950

Foreman, P. M., Friedman, G. K., Cassady, K. A., and Markert, J. M. (2017). Oncolytic virotherapy for the treatment of malignant glioma. Neurotherapeutics 14, 333-344. doi: 10.1007/s13311-017-0516-0

Freeman, A. I., Zakay-Rones, Z., Gomori, J. M., Linetsky, E., Rasooly, L., Greenbaum, E., et al. (2006). Phase I/II trial of intravenous NDV-HUJ oncolytic virus in recurrent glioblastoma multiforme. Mol. Ther. 13, 221-228. doi: 10.1016/j.ymthe.2005.08.016

Fueyo, J., Alemany, R., Gomez-Manzano, C., Fuller, G. N., Khan, A., Conrad, C. A., et al. (2003). Preclinical characterization of the antiglioma activity of a tropismenhanced adenovirus targeted to the retinoblastoma pathway. J. Natl. Cancer Inst. 95, 652-660. doi: 10.1093/jnci/95.9.652

Fueyo, J., Gomez-Manzano, C., Puduvalli, V. K., Martin-Duque, P., Perez-Soler, R., Levin, V. A., et al. (1998). Adenovirus-mediated p16 transfer to glioma cells induces G1 arrest and protects from paclitaxel and topotecan: implications for therapy. Int. J. Oncol. 12, 665-669. doi: 10.3892/ijo.12.3.665

Gabrilovich, D. I., Chen, H. L., Girgis, K. R., Cunningham, H. T., Meny, G. M., Nadaf, S., et al. (1996). Production of vascular endothelial growth factor by human tumors inhibits the functional maturation of dendritic cells. Nat. Med. 2, 1096-1103. doi: 10.1038/nm1096-1096

Galvao, R. P., and Zong, H. (2013). Inflammation and gliomagenesis: bi-directional communication at early and late stages of tumor progression. Curr. Pathobiol. Rep. 1, 19-28. doi: 10.1007/s40139-012-0006-3

Gan, H. K., Cvrljevic, A. N., and Johns, T. G. (2013). The epidermal growth factor receptor variant III (EGFRvIII): where wild things are altered. FEBS J. 280, 5350-5370. doi: 10.1111/febs.12393

Gersey, Z., Osiason, A. D., Bloom, L., Shah, S., Thompson, J. W., Bregy, A., et al. (2019). Therapeutic targeting of the notch pathway in glioblastoma multiforme. World Neurosurg. 131, 252-263 e252. doi: 10.1016/j.wneu.2019.07.180

Gomes, M. J., Martins, S., and Sarmento, B. (2015). siRNA as a tool to improve the treatment of brain diseases: mechanism, targets and delivery. Ageing Res. Rev. 21, 43-54. doi: 10.1016/j.arr.2015.03.001

Gregory, J. V., Kadiyala, P., Doherty, R., Cadena, M., Habeel, S., Ruoslahti, E., et al. (2020). Systemic brain tumor delivery of synthetic protein nanoparticles for glioblastoma therapy. Nat. Commun. 11:5687. doi: $10.1038 / \mathrm{s} 41467-020-19225-7$

Griscelli, F., Li, H., Cheong, C., Opolon, P., Bennaceur-Griscelli, A., Vassal, G., et al. (2000). Combined effects of radiotherapy and angiostatin gene therapy in glioma tumor model. Proc. Natl. Acad. Sci. U.S.A. 97, 6698-6703. doi: $10.1073 /$ pnas. 110134297

GuhaSarkar, D., Neiswender, J., Su, Q., Gao, G., and Sena-Esteves, M. (2017). Intracranial AAV-IFN-beta gene therapy eliminates invasive xenograft glioblastoma and improves survival in orthotopic syngeneic murine model. Mol. Oncol. 11, 180-193. doi: 10.1002/1878-0261.12020
Guo, H., Choudhury, Y., Yang, J., Chen, C., Tay, F. C., Lim, T. M., et al. (2011). Antiglioma effects of combined use of a baculovirual vector expressing wildtype p53 and sodium butyrate. J. Gene Med. 13, 26-36. doi: 10.1002/jgm.1522

Guo, X., Qiu, W., Liu, Q., Qian, M., Wang, S., Zhang, Z., et al. (2018). Immunosuppressive effects of hypoxia-induced glioma exosomes through myeloid-derived suppressor cells via the miR-10a/Rora and miR-21/Pten pathways. Oncogene 37, 4239-4259. doi: 10.1038/s41388-018-0261-9

Halatsch, M. E., Schmidt, U., Botefur, I. C., Holland, J. F., and Ohnuma, T. (2000). Marked inhibition of glioblastoma target cell tumorigenicity in vitro by retrovirus-mediated transfer of a hairpin ribozyme against deletion-mutant epidermal growth factor receptor messenger RNA. J. Neurosurg. 92, 297-305. doi: 10.3171/jns.2000.92.2.0297

Hama, S., Heike, Y., Naruse, I., Takahashi, M., Yoshioka, H., Arita, K., et al. (1998). Adenovirus-mediated p16 gene transfer prevents drug-induced cell death through G1 arrest in human glioma cells. Int. J. Cancer 77, 47-54. doi: 10.1002/(SICI) 1097-0215(19980703)77:1<47::AID-IJC9>3.0.CO;2-\#

Hama, S., Matsuura, S., Tauchi, H., Yamasaki, F., Kajiwara, Y., Arita, K., et al. (2003). p16 Gene transfer increases cell killing with abnormal nucleation after ionising radiation in glioma cells. Br. J. Cancer 89, 1802-1811. doi: 10.1038/sj.bjc.6601299

Hambardzumyan, D., Gutmann, D. H., and Kettenmann, H. (2016). The role of microglia and macrophages in glioma maintenance and progression. Nat. Neurosci. 19, 20-27. doi: 10.1038/nn.4185

Han, L., Zhang, A. L., Xu, P., Yue, X., Yang, Y., Wang, G. X., et al. (2010). Combination gene therapy with PTEN and EGFR siRNA suppresses U251 malignant glioma cell growth in vitro and in vivo. Med. Oncol. 27, 843-852. doi: 10.1007/s12032-009-9295-8

Harada, H., Nakagawa, K., Iwata, S., Saito, M., Kumon, Y., Sakaki, S., et al. (1999). Restoration of wild-type p16 down-regulates vascular endothelial growth factor expression and inhibits angiogenesis in human gliomas. Cancer Res. 59, 3783-3789.

Hardcastle, J., Mills, L., Malo, C. S., Jin, F., Kurokawa, C., Geekiyanage, H., et al. (2017). Immunovirotherapy with measles virus strains in combination with anti-PD-1 antibody blockade enhances antitumor activity in glioblastoma treatment. Neurooncology 19, 493-502. doi: 10.1093/neuonc/now179

Havel, J. J., Chowell, D., and Chan, T. A. (2019). The evolving landscape of biomarkers for checkpoint inhibitor immunotherapy. Nat. Rev. Cancer 19, 133-150. doi: 10.1038/s41568-019-0116-x

Hdeib, A., and Sloan, A. E. (2015). Dendritic cell immunotherapy for solid tumors: evaluation of the $\operatorname{DCVax}(\mathrm{R})$ platform in the treatment of glioblastoma multiforme. CNS Oncol. 4, 63-69. doi: 10.2217/cns.14.54

Heidenreich, R., Machein, M., Nicolaus, A., Hilbig, A., Wild, C., Clauss, M., et al. (2004). Inhibition of solid tumor growth by gene transfer of VEGF receptor-1 mutants. Int. J. Cancer 111, 348-357. doi: 10.1002/ijc. 20260

Hellums, E. K., Markert, J. M., Parker, J. N., He, B., Perbal, B., Roizman, B., et al. (2005). Increased efficacy of an interleukin-12-secreting herpes simplex virus in a syngeneic intracranial murine glioma model. Neurooncology 7, 213-224. doi: $10.1215 /$ S1152851705000074

Hoosain, F. G., Choonara, Y. E., Tomar, L. K., Kumar, P., Tyagi, C., du Toit, L. C., et al. (2015). Bypassing P-glycoprotein drug efflux mechanisms: possible applications in pharmacoresistant schizophrenia therapy. Biomed. Res. Int. 2015, 484963. doi: $10.1155 / 2015 / 484963$

Hsu, S. C., Volpert, O. V., Steck, P. A., Mikkelsen, T., Polverini, P. J., Rao, S., et al. (1996). Inhibition of angiogenesis in human glioblastomas by chromosome 10 induction of thrombospondin-1. Cancer Res. 56, 5684-5691.

Hung, K. S., Hong, C. Y., Lee, J., Lin, S. K., Huang, S. C., Wang, T. M., et al. (2000). Expression of p16(INK4A) induces dominant suppression of glioblastoma growth in situ through necrosis and cell cycle arrest. Biochem. Biophys. Res. Commun. 269, 718-725. doi: 10.1006/bbrc.2000.2339

Huszthy, P. C., Giroglou, T., Tsinkalovsky, O., Euskirchen, P., Skaftnesmo, K. O., Bjerkvig, R., et al. (2009). Remission of invasive, cancer stem-like glioblastoma xenografts using lentiviral vector-mediated suicide gene therapy. PLOS ONE 4:e6314. doi: 10.1371/journal.pone.0006314

Im, S. A., Gomez-Manzano, C., Fueyo, J., Liu, T. J., Ke, L. D., Kim, J. S., et al. (1999). Antiangiogenesis treatment for gliomas: transfer of antisensevascular endothelial growth factor inhibits tumor growth in vivo. Cancer Res. $59,895-900$. 
Inaba, N., Kimura, M., Fujioka, K., Ikeda, K., Somura, H., Akiyoshi, K., et al. (2011). The effect of PTEN on proliferation and drug-, and radiosensitivity in malignant glioma cells. Anticancer Res. 31, 1653-1658.

Ito, A., Shinkai, M., Bouhon, I. A., Honda, H., and Kobayashi, T. (2000). Bystander-killing effect and cyclic induction of TNF-alpha gene under heat-inducible promoter gadd 153. J. Biosci. Bioeng. 90, 437-441. doi: 10.1016/S1389-1723(01)80015-3

Iwami, K., Natsume, A., and Wakabayashi, T. (2010). Gene therapy for high-grade glioma. Neurol. Med. Chir. 50, 727-736. doi: 10.2176/nmc.50.727

Jensen, S. A., Day, E. S., Ko, C. H., Hurley, L. A., Luciano, J. P., Kouri, F. M., et al. (2013). Spherical nucleic acid nanoparticle conjugates as an RNAi-based therapy for glioblastoma. Sci. Transl. Med. 5:209ra152. doi: 10.1126/scitranslmed.3006839

Ji, N., Weng, D., Liu, C., Gu, Z., Chen, S., Guo, Y., et al. (2016). Adenovirusmediated delivery of herpes simplex virus thymidine kinase administration improves outcome of recurrent high-grade glioma. Oncotarget 7, 4369-4378. doi: 10.18632/oncotarget.6737

Johnsen, K. B., Burkhart, A., Thomsen, L. B., Andresen, T. L., and Moos, T. (2019). Targeting the transferrin receptor for brain drug delivery. Prog. Neurobiol. 181:101665. doi: 10.1016/j.pneurobio.2019.101665

Jones, C., Karajannis, M. A., Jones, D. T. W., Kieran, M. W., Monje, M., Baker, S. J., et al. (2017). Pediatric high-grade glioma: biologically and clinically in need of new thinking. Neurooncology 19, 153-161. doi: 10.1093/neuonc/now101

Juillerat-Jeanneret, L. (2008). The targeted delivery of cancer drugs across the blood-brain barrier: chemical modifications of drugs or drug-nanoparticles? Drug Discov. Today 13, 1099-1106. doi: 10.1016/j.drudis.2008.09.005

Kadiyala, P., Li, D., Nunez, F. M., Altshuler, D., Doherty, R., Kuai, R., et al. (2019). High-density lipoprotein-mimicking nanodiscs for chemoimmunotherapy against glioblastoma multiforme. ACS Nano 13, 1365-1384. doi: 10.1021/acsnano.8b06842

Kamran, N., Alghamri, M. S., Nunez, F. J., Shah, D., Asad, A. S., Candolfi, M., et al. (2018a). Current state and future prospects of immunotherapy for glioma. Immunotherapy 10, 317-339. doi: 10.2217/imt-2017-0122

Kamran, N., Calinescu, A., Candolfi, M., Chandran, M., Mineharu, Y., Asad, A. S., et al. (2016). Recent advances and future of immunotherapy for glioblastoma. Expert Opin. Biol. Ther. 16, 1245-1264. doi: 10.1080/14712598.2016.1212012

Kamran, N., Chandran, M., Lowenstein, P. R., and Castro, M. G. (2018b). Immature myeloid cells in the tumor microenvironment: implications for immunotherapy. Clin. Immunol. 189, 34-42. doi: 10.1016/j.clim.2016.10.008

Kamran, N., Kadiyala, P., Saxena, M., Candolfi, M., Li, Y., Moreno-Ayala, M. A., et al. (2017). Immunosuppressive myeloid cells' blockade in the glioma microenvironment enhances the efficacy of immune-stimulatory gene therapy. Mol. Ther. 25, 232-248. doi: 10.1016/j.ymthe.2016.10.003

Kang, C. S., Zhang, Z. Y., Jia, Z. F., Wang, G. X., Qiu, M. Z., Zhou, H. X., et al. (2006). Suppression of EGFR expression by antisense or small interference RNA inhibits U251 glioma cell growth in vitro and in vivo. Cancer Gene Ther. 13, 530-538. doi: 10.1038/sj.cgt.7700932

Kang, T., Jiang, M., Jiang, D., Feng, X., Yao, J., Song, Q., et al. (2015). Enhancing glioblastoma-specific penetration by functionalization of nanoparticles with an iron-mimic peptide targeting transferrin/transferrin receptor complex. Mol. Pharm. 12, 2947-2961. doi: 10.1021/acs.molpharmaceut.5b00222

Kang, Y. A., Shin, H. C., Yoo, J. Y., Kim, J. H., Kim, J. S., and Yun, C. O. (2008). Novel cancer antiangiotherapy using the VEGF promoter-targeted artificial zinc-finger protein and oncolytic adenovirus. Mol. Ther. 16, 1033-1040. doi: $10.1038 / \mathrm{mt} .2008 .63$

Kanu, O. O., Hughes, B., Di, C., Lin, N., Fu, J., Bigner, D. D., et al. (2009). Glioblastoma multiforme oncogenomics and signaling pathways. Clin. Med. Oncol. 3, 39-52. doi: 10.4137/CMO.S1008

Karim, R., Palazzo, C., Evrard, B., and Piel, G. (2016). Nanocarriers for the treatment of glioblastoma multiforme: current state-ofthe-art. J. Control. Release 227, 23-37. doi: 10.1016/j.jconrel.2016. 02.026

Karpel-Massler, G., Schmidt, U., Unterberg, A., and Halatsch, M. E. (2009). Therapeutic inhibition of the epidermal growth factor receptor in highgrade gliomas: where do we stand? Mol. Cancer Res. 7, 1000-1012. doi: 10.1158/1541-7786.MCR-08-0479

Kato, T., Natsume, A., Toda, H., Iwamizu, H., Sugita, T., Hachisu, R., et al. (2010). Efficient delivery of liposome-mediated MGMT-siRNA reinforces the cytotoxity of temozolomide in GBM-initiating cells. Gene Ther. 17, 1363-1371. doi: $10.1038 /$ gt.2010.88

Kazlauskas, A., Darinskas, A., Meskys, R., Tamasauskas, A., and Urbonavicius, J. (2019). Isocytosine deaminase $\mathrm{Vcz}$ as a novel tool for the prodrug cancer therapy. BMC Cancer 19:197. doi: 10.1186/s12885-019-5409-7

Kim, C., Shah, B. P., Subramaniam, P., and Lee, K. B. (2011). Synergistic induction of apoptosis in brain cancer cells by targeted codelivery of siRNA and anticancer drugs. Mol. Pharm. 8, 1955-1961. doi: 10.1021/mp100460h

Kim, J. W., Kane, J. R., Panek, W. K., Young, J. S., Rashidi, A., Yu, D., et al. (2018). A dendritic cell-targeted adenoviral vector facilitates adaptive immune response against human glioma antigen (CMV-IE) and prolongs survival in a human glioma tumor model. Neurotherapeutics 15, 1127-1138. doi: 10.1007/s13311-018-0650-3

Kim, S. S., Harford, J. B., Pirollo, K. F., and Chang, E. H. (2015a). Effective treatment of glioblastoma requires crossing the blood-brain barrier and targeting tumors including cancer stem cells: the promise of nanomedicine. Biochem. Biophys. Res. Commun. 468, 485-489. doi: 10.1016/j.bbrc.2015.06.137

Kim, S. S., Rait, A., Kim, E., Pirollo, K. F., and Chang, E. H. (2015b). A tumor-targeting p53 nanodelivery system limits chemoresistance to temozolomide prolonging survival in a mouse model of glioblastoma multiforme. Nanomedicine 11, 301-311. doi: 10.1016/j.nano.2014.09.005

Kim, S. S., Rait, A., Kim, E., Pirollo, K. F., Nishida, M., Farkas, N., et al. (2014). A nanoparticle carrying the p53 gene targets tumors including cancer stem cells, sensitizes glioblastoma to chemotherapy and improves survival. ACS Nano 8, 5494-5514. doi: 10.1021/nn5014484

Kumar, V., Patel, S., Tcyganov, E., and Gabrilovich, D. I. (2016). The nature of myeloid-derived suppressor cells in the tumor microenvironment. Trends Immunol. 37, 208-220. doi: 10.1016/j.it.2016.01.004

Kwiatkowska, A., Nandhu, M. S., Behera, P., Chiocca, E. A., and Viapiano, M. S. (2013). Strategies in gene therapy for glioblastoma. Cancers 5, 1271-1305. doi: $10.3390 /$ cancers5041271

Lajoie, J. M., and Shusta, E. V. (2015). Targeting receptor-mediated transport for delivery of biologics across the blood-brain barrier. Annu. Rev. Pharmacol. Toxicol. 55, 613-631. doi: 10.1146/annurev-pharmtox-010814-124852

Lang, F. F., Conrad, C., Gomez-Manzano, C., Yung, W. K. A., Sawaya, R., Weinberg, J. S., et al. (2018). Phase I study of DNX-2401 (Delta-24-RGD) oncolytic adenovirus: replication and immunotherapeutic effects in recurrent malignant glioma. J. Clin. Oncol. 36, 1419-1427. doi: 10.1200/JCO.2017.75.8219

Lang, F. F., Yung, W. K., Sawaya, R., and Tofilon, P. J. (1999). Adenovirusmediated p53 gene therapy for human gliomas. Neurosurgery 45, 1093-1104. doi: 10.1097/00006123-199911000-00016

Lee, T. J., Yoo, J. Y., Shu, D., Li, H., Zhang, J., Yu, J. G., et al. (2017). RNA nanoparticle-based targeted therapy for glioblastoma through inhibition of oncogenic miR-21. Mol. Ther. 25, 1544-1555. doi: 10.1016/j.ymthe.2016.11.016

Lee-Chang, C., Miska, J., Hou, D., Rashidi, A., Zhang, P., Burga, R. A., et al. (2021). Activation of 4-1BBL+ B cells with CD40 agonism and IFNgamma elicits potent immunity against glioblastoma. J. Exp. Med. 218:e20200913. doi: $10.1084 /$ jem. 20200913

Li, H., Alonso-Vanegas, M., Colicos, M. A., Jung, S. S., Lochmuller, H., Sadikot, A. F., et al. (1999). Intracerebral adenovirus-mediated p53 tumor suppressor gene therapy for experimental human glioma. Clin. Cancer Res. 5, 637-642.

Li, X., Wang, P., Li, H., Du, X., Liu, M., Huang, Q., et al. (2017). The efficacy of oncolytic adenovirus is mediated by T-cell responses against virus and tumor in syrian hamster model. Clin. Cancer Res. 23, 239-249. doi: 10.1158/1078-0432.CCR-16-0477

Liu, Y., Ehtesham, M., Samoto, K., Wheeler, C. J., Thompson, R. C., Villarreal, L. P., et al. (2002). In situ adenoviral interleukin 12 gene transfer confers potent and long-lasting cytotoxic immunity in glioma. Cancer Gene Ther. 9, 9-15. doi: 10.1038/sj.cgt.7700399

Louis, D. N., Ohgaki, H., Wiestler, O. D., Cavenee, W. K., Burger, P. C., Jouvet, A., et al. (2007). The 2007 WHO classification of tumours of the central nervous system. Acta Neuropathol. 114, 97-109. doi: 10.1007/s00401-007-0243-4

Louis, D. N., Perry, A., Reifenberger, G., von Deimling, A., Figarella-Branger, D., Cavenee, W. K., et al. (2016). The 2016 World Health Organization classification of tumors of the central nervous system: a summary. Acta Neuropathol. 131, 803-820. doi: 10.1007/s00401-016-1545-1

Lowenstein, P., Orringer, D. A., Sagher, O., Heth, J., Hervey-Jumper, S., Mammoser, A. G., et al. (2019). A phase I first-in-human trial of two 
adenoviral vectors expressing HSV1-TK and FLT3L for treating newly diagnosed resectable malignant glioma: therapeutic reprogramming of the brain immune system. Neurooncology 21:vi11. doi: 10.1093/neuonc/noz175.042

Lowenstein, P. R., and Castro, M. G. (2018). Evolutionary basis of a new gene-and immune-therapeutic approach for the treatment of malignant brain tumors: from mice to clinical trials for glioma patients. Clin. Immunol. 189, 43-51. doi: 10.1016/j.clim.2017.07.006

Lowenstein, P. R., Lowenstein, E. D., and Castro, M. G. (2009). Challenges in the evaluation, consent, ethics and history of early clinical trials - Implications of the Tuskegee 'trial' for safer and more ethical clinical trials. Curr. Opin. Mol. Ther. 11, 481-484.

Lu, W., Zhou, X., Hong, B., Liu, J., and Yue, Z. (2004). Suppression of invasion in human U87 glioma cells by adenovirus-mediated co-transfer of TIMP-2 and PTEN gene. Cancer Lett. 214, 205-213. doi: 10.1016/j.canlet.2003.08.012

Lu, Y., and Jiang, C. (2017). Brain-targeted polymers for gene delivery in the treatment of brain diseases. Top Curr. Chem. 375:48. doi: 10.1007/s41061-017-0138-3

Luan, Y., Zhang, S., Zuo, L., and Zhou, L. (2015). Overexpression of miR-100 inhibits cell proliferation, migration, and chemosensitivity in human glioblastoma through FGFR3. Onco Targets Ther. 8, 3391-3400. doi: 10.2147/OTT.S85677

Mackay, A., Burford, A., Carvalho, D., Izquierdo, E., Fazal-Salom, J., Taylor, K. R., et al. (2017). Integrated molecular meta-analysis of 1,000 pediatric highgrade and diffuse intrinsic pontine glioma. Cancer Cell 32, 520-537 e525. doi: 10.1016/j.ccell.2017.08.017

Madhankumar, A. B., Slagle-Webb, B., Mintz, A., Sheehan, J. S., and Connor, J. R. (2006). Interleukin-13 receptor-targeted nanovesicles are a potential therapy for glioblastoma multiforme. Mol. Cancer Ther. 5, 3162-3169. doi: 10.1158/1535-7163.MCT-06-0480

Maguire, C. A., Gianni, D., Meijer, D. H., Shaket, L. A., Wakimoto, H., Rabkin, S. D., et al. (2010). Directed evolution of adeno-associated virus for glioma cell transduction. J. Neurooncol. 96, 337-347. doi: 10.1007/s11060-009-9972-7

Mangraviti, A., Tzeng, S. Y., Kozielski, K. L., Wang, Y., Jin, Y., Gullotti, D., et al. (2015). Polymeric nanoparticles for nonviral gene therapy extend brain tumor survival in vivo. ACS Nano 9, 1236-1249. doi: 10.1021/nn504905q

Marelli, G., Howells, A., Lemoine, N. R., and Wang, Y. (2018). Oncolytic viral therapy and the immune system: a double-edged sword against cancer. Front. Immunol. 9:866. doi: 10.3389/fimmu.2018.00866

Markert, J. M., Liechty, P. G., Wang, W., Gaston, S., Braz, E., Karrasch, M., et al. (2009). Phase Ib trial of mutant herpes simplex virus G207 inoculated pre-and post-tumor resection for recurrent GBM. Mol. Ther. 17, 199-207. doi: $10.1038 / \mathrm{mt} .2008 .228$

Markert, J. M., Medlock, M. D., Rabkin, S. D., Gillespie, G. Y., Todo, T., Hunter, W. D., et al. (2000). Conditionally replicating herpes simplex virus mutant, G207 for the treatment of malignant glioma: results of a phase I trial. Gene Ther. 7, 867-874. doi: 10.1038/sj.gt.3301205

Martuza, R. L., Malick, A., Markert, J. M., Ruffner, K. L., and Coen, D. M. (1991). Experimental therapy of human glioma by means of a genetically engineered virus mutant. Science 252, 854-856. doi: 10.1126/science. 1851332

Masui, K., Mischel, P. S., and Reifenberger, G. (2016). Molecular classification of gliomas. Handb. Clin. Neurol. 134, 97-120. doi: 10.1016/B978-0-12-802997-8.00006-2

Mendez, F., Kadiyala, P., Nunez, F. J., Carney, S., Nunez, F. M., Gauss, J. C., et al. (2020). Therapeutic efficacy of immune stimulatory thymidine kinase and fms-like tyrosine kinase 3 ligand (TK/Flt3L) gene therapy in a mouse model of high-grade brainstem glioma. Clin. Cancer Res. 26, 4080-4092. doi: 10.1158/1078-0432.CCR-19-3714

Miletic, H., Fischer, Y. H., Neumann, H., Hans, V., Stenzel, W., Giroglou, T., et al. (2004). Selective transduction of malignant glioma by lentiviral vectors pseudotyped with lymphocytic choriomeningitis virus glycoproteins. Hum. Gene Ther. 15, 1091-1100. doi: 10.1089/hum.2004.15.1091

Mineharu, Y., King, G. D., Muhammad, A. K., Bannykh, S., Kroeger, K. M., Liu, C., et al. (2011). Engineering the brain tumor microenvironment enhances the efficacy of dendritic cell vaccination: implications for clinical trial design. Clin. Cancer Res. 17, 4705-4718. doi: 10.1158/1078-0432.CCR-11-0915

Mineharu, Y., Muhammad, A. K., Yagiz, K., Candolfi, M., Kroeger, K. M., Xiong, W., et al. (2012). Gene therapy-mediated reprogramming tumor infiltrating $\mathrm{T}$ cells using IL-2 and inhibiting NF-kappaB signaling improves the efficacy of immunotherapy in a brain cancer model. Neurotherapeutics 9, 827-843. doi: 10.1007/s13311-012-0144-7

Mirghorbani, M., Van Gool, S., and Rezaei, N. (2013). Myeloid-derived suppressor cells in glioma. Expert Rev. Neurother. 13, 1395-1406. doi: $10.1586 / 14737175.2013 .857603$

Misra, S. K., Naz, S., Kondaiah, P., and Bhattacharya, S. (2014). A cationic cholesterol based nanocarrier for the delivery of p53EGFP-C3 plasmid to cancer cells. Biomaterials 35, 1334-1346. doi: 10.1016/j.biomaterials.2013.10.062

Mitchell, L. A., Lopez Espinoza, F., Mendoza, D., Kato, Y., Inagaki, A., Hiraoka, K., et al. (2017). Toca 511 gene transfer and treatment with the prodrug, 5 -fluorocytosine, promotes durable antitumor immunity in a mouse glioma model. Neurooncology 19, 930-939. doi: 10.1093/neuonc/nox037

Mitha, A. T., and Rekha, M. R. (2014). Multifunctional polymeric nanoplexes for anticancer co-delivery of p53 and mitoxantrone. J. Mater. Chem. B 2, 8005-8016. doi: 10.1039/C4TB01298D

Mooney, R., Majid, A. A., Batalla-Covello, J., Machado, D., Liu, X., Gonzaga, J., et al. (2019). Enhanced delivery of oncolytic adenovirus by neural stem cells for treatment of metastatic ovarian cancer. Mol. Ther. Oncolytics 12, 79-92. doi: 10.1016/j.omto.2018.12.003

Moore, K. W., de Waal Malefyt, R., Coffman, R. L., and O'Garra, A. (2001). Interleukin-10 and the interleukin-10 receptor. Annu. Rev. Immunol. 19, 683-765. doi: 10.1146/annurev.immunol.19.1.683

Mu, L., Yang, C., Gao, Q., Long, Y., Ge, H., DeLeon, G., et al. (2017). CD4+ and perivascular Foxp3 $+\mathrm{T}$ cells in glioma correlate with angiogenesis and tumor progression. Front. Immunol. 8:1451. doi: 10.3389/fimmu.2017.01451

Muralidharan, K., Gawargi, F. I., and Fuoco, K. (2019). "RNA therapeutic strategies to block VEGFR2 expression and angiogenesis in glioblastoma multiforme," in Experimental Biology 2019 Meeting Abstract, Orlando, FL 459.12.

Murphy, A. M., and Rabkin, S. D. (2013). Current status of gene therapy for brain tumors. Transl. Res. 161, 339-354. doi: 10.1016/j.trsl.2012.11.003

Nakada, M., Kita, D., Watanabe, T., Hayashi, Y., Teng, L., Pyko, I. V., et al. (2011). Aberrant signaling pathways in glioma. Cancers 3, 3242-3278. doi: $10.3390 /$ cancers3033242

Naldini, L., Blomer, U., Gallay, P., Ory, D., Mulligan, R., Gage, F. H., et al. (1996). In vivo gene delivery and stable transduction of nondividing cells by a lentiviral vector. Science 272, 263-267. doi: 10.1126/science.272.5259.263

Natsume, A., and Yoshida, J. (2008). Gene therapy for high-grade glioma: current approaches and future directions. Cell Adh. Migr. 2, 186-191. doi: $10.4161 /$ cam.2.3.6278

Nazarenko, I., Hede, S. M., He, X., Hedren, A., Thompson, J., Lindstrom, M. S., et al. (2012). PDGF and PDGF receptors in glioma. Ups. J. Med. Sci. 117, 99-112. doi: 10.3109/03009734.2012.665097

Nduom, E. K., Weller, M., and Heimberger, A. B. (2015). Immunosuppressive mechanisms in glioblastoma. Neuro Oncol. (17 Suppl. 7), vii9-viil4. doi: 10.1093/neuonc/nov151

Ning, J., and Wakimoto, H. (2014). Oncolytic herpes simplex virus-based strategies: toward a breakthrough in glioblastoma therapy. Front. Microbiol. 5:303. doi: $10.3389 /$ fmicb. 2014.00303

Niola, F., Evangelisti, C., Campagnolo, L., Massalini, S., Bue, M. C., Mangiola, A., et al. (2006). A plasmid-encoded VEGF siRNA reduces glioblastoma angiogenesis and its combination with interleukin-4 blocks tumor growth in a xenograft mouse model. Cancer Biol. Ther. 5, 174-179. doi: $10.4161 /$ cbt.5.2.2317

Noushmehr, H., Weisenberger, D. J., Diefes, K., Phillips, H. S., Pujara, K., Berman, B. P., et al. (2010). Identification of a CpG island methylator phenotype that defines a distinct subgroup of glioma. Cancer Cell 17, 510-522. doi: 10.1016/j.ccr.2010.03.017

Nunez, F. M., Gauss, J. C., Mendez, F. M., Haase, S., Lowenstein, P. R., and Castro, M. G. (2020). Genetically engineered mouse model of brainstem high-grade glioma. STAR Protoc. 1:100165. doi: 10.1016/j.xpro.2020.100165

Ohlfest, J. R., Demorest, Z. L., Motooka, Y., Vengco, I., Oh, S., Chen, E., et al. (2005). Combinatorial antiangiogenic gene therapy by nonviral gene transfer using the sleeping beauty transposon causes tumor regression and improves survival in mice bearing intracranial human glioblastoma. Mol. Ther. 12, 778-788. doi: 10.1016/j.ymthe.2005.07.689

Okura, H., Smith, C. A., and Rutka, J. T. (2014). Gene therapy for malignant glioma. Mol. Cell Ther. 2:21. doi: 10.1186/2052-8426-2-21 
Olsen, O. E., Wader, K. F., Misund, K., Vatsveen, T. K., Ro, T. B., Mylin, A. K., et al. (2014). Bone morphogenetic protein-9 suppresses growth of myeloma cells by signaling through ALK2 but is inhibited by endoglin. Blood Cancer J. 4:e196. doi: $10.1038 /$ bcj.2014.16

Ostertag, D., Amundson, K. K., Lopez Espinoza, F., Martin, B., Buckley, T., Galvao da Silva, A. P., et al. (2012). Brain tumor eradication and prolonged survival from intratumoral conversion of 5-fluorocytosine to 5-fluorouracil using a nonlytic retroviral replicating vector. Neurooncology 14, 145-159. doi: 10.1093/neuonc/nor199

Ostrand-Rosenberg, S., and Fenselau, C. (2018). Myeloid-derived suppressor cells: immune-suppressive cells that impair antitumor immunity and are sculpted by their environment. J. Immunol. 200, 422-431. doi: 10.4049/jimmunol. 1701019

Ostrom, Q. T., Gittleman, H., Fulop, J., Liu, M., Blanda, R., Kromer, C., et al. (2015). CBTRUS statistical report: primary brain and central nervous system tumors diagnosed in the United States in 2008-2012. Neuro Oncol. 17(Suppl. 4), iv1-iv62. doi: 10.1093/neuonc/nov189

Ostrom, Q. T., Gittleman, H., Truitt, G., Boscia, A., Kruchko, C., and BarnholtzSloan, J. S. (2018). CBTRUS statistical report: primary brain and other central nervous system tumors diagnosed in the United States in 2011-2015. Neuro Oncol. 20, iv1-iv86. doi: 10.1093/neuonc/noy131

Osuch, S., Laskus, T., Berak, H., Perlejewski, K., Metzner, K. J., Paciorek, M., et al. (2020). Decrease of T-cells exhaustion markers programmed cell death-1 and T-cell immunoglobulin and mucin domain-containing protein 3 and plasma IL-10 levels after successful treatment of chronic hepatitis C. Sci. Rep. 10:16060. doi: 10.1038/s41598-020-73137-6

Packer, R. J., Pfister, S., Bouffet, E., Avery, R., Bandopadhayay, P., Bornhorst, M., et al. (2017). Pediatric low-grade gliomas: implications of the biologic era. Neurooncology 19, 750-761. doi: 10.1093/neuonc/now209

Padfield, E., Ellis, H. P., and Kurian, K. M. (2015). Current therapeutic advances targeting EGFR and EGFRvIII in glioblastoma. Front. Oncol. 5:5. doi: $10.3389 /$ fonc. 2015.00005

Pan, D., Wei, X., Liu, M., Feng, S., Tian, X., Feng, X., et al. (2010). Adenovirus mediated transfer of p53, GM-CSF and B7-1 suppresses growth and enhances immunogenicity of glioma cells. Neurol. Res. 32, 502-509. doi: 10.1179/174313209X455736

Papachristodoulou, A., Signorell, R. D., Werner, B., Brambilla, D., Luciani, P., Cavusoglu, M., et al. (2019). Chemotherapy sensitization of glioblastoma by focused ultrasound-mediated delivery of therapeutic liposomes. J. Control. Release 295, 130-139. doi: 10.1016/j.jconrel.2018.12.009

Parolin, C., Dorfman, T., Palu, G., Gottlinger, H., and Sodroski, J. (1994). Analysis in human immunodeficiency virus type 1 vectors of cis-acting sequences that affect gene transfer into human lymphocytes. J. Virol. 68, 3888-3895. doi: 10.1128/JVI.68.6.3888-3895.1994

Parrish, K. E., Pokorny, J., Mittapalli, R. K., Bakken, K., Sarkaria, J. N., and Elmquist, W. F. (2015). Efflux transporters at the blood-brain barrier limit delivery and efficacy of cyclin-dependent kinase $4 / 6$ inhibitor palbociclib (PD0332991) in an orthotopic brain tumor model. J. Pharmacol. Exp. Ther. 355, 264-271. doi: 10.1124/jpet.115.228213

Parsons, D. W., Jones, S., Zhang, X., Lin, J. C., Leary, R. J., Angenendt, P., et al. (2008). An integrated genomic analysis of human glioblastoma multiforme. Science 321, 1807-1812. doi: 10.1126/science.1164382

Perng, P., and Lim, M. (2015). Immunosuppressive mechanisms of malignant gliomas: parallels at non-CNS sites. Front. Oncol. 5:153. doi: $10.3389 /$ fonc. 2015.00153

Perry, A., and Wesseling, P. (2016). Histologic classification of gliomas. Handb. Clin. Neurol. 134, 71-95. doi: 10.1016/B978-0-12-802997-8.00005-0

Pituch, K. C., Miska, J., Krenciute, G., Panek, W. K., Li, G., Rodriguez-Cruz, T., et al. (2018). Adoptive transfer of IL13Ralpha2-specific chimeric antigen receptor T cells creates a pro-inflammatory environment in glioblastoma. Mol. Ther. 26, 986-995. doi: 10.1016/j.ymthe.2018.02.001

Polivka, J. Jr., Polivka, J., Holubec, L., Kubikova, T., Priban, V., Hes, O., et al. (2017). Advances in experimental targeted therapy and immunotherapy for patients with glioblastoma multiforme. Anticancer Res. 37, 21-33. doi: 10.21873/anticanres.11285

Puntel, M., Muhammad, A. K., Candolfi, M., Salem, A., Yagiz, K., Farrokhi, C., et al. (2010). A novel bicistronic high-capacity gutless adenovirus vector that drives constitutive expression of herpes simplex virus type 1 thymidine kinase and tetinducible expression of Flt3L for glioma therapeutics. J. Virol. 84, 6007-6017. doi: 10.1128/JVI.00398-10

Pyonteck, S. M., Akkari, L., Schuhmacher, A. J., Bowman, R. L., Sevenich, L., Quail, D. F., et al. (2013). CSF-1R inhibition alters macrophage polarization and blocks glioma progression. Nat. Med. 19, 1264-1272. doi: 10.1038/nm.3337

Qin, X. Q., Beckham, C., Brown, J. L., Lukashev, M., and Barsoum, J. (2001). Human and mouse IFN-beta gene therapy exhibits different anti-tumor mechanisms in mouse models. Mol. Ther. 4, 356-364. doi: $10.1006 / \mathrm{mthe} .2001 .0464$

Rainov, N. G. (2000). A phase III clinical evaluation of herpes simplex virus type 1 thymidine kinase and ganciclovir gene therapy as an adjuvant to surgical resection and radiation in adults with previously untreated glioblastoma multiforme. Hum. Gene Ther. 11, 2389-2401. doi: 10.1089/104303400750038499

Rajan, W. D., Wojtas, B., Gielniewski, B., Miro-Mur, F., Pedragosa, J., Zawadzka, M., et al. (2020). Defining molecular identity and fates of CNS-border associated macrophages after ischemic stroke in rodents and humans. Neurobiol. Dis. 137:104722. doi: 10.1016/j.nbd.2019.104722

Reifenberger, G., Wirsching, H. G., Knobbe-Thomsen, C. B., and Weller, M. (2017). Advances in the molecular genetics of gliomas - implications for classification and therapy. Nat. Rev. Clin. Oncol. 14, 434-452. doi: 10.1038/nrclinonc.2016.204

Reszka, R. C., Jacobs, A., and Voges, J. (2005). Liposome-mediated suicide gene therapy in humans. Meth. Enzymol. 391, 200-208. doi: 10.1016/S0076-6879(05)91012-4

Roche, F. P., Sheahan, B. J., O'Mara, S. M., and Atkins, G. J. (2010). Semliki Forest virus-mediated gene therapy of the RG2 rat glioma. Neuropathol. Appl. Neurobiol. 36, 648-660. doi: 10.1111/j.1365-2990.2010.01110.x

Roesch, S., Rapp, C., Dettling, S., and Herold-Mende, C. (2018). When immune cells turn bad-tumor-associated microglia/macrophages in glioma. Int. J. Mol. Sci. 19:436. doi: 10.3390/ijms19020436

Rogers, M. L., and Rush, R. A. (2012). Non-viral gene therapy for neurological diseases, with an emphasis on targeted gene delivery. J. Control. Release 157, 183-189. doi: 10.1016/j.jconrel.2011.08.026

Ryu, C. H., Park, S. H., Park, S. A., Kim, S. M., Lim, J. Y., Jeong, C. H., et al. (2011). Gene therapy of intracranial glioma using interleukin 12-secreting human umbilical cord blood-derived mesenchymal stem cells. Hum. Gene Ther. 22, 733-743. doi: 10.1089/hum.2010.187

Samson, A., Scott, K. J., Taggart, D., West, E. J., Wilson, E., Nuovo, G. J., et al. (2018). Intravenous delivery of oncolytic reovirus to brain tumor patients immunologically primes for subsequent checkpoint blockade. Sci. Transl. Med. 10:eaam7577. doi: 10.1126/scitranslmed.aam7577

Sanchez-Hernandez, L., Hernandez-Soto, J., Vergara, P., Gonzalez, R. O., and Segovia, J. (2018). Additive effects of the combined expression of soluble forms of GAS1 and PTEN inhibiting glioblastoma growth. Gene Ther. 25, 439-449. doi: 10.1038/s41434-018-0020-0

Sandmair, A. M., Loimas, S., Puranen, P., Immonen, A., Kossila, M., Puranen, M., et al. (2000). Thymidine kinase gene therapy for human malignant glioma, using replication-deficient retroviruses or adenoviruses. Hum. Gene Ther. 11, 2197-2205. doi: 10.1089/104303400750035726

Santiago-Ortiz, J. L., and Schaffer, D. V. (2016). Adeno-associated virus (AAV) vectors in cancer gene therapy. J. Control. Release 240, 287-301. doi: 10.1016/j.jconrel.2016.01.001

Sarkaria, J. N., Hu, L. S., Parney, I. F., Pafundi, D. H., Brinkmann, D. H., Laack, N. N., et al. (2018). Is the blood-brain barrier really disrupted in all glioblastoma? A clinical assessment of existing clinical data. Neurooncology 20, 184-191. doi: 10.1093/neuonc/nox175

Schirrmacher, V., van Gool, S., and Stuecker, W. (2019). Breaking therapy resistance: an update on oncolytic newcastle disease virus for improvements of cancer therapy. Biomedicines 7:66. doi: 10.3390/biomedicines7030066

Schroder, K., Hertzog, P. J., Ravasi, T., and Hume, D. A. (2004). Interferon-gamma: an overview of signals, mechanisms and functions. J. Leukoc. Biol. 75, 163-189. doi: $10.1189 / \mathrm{jlb} .0603252$

Shah, A. C., Parker, J. N., Gillespie, G. Y., Lakeman, F. D., Meleth, S., Markert, J. M., et al. (2007). Enhanced antiglioma activity of chimeric HCMV/HSV-1 oncolytic viruses. Gene Ther. 14, 1045-1054. doi: 10.1038/sj.gt.3302942 
Shergalis, A., Bankhead, A. 3rd, Luesakul, U., Muangsin, N., and Neamati, N. (2018). Current challenges and opportunities in treating glioblastoma. Pharmacol. Rev. 70, 412-445. doi: 10.1124/pr.117.014944

Shinojima, N., Tada, K., Shiraishi, S., Kamiryo, T., Kochi, M., Nakamura, H., et al. (2003). Prognostic value of epidermal growth factor receptor in patients with glioblastoma multiforme. Cancer Res. 63, 6962-6970.

Shinoura, N., Yoshida, Y., Asai, A., Kirino, T., and Hamada, H. (2000). Adenovirus-mediated transfer of p53 and Fas ligand drastically enhances apoptosis in gliomas. Cancer Gene Ther. 7, 732-738. doi: 10.1038/sj.cgt.7700160

Shir, A., and Levitzki, A. (2002). Inhibition of glioma growth by tumor-specific activation of double-stranded RNA-dependent protein kinase PKR. Nat. Biotechnol. 20, 895-900. doi: 10.1038/nbt730

Shono, T., Tofilon, P. J., Schaefer, T. S., Parikh, D., Liu, T. J., and Lang, F. F. (2002). Apoptosis induced by adenovirus-mediated $\mathrm{p} 53$ gene transfer in human glioma correlates with site-specific phosphorylation. Cancer Res. 62, 1069-1076.

Shu, Y., Pi, F., Sharma, A., Rajabi, M., Haque, F., Shu, D., et al. (2014). Stable RNA nanoparticles as potential new generation drugs for cancer therapy. Adv. Drug Deliv. Rev. 66, 74-89. doi: 10.1016/j.addr.2013.11.006

Simon, M., Simon, C., Koster, G., Hans, V. H., and Schramm, J. (2002). Conditional expression of the tumor suppressor p16 in a heterotopic glioblastoma model results in loss of pRB expression. J. Neurooncol. 60, 1-12. doi: 10.1023/A:1020226130478

Sturm, D., Witt, H., Hovestadt, V., Khuong-Quang, D. A., Jones, D. T., Konermann, C., et al. (2012). Hotspot mutations in H3F3A and IDH1 define distinct epigenetic and biological subgroups of glioblastoma. Cancer Cell 22, 425-437. doi: 10.1016/j.ccr.2012.08.024

Sun, X., Pang, Z., Ye, H., Qiu, B., Guo, L., Li, J., et al. (2012). Co-delivery of pEGFPhTRAIL and paclitaxel to brain glioma mediated by an angiopep-conjugated liposome. Biomaterials 33, 916-924. doi: 10.1016/j.biomaterials.2011.10.035

Takahashi, M., Valdes, G., Hiraoka, K., Inagaki, A., Kamijima, S., Micewicz, E., et al. (2014). Radiosensitization of gliomas by intracellular generation of 5 -fluorouracil potentiates prodrug activator gene therapy with a retroviral replicating vector. Cancer Gene Ther. 21, 405-410. doi: 10.1038/cgt.2014.38

Tamura, R., Miyoshi, H., Morimoto, Y., Oishi, Y., Sampetrean, O., Iwasawa, C., et al. (2020). Gene therapy using neural stem/progenitor cells derived from human induced pluripotent stem cells: visualization of migration and bystander killing effect. Hum. Gene Ther. 31, 352-366. doi: 10.1089/hum.2019.326

Tanikawa, T., Wilke, C. M., Kryczek, I., Chen, G. Y., Kao, J., Nunez, G., et al. (2012). Interleukin-10 ablation promotes tumor development, growth, and metastasis. Cancer Res. 72, 420-429. doi: 10.1158/0008-5472.CAN-10-4627

Tatsumi, T., Huang, J., Gooding, W. E., Gambotto, A., Robbins, P. D., Vujanovic, N. L., et al. (2003). Intratumoral delivery of dendritic cells engineered to secrete both interleukin (IL)-12 and IL-18 effectively treats local and distant disease in association with broadly reactive Tc1-type immunity. Cancer Res. 63, 6378-6386.

Thorne, S. H., Tam, B. Y., Kirn, D. H., Contag, C. H., and Kuo, C. J. (2006). Selective intratumoral amplification of an antiangiogenic vector by an oncolytic virus produces enhanced antivascular and anti-tumor efficacy. Mol. Ther. 13, 938-946. doi: 10.1016/j.ymthe.2005.12.010

Tobias, A., Ahmed, A., Moon, K. S., and Lesniak, M. S. (2013). The art of gene therapy for glioma: a review of the challenging road to the bedside. J. Neurol. Neurosurg. Psychiatr. 84, 213-222. doi: 10.1136/jnnp-2012-302946

Todo, T. (2019). Atim-14. Results of phase II clinical trial of oncolytic herpes virus g47 in patients with glioblastoma. Neurooncology 21:vi4. doi: 10.1093/neuonc/noz175.014

Tome-Garcia, J., Erfani, P., Nudelman, G., Tsankov, A. M., Katsyv, I., Tejero, R., et al. (2018). Analysis of chromatin accessibility uncovers TEAD1 as a regulator of migration in human glioblastoma. Nat. Commun. 9:4020. doi: 10.1038/s41467-018-06258-2

Treat, L. H., McDannold, N., Zhang, Y., Vykhodtseva, N., and Hynynen, K. (2012). Improved anti-tumor effect of liposomal doxorubicin after targeted blood-brain barrier disruption by MRI-guided focused ultrasound in rat glioma. Ultrasound Med. Biol. 38, 1716-1725. doi: 10.1016/j.ultrasmedbio.2012. 04.015

Truong, A. Y., and Nicolaides, T. P. (2015). Targeted therapy for MAPK alterations in pediatric gliomas. Brain Disord. Ther. Suppl 2, 005. doi: 10.4172/2168-975X.S2-005
Van Meir, E. G., Polverini, P. J., Chazin, V. R., Su Huang, H. J., de Tribolet, N., and Cavenee, W. K. (1994). Release of an inhibitor of angiogenesis upon induction of wild type p53 expression in glioblastoma cells. Nat. Genet. 8, 171-176. doi: 10.1038/ng1094-171

van Putten, E. H., Dirven, C. M., van den Bent, M. J., and Lamfers, M. L. (2010). Sitimagene ceradenovec: a gene-based drug for the treatment of operable high-grade glioma. Future Oncol. 6, 1691-1710. doi: 10.2217/fon.10.134

Venteicher, A. S., Tirosh, I., Hebert, C., Yizhak, K., Neftel, C., Filbin, M. G., et al. (2017). Decoupling genetics, lineages, and microenvironment in IDH-mutant gliomas by single-cell RNA-seq. Science 355:eaai8478. doi: $10.1126 /$ science.aai8478

Verhaak, R. G., Hoadley, K. A., Purdom, E., Wang, V., Qi, Y., Wilkerson, M. D., et al. (2010). Integrated genomic analysis identifies clinically relevant subtypes of glioblastoma characterized by abnormalities in PDGFRA, IDH1, EGFR, and NF1. Cancer Cell 17, 98-110. doi: 10.1016/j.ccr.2009.12.020

Vorbrodt, A. W., and Dobrogowska, D. H. (2003). Molecular anatomy of intercellular junctions in brain endothelial and epithelial barriers: electron microscopist's view. Brain Res. Brain Res. Rev. 42, 221-242. doi: 10.1016/S0165-0173(03)00177-2

Wainwright, D. A., Balyasnikova, I. V., Chang, A. L., Ahmed, A. U., Moon, K. S., Auffinger, B., et al. (2012). IDO expression in brain tumors increases the recruitment of regulatory $\mathrm{T}$ cells and negatively impacts survival. Clin. Cancer Res. 18, 6110-6121. doi: 10.1158/1078-0432.CCR-12-2130

Wakabayashi, T., Natsume, A., Hashizume, Y., Fujii, M., Mizuno, M., and Yoshida, J. (2008). A phase I clinical trial of interferon-beta gene therapy for high-grade glioma: novel findings from gene expression profiling and autopsy. J. Gene Med. 10, 329-339. doi: 10.1002/jgm.1160

Walker, D. G., Shakya, R., Morrison, B., Neller, M. A., Matthews, K. K., Nicholls, J., et al. (2019). Impact of pre-therapy glioblastoma multiforme microenvironment on clinical response to autologous CMV-specific T-cell therapy. Clin. Transl. Immunol. 8:e01088. doi: 10.1002/cti2.1088

Wang, K., Park, J. O., and Zhang, M. (2013). Treatment of glioblastoma multiforme using a combination of small interfering RNA targeting epidermal growth factor receptor and beta-catenin. J. Gene Med. 15, 42-50. doi: 10.1002/jgm.2693

Wang, T. J., Huang, M. S., Hong, C. Y., Tse, V., Silverberg, G. D., and Hsiao, M. (2001). Comparisons of tumor suppressor p53, p21, and p16 gene therapy effects on glioblastoma tumorigenicity in situ. Biochem. Biophys. Res. Commun. 287, 173-180. doi: 10.1006/bbrc.2001.5565

Wei, J., Chen, P., Gupta, P., Ott, M., Zamler, D., Kassab, C., et al. (2020). Immune biology of glioma-associated macrophages and microglia: functional and therapeutic implications. Neurooncology 22, 180-194. doi: $10.1093 /$ neuonc/noz212

Wei, L., Guo, X-Y., Yang, T., Yu, M-Z., Chen, D-W., and Wang, J-C. (2016). Brain tumor-targeted therapy by systemic delivery of siRNA with Transferrin receptor-mediated core-shell nanoparticles. Int. J. Pharm. 510, 394-405. doi: 10.1016/j.ijpharm.2016.06.127

Wei, X., Chen, X., Ying, M., and Lu, W. (2014). Brain tumor-targeted drug delivery strategies. Acta Pharm. Sin. B 4, 193-201. doi: 10.1016/j.apsb.2014.03.001

Wesseling, P., and Capper, D. (2018). WHO 2016 classification of gliomas. Neuropathol. Appl. Neurobiol. 44, 139-150. doi: 10.1111/nan.12432

Wheeler, L. A., Manzanera, A. G., Bell, S. D., Cavaliere, R., McGregor, J. M., Grecula, J. C., et al. (2016). Phase II multicenter study of gene-mediated cytotoxic immunotherapy as adjuvant to surgical resection for newly diagnosed malignant glioma. Neurooncology 18, 1137-1145. doi: 10.1093/neuonc/ now002

Wherry, E. J., and Kurachi, M. (2015). Molecular and cellular insights into T cell exhaustion. Nat. Rev. Immunol. 15, 486-499. doi: 10.1038/ nri3862

Wick, W., Weller, M., van den Bent, M., Sanson, M., Weiler, M., von Deimling, A., et al. (2014). MGMT testing-the challenges for biomarker-based glioma treatment. Nat. Rev. Neurol. 10, 372-385. doi: 10.1038/nrneurol.2014.100

Wiestler, B., Capper, D., Sill, M., Jones, D. T., Hovestadt, V., Sturm, D., et al. (2014). Integrated DNA methylation and copy-number profiling identify three clinically and biologically relevant groups of anaplastic glioma. Acta Neuropathol. 128, 561-571. doi: 10.1007/s00401-014-1315-x

Woroniecka, K., Chongsathidkiet, P., Rhodin, K., Kemeny, H., Dechant, C., Farber, S. H., et al. (2018). T-cell exhaustion signatures vary with tumor 
type and are severe in glioblastoma. Clin. Cancer Res. 24, 4175-4186. doi: 10.1158/1078-0432.CCR-17-1846

Woroniecka, K., and Fecci, P. E. (2018). T-cell exhaustion in glioblastoma. Oncotarget 9, 35287-35288. doi: 10.18632/oncotarget.26228

Xande, J. G., Dias, A. P., Tamura, R. E., Cruz, M. C., Brito, B., Ferreira, R. A., et al. (2020). Bicistronic transfer of CDKN2A and p53 culminates in collaborative killing of human lung cancer cells in vitro and in vivo. Gene Ther. 27, 51-61. doi: 10.1038/s41434-019-0096-1

Yacoub, A., Mitchell, C., Lebedeva, I. V., Sarkar, D., Su, Z. Z., McKinstry, R., et al. (2003a). mda-7 (IL-24) Inhibits growth and enhances radiosensitivity of glioma cells in vitro via JNK signaling. Cancer Biol. Ther. 2, 347-353. doi: $10.4161 /$ cbt.2.4.422

Yacoub, A., Mitchell, C., Lister, A., Lebedeva, I. V., Sarkar, D., Su, Z. Z., et al. (2003b). Melanoma differentiation-associated 7 (interleukin 24) inhibits growth and enhances radiosensitivity of glioma cells in vitro and in vivo. Clin. Cancer Res. 9, 3272-3281.

Yang, S-Y., Liu, H., and Zhang, J-N. (2004). Gene therapy of rat malignant gliomas using neural stem cells expressing IL-12. DNA Cell Biol. 23, 381-389. doi: 10.1089/104454904323145263

Yoo, J. Y., Kim, J. H., Kwon, Y. G., Kim, E. C., Kim, N. K., Choi, H. J., et al. (2007). VEGF-specific short hairpin RNA-expressing oncolytic adenovirus elicits potent inhibition of angiogenesis and tumor growth. Mol. Ther. 15, 295-302. doi: 10.1038/sj.mt.6300023

Yoshida, J., Mizuno, M., Fujii, M., Kajita, Y., Nakahara, N., Hatano, M., et al. (2004). Human gene therapy for malignant gliomas (glioblastoma multiforme and anaplastic astrocytoma) by in vivo transduction with human interferon beta gene using cationic liposomes. Hum. Gene Ther. 15, 77-86. doi: 10.1089/10430340460732472

You, Y., Geng, X., Zhao, P., Fu, Z., Wang, C., Chao, S., et al. (2007). Evaluation of combination gene therapy with PTEN and antisense hTERT for malignant glioma in vitro and xenografts. Cell. Mol. Life Sci. 64, 621-631. doi: 10.1007/s00018-007-6424-4

Yu, S., Li, A., Liu, Q., Li, T., Yuan, X., Han, X., et al. (2017). Chimeric antigen receptor T cells: a novel therapy for solid tumors. J. Hematol. Oncol. 10:78. doi: 10.1186/s13045-017-0444-9

Yu, X., Trase, I., Ren, M., Duval, K., Guo, X., and Chen, Z. (2016). Design of nanoparticle-based carriers for targeted drug delivery. J. Nanomater. 2016, 1087250. doi: 10.1155/2016/1087250

Yue, P. J., He, L., Qiu, S. W., Li, Y., Liao, Y. J., Li, X. P., et al. (2014). OX26/CTX-conjugated PEGylated liposome as a dual-targeting gene delivery system for brain glioma. Mol. Cancer 13:191. doi: 10.1186/1476-4598 13-191

Zhang, J., Yang, W., Zhao, D., Han, Y., Liu, B., Zhao, H., et al. (2014). Correlation between TSP-1, TGF-beta and PPAR-gamma expression levels and glioma microvascular density. Oncol. Lett. 7, 95-100. doi: 10.3892/ol.2013.1650

Zhang, N., Wei, L., Ye, M., Kang, C., and You, H. (2020). Treatment progress of immune checkpoint blockade therapy for glioblastoma. Front. Immunol. 11:592612. doi: 10.3389/fimmu.2020.592612

Zhang, Y., Zhai, M., Chen, Z., Han, X., Yu, F., Li, Z., et al. (2017). Dual-modified liposome codelivery of doxorubicin and vincristine improve targeting and therapeutic efficacy of glioma. Drug Deliv. 24, 1045-1055. doi: 10.1080/10717544.2017.1344334

Zhao, X., Chester, C., Rajasekaran, N., He, Z., and Kohrt, H. E. (2016). Strategic combinations: the future of oncolytic virotherapy with reovirus. Mol. Cancer Ther. 15, 767-773. doi: 10.1158/1535-7163.MCT-15-0695

Zolotukhin, I., Luo, D., Gorbatyuk, O., Hoffman, B., Warrington, K. Jr., Herzog, R., et al. (2013). Improved adeno-associated viral gene transfer to murine glioma. J. Genet. Syndr. Gene Ther. 4:12815. doi: 10.4172/2157-7412.1000133

Zong, H., Parada, L. F., and Baker, S. J. (2015). Cell of origin for malignant gliomas and its implication in therapeutic development. Cold Spring Harb. Perspect. Biol. 7:a020610. doi: 10.1101/cshperspect.a020610

Zong, H., Verhaak, R. G., and Canoll, P. (2012). The cellular origin for malignant glioma and prospects for clinical advancements. Expert Rev. Mol. Diagn. 12, 383-394. doi: 10.1586/erm.12.30

Zong, T., Mei, L., Gao, H., Cai, W., Zhu, P., Shi, K., et al. (2014). Synergistic dualligand doxorubicin liposomes improve targeting and therapeutic efficacy of brain glioma in animals. Mol. Pharm. 11, 2346-2357. doi: 10.1021/mp500057n

Conflict of Interest: The authors declare that the research was conducted in the absence of any commercial or financial relationships that could be construed as a potential conflict of interest.

Copyright (C) 2021 Banerjee, Núñez, Haase, McClellan, Faisal, Carney, Yu, Alghamri, Asad, Candia, Varela, Candolfi, Lowenstein and Castro. This is an open-access article distributed under the terms of the Creative Commons Attribution License (CC BY). The use, distribution or reproduction in other forums is permitted, provided the original author(s) and the copyright owner(s) are credited and that the original publication in this journal is cited, in accordance with accepted academic practice. No use, distribution or reproduction is permitted which does not comply with these terms. 